\title{
Hearing in larvae of the monarch butterfly, Danaus plexippus, and selected other Lepidoptera
}

\author{
By Chantel J. Taylor
}

\begin{abstract}
A dissertation submitted to the Faculty of Graduate Studies in partial fulfilment of the requirements

for the degree of Master of Science in Biology.
\end{abstract}

\author{
Carleton University \\ Ottawa, Ontario
}

(C) 2008, Chantel J. Taylor 


$\begin{array}{ll}\begin{array}{l}\text { Library and } \\ \text { Archives Canada }\end{array} & \begin{array}{l}\text { Bibliothèque et } \\ \text { Archives Canada }\end{array} \\ \begin{array}{l}\text { Published Heritage } \\ \text { Branch }\end{array} & \begin{array}{l}\text { Direction du } \\ \text { Patrimoine de l'édition }\end{array} \\ \begin{array}{l}\text { 395 Wellington Street } \\ \text { Ottawa ON K1A 0N4 } \\ \text { Canada }\end{array} & \begin{array}{l}\text { 395, rue Wellington } \\ \text { Ottawa ON K1A 0N4 } \\ \text { Canada }\end{array}\end{array}$

Your file Votre référence ISBN: 978-0-494-47537-9

Our file Notre référence

ISBN: 978-0-494-47537-9

NOTICE:

The author has granted a nonexclusive license allowing Library and Archives Canada to reproduce, publish, archive, preserve, conserve, communicate to the public by telecommunication or on the Internet, loan, distribute and sell theses worldwide, for commercial or noncommercial purposes, in microform, paper, electronic and/or any other formats.

The author retains copyright ownership and moral rights in this thesis. Neither the thesis nor substantial extracts from it may be printed or otherwise reproduced without the author's permission.
AVIS:

L'auteur a accordé une licence non exclusive permettant à la Bibliothèque et Archives Canada de reproduire, publier, archiver, sauvegarder, conserver, transmettre au public par télécommunication ou par l'Internet, prêter, distribuer et vendre des thèses partout dans le monde, à des fins commerciales ou autres, sur support microforme, papier, électronique et/ou autres formats.

L'auteur conserve la propriété du droit d'auteur et des droits moraux qui protège cette thèse. $\mathrm{Ni}$ la thèse ni des extraits substantiels de celle-ci ne doivent être imprimés ou autrement reproduits sans son autorisation.
In compliance with the Canadian Privacy Act some supporting forms may have been removed from this thesis.

While these forms may be included in the document page count, their removal does not represent any loss of content from the thesis.
Conformément à la loi canadienne sur la protection de la vie privée, quelques formulaires secondaires ont été enlevés de cette thèse.

Bien que ces formulaires aient inclus dans la pagination, il n'y aura aucun contenu manquant.

\section{Canada}




\begin{abstract}
Many species of larval Lepidoptera have been observed to respond to sound, but only one species has been thoroughly studied. The present investigation sought to confirm earlier reports that Danaus plexippus L. (Lepidoptera: Nymphalidae) larvae responded to sound, and to describe their responses to sound in detail. Preliminary investigations of behavioural responses to sound of six other species of larval Lepidoptera were also conducted for comparative purposes. D. plexippus larvae responded to sound by ceasing movement, retracting their heads, or flicking their bodies dorsally. Danaus plexippus was particularly responsive to low frequency sounds, and further analysis showed that they responded more vigorously to lounder sounds. A pair of filiform sensilla on the prothorax was shown to be primilarily responsible for sound reception. Hearing in $D$. plexippus may function to detect aerial insect predators or parasitoids, as has been shown in other lepidopterous larvae.
\end{abstract}




\section{ACKNOWLEDGEMENTS}

I have learned a great deal over the two years of my Master's program, and I am grateful to a number of people whose assistance and knowledge have been invaluable. First and foremost, I would like to express gratitude to my supervisor, Dr. Jayne Yack, for her valuable guidance throughout all stages of my research, and advice on the composition of my thesis. I am very grateful to Dr. Jeff Dawson, who was always willing and able to provide insightful advice on a wide range of topics, and for sitting on my defense committee. I would also like to thank Dr. John Lewis, for his feedback and participating as part of my thesis committee, and to Peter Mason for agreeing to act as an examiner for my thesis defense.

I am grateful for the assistance and green thumbs of Ed Bruggink, especially for helping my milkweed plants thrive. I would like to acknowledge the hard work of Dave Omond, for his immense assistance in constructing the tent caterpillar enclosure. Caroline Boudreault kindly allowed me to use her critical point dryer, without which my SEM figures would not have been possible. I would also like to thank Peter Jones and Jianqun Wang for their technical assistance with scanning electron microscopy.

I would like to thank the members of the Yack lab, for their help with various issues that arose throughout the last two years. In particular Alan Flemming provided valuable technical advice, and helped locate my colony of tent caterpillars. Veronica Bura, Antoine Hnain, and Sarah Brown kindly allowed me to include their photographs for several figures.

Last, but not least, I am forever indebted to Sada Murugan, for agreeing to iii 
relocate to Ottawa so I could pursue my Master's, and providing encouragement and technical support. 


\section{TABLE OF CONTENTS}

CHAPTER 1: General Introduction....................................................................1-11

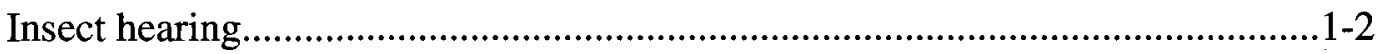

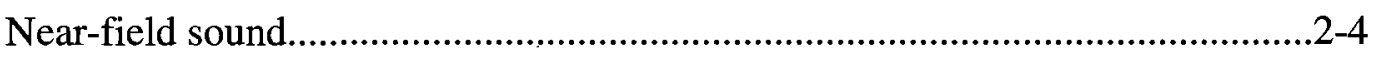

Near-field hearing in Lepidoptera.........................................................................4-9

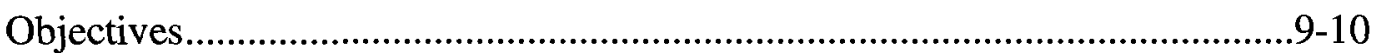

CHAPTER 2: Hearing in Danaus plexippus.............................................................12-84

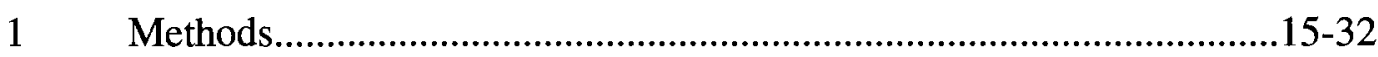

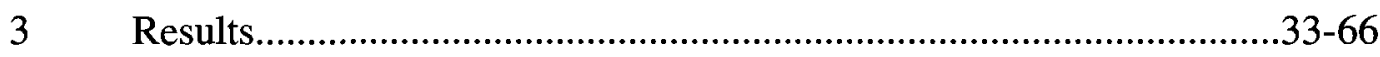

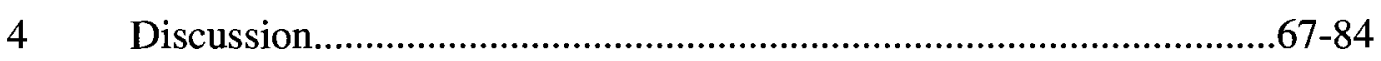

CHAPTER 3: Hearing in other lepidopterous larvae................................................84-115

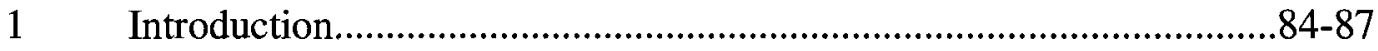

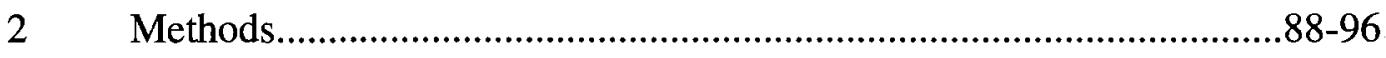

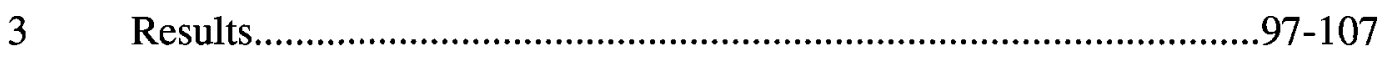

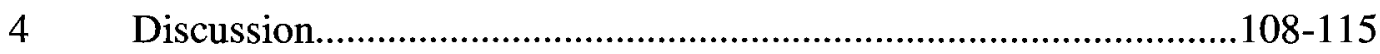

CHAPTER 4: General Discussion..................................................................116-120

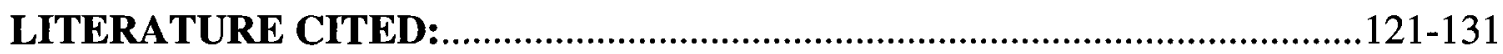




\section{LIST OF TABLES}

1.1 Lepidopteran larvae reported to respond to sound...................................5-6

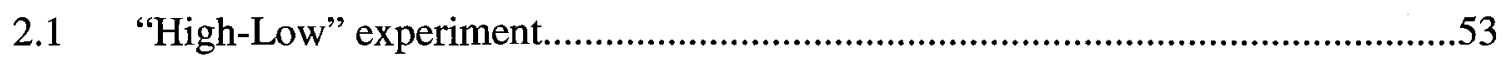

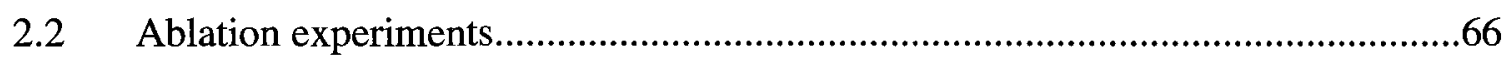

2.3 Flight sounds of selected representatives of Diptera and Hymenoptera...............73 


\section{LIST OF FIGURES}

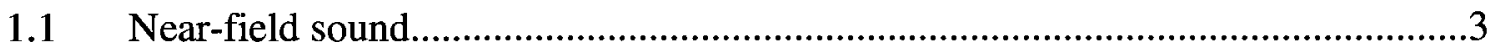

1.2 Location of near-field receptors on a Mamestra brassicae larva..........................8

2.1 Behavioural audiogram trial set-up.............................................................17

2.2 Calibration curve for woofer used in behavioural audiogram trials....................19

2.3 High speed video and laser vibrometry set-up...............................................24

2.4 Behavioural audiogram considering all responses,

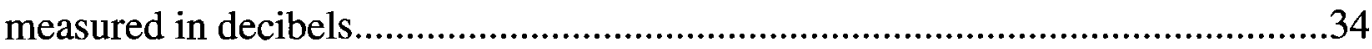

2.5 Behavioural audiogram considering all responses, measured in particle velocity 35

2.6 Behavioural audiogram considering all responses,

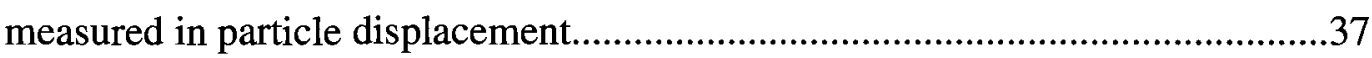

2.7 Behavioural audiogram considering only flicks,

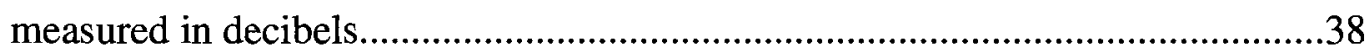

2.8 Habituation/sensitization experiment: repeated $200 \mathrm{~Hz}$ tones at $\mathrm{dB}_{\mathrm{SPL}}$

2.9 Contraction response recorded with high speed video and laser vibrometry.

2.10 Contractions, partial flicks, and full flicks in response to different sound intensities of $200 \mathrm{~Hz}$ tones recorded with high speed video and laser vibrometry . .43

vii 
2.11 Train of six flicks response recorded with high speed video and laser vibrometry.

2.12 Contractions and increasing flick magnitude recorded with high speed video and laser vibrometry 46

2.13 Flick detail magnitude recorded with high speed video and laser vibrometry 47

2.14 Relationship between flick number and flick angle.

2.15 Number and proportion of larvae responding with flicks during in response to increasing intensity of $200 \mathrm{~Hz}$ tones......................................................................

2.16 Anatomy of setae that cover the body..............................................................54

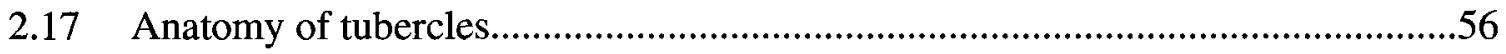

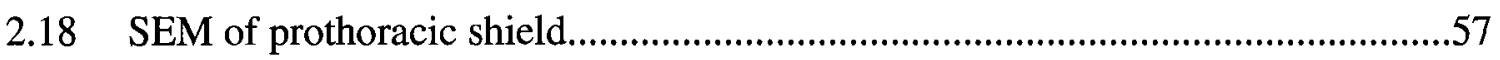

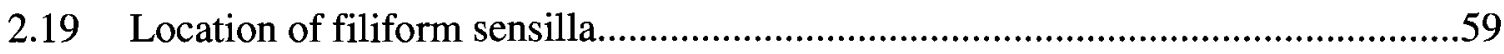

2.20 Anatomy of upper anterior filiform sensilla .......................................................61

2.21 Anatomy of lower anterior filiform sensilla.......................................................62

2.22 Anatomy of filiform sensilla on tenth abdominal segment.....................................63

2.23 Anatomy of abdominal filiform sensilla on third through sixth abdominal segments....................................................................64

3.1 Malacosoma spp. setup.............................................................................

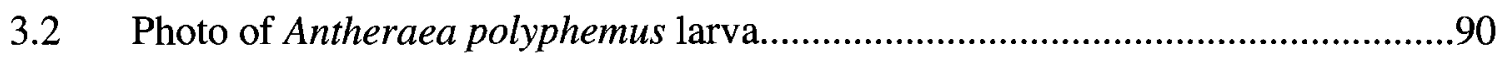

3.3 Photo of Automeris io larvae............................................................................

3.4 Photo of Spilosoma virginica larvae....................................................................92 viii 


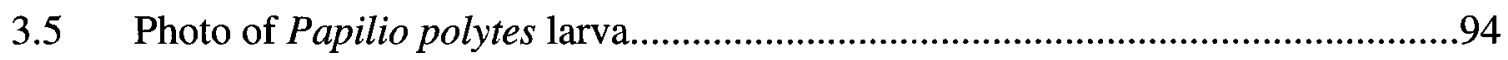

3.6 Freezing response by Malacosoma americanum recorded with sound and laser vibrometer on tent.

3.7 Flicking response by Malacosoma americanum recorded with high speed video and laser vibrometer..

3.8 Flicking response by Malacosoma americanum recorded with high speed video and laser vibrometer on tent.

3.9 Flicking and falling response by Malacosoma disstria recorded with

high speed video and laser vibrometer.

$3.10 \quad$ Filiform sensilla of Papilio polytes.................................................................107

4.1 Phylogeny of superfamilies within Lepidoptera that have been

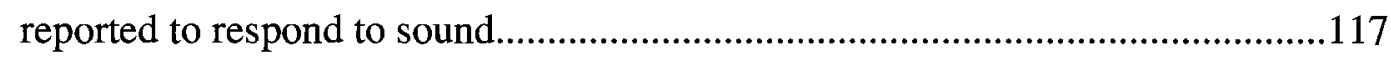




\section{LIST OF APPENDICES}

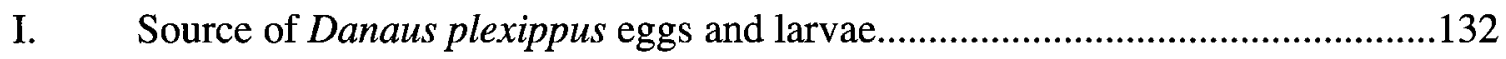




\section{CHAPTER 1: GENERAL INTRODUCTION}

\section{Insect Hearing}

Many insects are heavily reliant on the perception of sound. Perhaps most conspicuous are male adult insects that stridulate in order to attract female conspecifics, such as many ensiferans (Gwynne, 1995). Parasitoids sometimes locate hosts by orienting to these mating songs (e.g. Hunt and Allen, 1998; Schniederkotter and Lakes-Harlan, 2004). Conversely, other insects are able to detect substrate-borne vibrations produced by parasitoids (e.g. Bacher et al., 1996) or predators (e.g. Castellanos and Barbosa, 2006), or sounds produced by parasitoids (e.g. Tautz and Markl, 1978) or predators (e.g. Yager et al., 1990) nearby. Hearing has evolved at least 19 times throughout insect evolution, and the location of ears and their function are as diverse as the insects in which they are found (Yager, 1999). Hearing in adult Lepidoptera evolved multiple times in both moths and butterflies, and has been shown to function in bat detection (Minet and Surlykke, 2003), social communication (e.g. Conner, 1999), and possibly detection of avian predators (Lane et al., 2007).

Tympanal hearing, including the above examples, has been extensively researched in insects. Insect ears of this type function according to the same principles that humans use for audition (Hoy and Robert, 1996; Yack, 2004; Yager, 1999). Tympanal ears detect far-field sound, which is defined as the compressions and rarefractions of air or other fluid media that occur in a sound wave (Beranek, 1954). The pressure peak of a sound wave compresses the tympanum and the air-filled space behind it, and conversely, during the low pressure trough of a sound wave, the tympanum undergoes rarefraction. It is this movement of the tympanal membrane that is transduced to neural impulses by the tympanal organ, which is composed of scolopidia (Yack, 2004; Yager, 1999). Tympanal 
ears are most effective at detecting high frequency sound $(2-100 \mathrm{kHz})$ from long distances (Hoy and Robert, 1996; Stumpner and von Helversen, 2001).

\section{Near-Field Sound}

Near-field sound is a different component of sound that can be detected (Fig. 1.1), but a different type of ear is required to hear it. Near-field sound is generally audible within a radius measuring one wavelength from the sound source, whereas the far-field extends beyond this point (Beranek, 1954). Within this radius, particle velocity and pressure are out of phase, and air molecules experience relatively large translational movements that represent a significant proportion of the total intensity of the sound signal (Fig. 1.1) (Tautz, 1979). This proportion attenuates rapidly as distance from the sound source increases, because close to a sound source the shape of the wave propagation is approximately spherical, unlike the far field, in which waves are in a plane (Beranek, 1954).

Insect near-field receptors, or movement receivers, are typically long and thin sensory setae, or antennae that can be deflected and vibrate optimally by the oscillating air particles (Tautz, 1979; Ewing, 1989). Filiform sensilla are the simplest type of receptors used by insects to receive near-field auditory information, and consist of a type of seta called a filiform sensillum, and its associated mechanosensitive neuron (Camhi, 1984; Ewing, 1989; Tautz, 1979). Since these trichoid or filiform sensilla have equal pressure on all sides, they cannot respond to pressure waves caused by sound. Instead, the seta can move freely in the flexible, cuticular socket in response to directional movements caused by particle oscillation (Camhi, 1984; Fletcher, 1978; Michelsen and Nocke, 1974). An interesting property of particle displacement is that it is a vector 


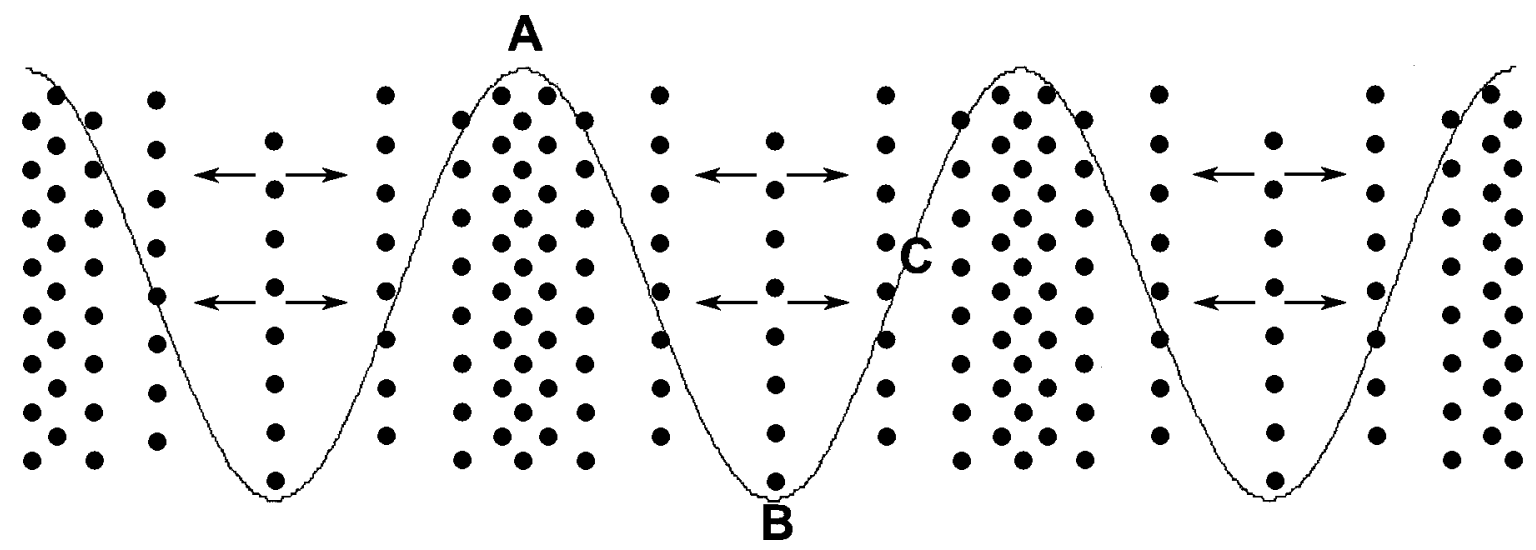

Figure 1.1. Diagrammatic representation of a sound wave. Tympanal ears detect pressure oscillations (far-field sound), whereas movement receptors detect particle displacement (near-field sound). A: Compression of particles causes pressure maxima at the wave peak, and particle displacement is minimal. B: Rarefraction of particles causes pressure minima at the wave trough, and particle displacement is minimal. C: Between peaks and troughs, there is no pressure change, and particle displacement and velocity are maximal. 
quantity, which means that a displacement receiver can detect its orientation in a sound field, whereas tympanal ears cannot, because pressure is a scalar quantity (Camhi, 1984). Filiform sensilla sensitive to particle displacement are found in a wide range of arthropod taxa, including crayfish (Wiese, 1976), spiders (Shaw, 1994), cockroaches (Pflüger and Tautz, 1981), locusts (Barth and Höller, 1999), and lepidopterous larvae (Mark1 and Tautz, 1975). These near-field receptors are generally sensitive to lower sound frequencies than tympanal ears (Yack, 2004).

Some other taxa possess more complex near-field receptors, composed of chordotonal organs. For example, the Johnston's organ in insect antennae uses many more mechanoreceptors than simple filiform sensilla, but the receiver, usually the flagellum or arista, functions according to the same principles (Ewing 1989). Male Drosophila spp. (Diptera: Drosophilidae) vibrate either one or both wings to produce species-specific songs during courtship rituals (Ewing 1968; Bennet-Clark, 1971; Rybak et al., 2002). These songs utilize a relatively narrow carrier frequency, usually between $100-450 \mathrm{~Hz}$, which is received by females as near-field sound (Rybak et al., 2002). Conversely, male mosquitoes (Diptera: Culicidae) hear the near-field sounds produced by wingbeats of female conspecifics during courtship (e.g. Gopfert et al., 1999; Gopfert and Robert, 2000; Gibson and Russell, 2006). It has also been established that near-field sound is an important component of the waggle dance in honeybees (Hymenoptera: Apidae) (Kirchner, 1994; Michelsen et al., 1987).

\section{Near-Field Hearing in Lepidoptera}

Although lepidopterous larvae are also capable of hearing near-field sound, this group has not received as much attention as honeybees, mosquitoes, and fruit flies. At 
Table 1.1. Lepidopteran taxa in which larvae have been reported to respond to sounds.

\begin{tabular}{|c|c|c|c|c|c|c|}
\hline Species & Family & Superfamily & Sound Source & $\begin{array}{l}\text { Best Frequency } \\
(\mathbf{H z})\end{array}$ & Typical Response & References \\
\hline Actias luna & Saturniidae & Bombycoidea & Tuning fork & 512 & head retraction & Minnich 1936 \\
\hline Antheraea polyphemus & Saturniidae & Bombycoidea & Tuning fork & $256 \& 512$ & head retraction & Minnich 1936 \\
\hline Automeris io & Saturniidae & Bombycoidea & Tuning fork & 256 & head retraction & Minnich 1936 \\
\hline Hylesias sp. & Saturniidae & Bombycoidea & Voice, parasitoids & $\mathrm{n} / \mathrm{a}$ & $\begin{array}{l}\text { dorsal or lateral } \\
\text { flicking }\end{array}$ & Hogue 1972 \\
\hline unknown sp. & Geometridae & Geometroidea & Tuning fork & 512 & freezing & Minnich 1936 \\
\hline Lasiocampa quercus & Lasiocampidae & Lasiocampoidea & clapping, whistles & $\mathrm{n} / \mathrm{a}$ & jerking heads & Johnson 1893 \\
\hline Malacosoma pluviale & Lasiocampidae & Lasiocampoidea & $\begin{array}{l}\text { Frequency } \\
\text { generator }\end{array}$ & $300-900$ & lateral flicking & $\begin{array}{l}\text { Myers and Smith } \\
1978\end{array}$ \\
\hline unknown sp. & Arctiidae & Noctuoidea & Tuning fork & $256 \& 512$ & & Minnich 1936 \\
\hline Callimorpha dominula & Arctiidae & Noctuoidea & voice & $n / a$ & lateral flicking & Tutt, 1893 \\
\hline Euchaetes egle & Arctiidae & Noctuoidea & Tuning fork & $256 \& 512$ & lateral flicking & Minnich 1936 \\
\hline Parasemia plantaginis & Arctiidae & Noctuoidea & voice & $\mathrm{n} / \mathrm{a}$ & lateral flicking & Tutt, 1893 \\
\hline Alypia octomaculata & Noctuidae & Noctuoidea & Tuning fork & $\mathrm{n} / \mathrm{a}$ & head retraction & Minnich 1925 \\
\hline Mamestra brassicae & Noctuidae & Noctuoidea & Tuning fork & $100-600$ & lateral flicking & $\begin{array}{l}\text { Markl and Tautz, } \\
1975\end{array}$ \\
\hline Mamestra picta & Noctuidae & Noctuoidea & Tuning fork & $256 \& 512$ & lateral flicking & Minnich 1936 \\
\hline $\begin{array}{l}\text { Cerura scitiscripta } \\
\text { multiscripta }\end{array}$ & Notodontidae & Noctuoidea & Human voice & $\mathrm{n} / \mathrm{a}$ & $\begin{array}{c}\text { "stabbing" with anal } \\
\text { prolegs }\end{array}$ & Klots 1969 \\
\hline Datana ministra & Notodontidae & Noctuoidea & Tuning fork & 256 & & Minnich 1936 \\
\hline Datana perspicua & Notodontidae & Noctuoidea & Tuning fork & 256 & & Minnich 1936 \\
\hline Furcula borealis & Notodontidae & Noctuoidea & $\begin{array}{l}\text { Frequency } \\
\text { generator }\end{array}$ & $330-360$ & $\begin{array}{c}\text { "stabbing" with anal } \\
\text { prolegs }\end{array}$ & White et al. 1983 \\
\hline Danaus plexippus & Nymphalidae & Papilionoidea & Tuning fork & 512 & dorsal flicking & $\begin{array}{l}\text { Minnich } 1936 \\
\text { Rothschild and } \\
\text { Bergstrom } 1997\end{array}$ \\
\hline Inachis io & Nymphalidae & Papilionoidea & $\mathrm{n} / \mathrm{a}$ & n/a & $\mathrm{n} / \mathrm{a}$ & $\begin{array}{l}\text { (cited in Minnich, } \\
\text { 1925) }\end{array}$ \\
\hline Limenitis archippus & Nymphalidae & Papilionoidea & Tuning fork & & head retraction & Minnich 1925 \\
\hline Limenitis arthemis & Nymphalidae & Papilionoidea & Tuning fork & $256 \& 512$ & & Minnich 1936 \\
\hline Nymphalis antiopa & Nymphalidae & Papilionoidea & Tuning fork & 256 & $\begin{array}{l}\text { dorsal or lateral } \\
\text { flicking }\end{array}$ & $\begin{array}{l}\text { Minnich } 1925 \\
\text { Minnich } 1936\end{array}$ \\
\hline
\end{tabular}




\begin{tabular}{|c|c|c|c|c|c|c|}
\hline Nymphalis polychloros & Nymphalidae & Papilionoidea & $n / a$ & $\mathrm{n} / \mathrm{a}$ & & $\begin{array}{l}\text { (cited in Minnich, } \\
1925 \text { ) }\end{array}$ \\
\hline Nymphalis urticae & Nymphalidae & Papilionoidea & voice & $n / a$ & lateral flicking & Tutt, 1893 \\
\hline Vanessa atalanta & Nymphalidae & Papilionoidea & Tuning fork & $256 \& 512$ & head retraction & Minnich 1936 \\
\hline Vanessa cardui & Nymphalidae & Papilionoidea & Tuning fork & 1024 & head retraction & Minnich 1936 \\
\hline Papilio polyxenes & Papilionidae & Papilionoidea & Tuning fork & 256 & $n / a$ & Minnich 1936 \\
\hline Papilio turnus & Papilionidae & Papilionoidea & Tuning fork & 512 & $\mathrm{n} / \mathrm{a}$ & Minnich 1936 \\
\hline Colias philodice & Pieridae & Papilionoidea & Tuning fork & 512 & $\mathrm{n} / \mathrm{a}$ & Minnich 1936 \\
\hline
\end{tabular}


least 30 species of Lepidoptera have been reported to have some sort of response to sound, and these responses are highly variable (Table 1.1). Species vary in their types of response and their sensitivity to different sounds, yet all species that have been thoroughly tested for their ability to hear have been shown to be at least somewhat responsive to relatively low frequencies of sound (Minnich, 1936).

Only one species of Lepidoptera has received a considerable amount of attention with respect to sound perception: Mamestra (Barathra) brassicae Lepidoptera: Noctuidae). Markl and Tautz (1975) located near-field receptors on this species using ablation experiments, and found that they have four pairs of filiform sensilla on the thorax (Fig. 1.2) which are responsive to medium vibration: two pairs on the prothorax, and one pair each on the mesothorax and metathorax. Markl and Tautz (1975) were also the first to use a standing wave tube to demonstrate that it was near-field sound to which the caterpillars were sensitive, and not sound pressure. The sensilla are an average of 5 $\mu \mathrm{m}$ in diameter, and $508 \mu \mathrm{m}$ in length (Markl and Tautz, 1975). On the prothorax, the sensilla are bent and have elliptically shaped mobility. The rest of the sensilla are straight and erect, with circular mobility. Each sensillum was innervated by a single sensory neuron (Tautz, 1978). The mechanical model developed by Tautz shows that these sensilla are nearly optimally adapted receivers for particle velocity in the range of $100-$ $400 \mathrm{~Hz}$ (Markl and Tautz, 1975). Behavioural audiograms demonstrate that M. brassicae larvae respond to sound frequencies between 40 and $1000 \mathrm{~Hz}$ (Markl and Tautz, 1975). Markl and Tautz (1975) also performed ablation experiments that revealed that sensitivity of the larvae to sound was dependent only on the number of sensilla left intact, and that removal of different combinations of the same number of sensilla did not affect the sound intensity threshold. 


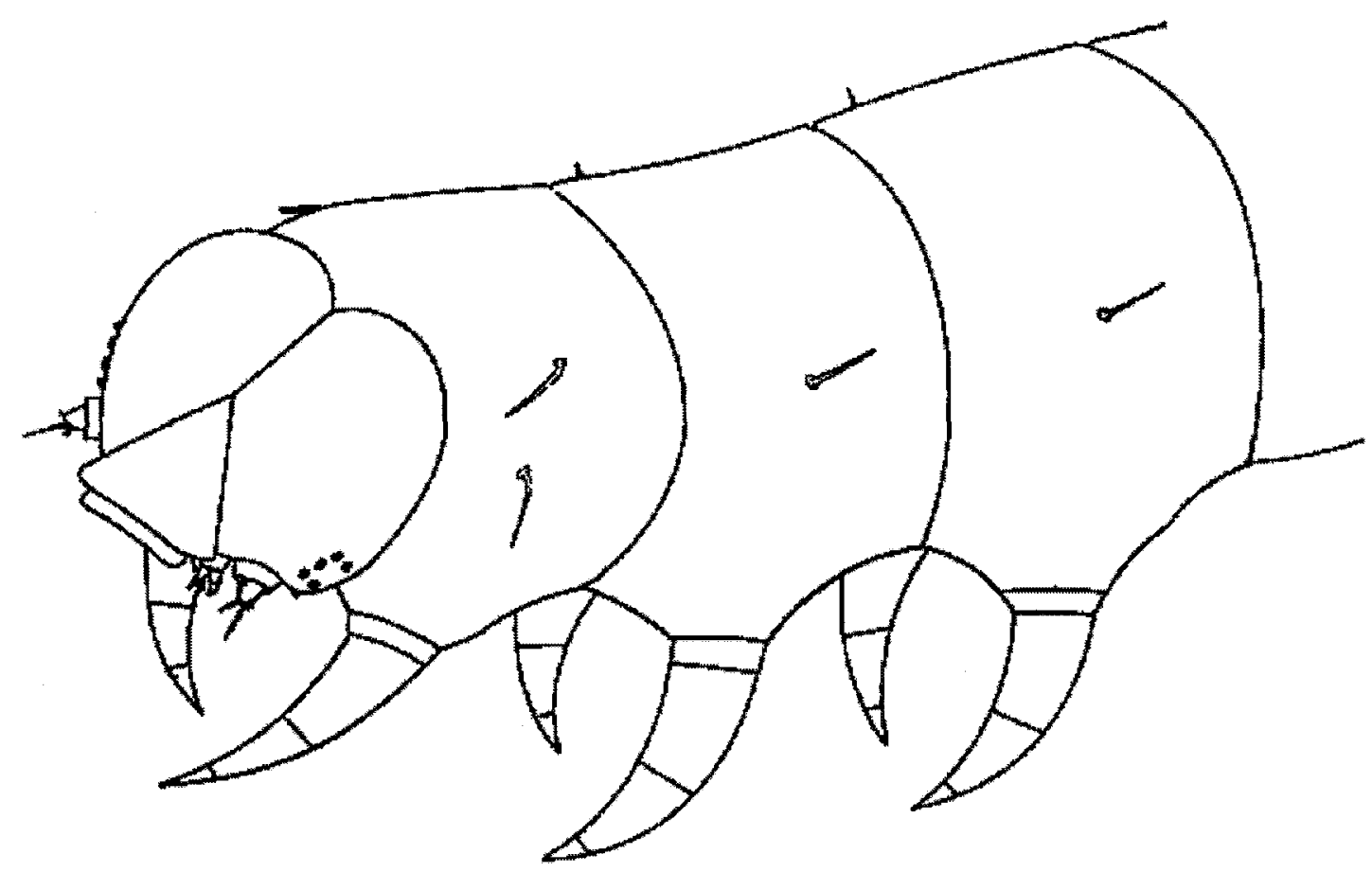

Figure 1.2. Distribution of the eight near-field receptors (filiform sensilla) on the thorax of Mamestra brassica. All four pairs of filiform sensilla are equally involved in sound reception. Mean length for all sensilla is $508 \mu \mathrm{m}$ and a basal width is $5 \mu \mathrm{m}$. The two pairs on the prothorax are bent and have elliptical mobility, and the pairs on the mesothorax and metathorax have circular mobility. Reproduced from Markl and Tautz, 1975. 
Behavioural experiments by Tautz and Markl (1978) showed that the responses of $M$. brassicae are effective at deterring predation. When exposed to sound or the predatory wasp Dolichovespula media (Hymenoptera: Vespidae), the larvae will freeze, flick laterally, or drop to the ground, which improved the chances of surviving an attack, compared to larvae that had their sensilla removed (Tautz and Markl, 1978). This suggests that near-field hearing may have evolved to detect flying predators or parasitoids.

Aside from the thorough research on $M$. brassicae, descriptions of responses to sound tend to occur in one of two types of publications. The first type is a general description of a species, which only briefly mentions the phenomenon, such as Frohawk (1903), who noted that "any sudden noise sufficient to cause concussion of the air causes the whole brood [of Nymphalis antiopa larvae] to give a violent jerk." Other publications are short exploratory research papers that examined the behaviour or some facet thereof (e.g. Klots, 1969; White et al., 1983; Myers and Smith, 1978). Evidence of hearing in general species descriptions is more difficult to locate, since a priori knowledge of the behaviour in a particular species is necessary to search for these publications. With this in mind, the compiled list of species known to be responsive to sound (Table 1.1) is not likely exhaustive. Indeed, Minnich (1936) surmised that "the response [to sound] is so widespread as to indicate a very general, perhaps universal, characteristic of lepidopterous larvae."

\section{Objectives}

Given the diversity of the lepidopterous larvae that demonstrate the ability to perceive sound, and the different types of responses that have been reported, it is possible 
that the receptor mechanisms have evolved independently in different taxa, as tympanal ears did in adult representatives of this order. However, to date, hearing has not been studied in as much detail as in M. brassicae.

The main purpose of this thesis, and the focus of Chapter 2, is to explore nearfield hearing in the larvae of Danaus plexippus L., the monarch butterfly (Lepidoptera: Danaidae). A previous study of $D$. plexippus confirmed that the larvae respond to sound (Table 1.1), and also that numerous volatile chemicals are released by the insect when it is physically disturbed (Rothschild and Bergström, 1997). Rothschild and Bergström (1997) speculated that these volatile chemicals are released by the caterpillar in response to sound, and that flicking was performed to disperse these chemicals as a defensive reaction to predators or parasitoids. It is not yet known if these chemicals are released in response to sound only. Danaus plexippus was chosen as an ideal candidate for primary investigation for a number of reasons. Larvae of this species have been reported in the literature to vigorously and consistently respond to sound (Rothschild and Bergström, 1997; Minnich, 1936), which are convenient traits for behavioural studies. Despite having been reported to respond to sound, no previous research has described their behaviour in detail, and near-field receptors have never been located. These larvae are also relatively hairless, which means that filiform sensilla would be more conspicuous, making observations and ablations simpler to perform. Additionally, this species can be obtained from a number of local sources, and is easy to rear. There were several objectives of the research conducted with $D$. plexippus. The behavioural response to sound of $D$. plexippus was characterized with behavioural audiograms and observations using high speed video. Their near-field receptors were identified using experimental ablations, and described morphologically using scanning electron microscopy and histology. 
The main objective of Chapter 3 was to expand the knowledge of hearing caterpillars by testing available species, representing the superfamilies Lasiocampoidea, Bombycoidea, Noctuoidea, and Papilionoidea. Behavioural audiograms were attempted with each species in order to characterize their behavioural response to sound. In addition, the behaviour of Malacosoma americanum F. (Lepidoptera: Lasiocampidae) was observed using high speed videography, and putative near-field receptors of Papilio polytes L. (Lepidoptera: Papilionidae), were identified and described.

Chapter 4 is a general discussion that integrates observations from the other chapters, and discusses near-field hearing in an evolutionary context. 


\section{CHAPTER 2}

\section{INTRODUCTION}

Reports of responses to sound by caterpillars date as far back as 1779 (Bonnet, 1779, cited in Minnich, 1936) and review of the literature reveals a diversity of responses across a large number of lepidopteran taxa (Table 1.1). Minnich (1936) demonstrated that all eight species of moth larvae and seven species of butterfly larvae that he tested were responsive to sound, and even surmised that all caterpillars might possess this sense to some degree. There exist anecdotal observations of larval Lepidoptera responding to the human voice, clapping, hovering insects, tuning forks, doors slamming, and even jet aircraft flying overhead (e.g. Tutt, 1893; Minnich, 1925: Rothschild and Bergström, 1997). Responses to these sounds vary by species and sound intensity, and include cessation of movement, contraction of the body, squirming and falling off its support, flicking the head upwards or side to side, and waving or stabbing its furcula (Table 1.1). Given the ubiquitous nature of these responses within larval Lepidoptera, it is surprising that so little formal research has been undertaken on the study of the characteristics of sound that induce a response, the hearing receptors, and the function of hearing.

Formal study has only focused on one species in detail, Mamestra (Barathra) brassicae (Lepidoptera: Noctuidae), the cabbage moth caterpillar. Mamestra brassicae larvae have been demonstrated to respond to near field sounds in the frequency range of $40-1000 \mathrm{~Hz}$, with best frequencies in the range of $100-150 \mathrm{~Hz}$ (Markl and Tautz 1975, Tautz, 1977). The receptor organs were identified using ablation experiments, electrophysiology, and observations of their physical resonant properties (Markl and Tautz 1975; Tautz; 1977; Tautz; 1978). Four pairs of filiform sensilla were identified as the receptors responsible for transducing air vibrations, with two pairs on the prothoracic 
segment, and one pair on each of meso- and metathoracic segments (Markl and Tautz 1975). Further experiments showed that these caterpillars use their unique sense of hearing to detect the air disturbances caused by wingbeats of approaching insect predators. This was evinced by the fact that significantly more intact $M$. brassicae survived attacks by the wasp Dolichovespula media, when compared to those that had their receptors ablated (Tautz and Markl, 1978).

Although thoroughly researched, and an excellent example of hearing in caterpillars, the biology of $M$. brassicae is not necessarily representative of all other species. Given the diversity of Lepidoptera, the behavioural responses to sound, and external morphology, it is possible that different evolutionary histories have led to the evolution of hearing more than once. Selective pressures, such as the relative proportions of predators and parastioids that fly and directly attack lepidopterous larvae, vary widely (Hawkins et al., 1997). Some species face greater adversity from flightless insects or parasitoids that lay their eggs or larvae near the host, but not directly on it; logically, the ability to hear sounds in the near-field should not be effective against these types of enemy. Tympanal (far-field) hearing has evolved independently on at least seven separate occasions in adult Lepidoptera (Minet and Surlykke, 2003; Yack, 2004; Yack and Dawson, 2008), so it is not unreasonable to propose that near-field hearing in larvae may have done the same. Thus, the purpose of this study is to explore hearing in a representative of an entirely different superfamily than Noctuoidea.

Monarch butterflies, Danaus plexippus (Lepidoptera: Nymphalidae), are an extensively researched species, in part due to their large, conspicuous, and colourful adult form, and unique life history, including the vast annual migration to Mexico that is made by some North American populations (Wells and Wells, 1992; Brower, 1995). Minnich 
(1936) first noted larval D. plexippus' tendency to jerk its head in response to sound produced by tuning forks. Rothschild and Bergström (1997) later briefly revisited the phenomenon of monarch larval hearing, but focussed primarily on volatile chemicals released by the larvae when agitated. They identified chemicals that included a known alarm signal and deterrent, but were unable to conclude that these volatiles were released in response to sound (Rothschild and Bergström, 1997). The volatiles were thought to be released from an area near the headcollar region, and the authors supposed that flicking and movement of the tubercles would expose the area from which the chemicals were secreted, and simultaneously facilitate dispersal of the chemicals (Rothschild and Bergström, 1997).

While Rothschild and Bergström (1997) noted several natural and unnatural sounds to which monarch larvae responded, it was by no means a formal study of larval sound reception, and they left many questions unanswered. The frequencies and intensities to which the larvae are responsive are unknown, excepting the broad ranges that Minnich (1936) and his tuning fork experiments delimited. In addition, neither Minnich (1936) nor Rothschild and Bergström (1997) thoroughly described the behavioural responses of the larvae. The main intent of the present study was to explore these issues. Specifically, experiments were designed to characterize the frequencies to which Danaus plexippus larvae were sensitive, describe their behaviour in response to sound, and identify sound receptors. 


\section{MATERIALS AND METHODS}

\section{Animals}

Danaus plexippus (Linn.) were purchased as eggs or larvae from several sources: Gaïa Nature (Granby, QC), Monsieur Papillon (Chambly, QC), and Wish Upon a Butterfly (New Castle, PA, Permit No. P-2008-02240) (see Appendix I). Larvae were raised on milkweed, Asclepias spp. (Gentianales: Apocynaceae), either collected as plants near Carleton University campus (Ottawa, Ontario, Canada) or grown from seed in the greenhouse facility at Carleton. Asclepias sp. plants were planted in individual pots housed in a greenhouse from April to October 2008, and once the plants attained a height of approximately $150 \mathrm{~mm}$, monarch larvae were transferred to the plants in a mesh enclosure. During the spring and autumn, plants and larvae were kept in the greenhouse, but during the hottest months of the summer they were kept in a room $21-23^{\circ} \mathrm{C}$, with a photoperiod of 16:8 (L:D). All larvae used in experiments were in their third, fourth, and fifth instars.

\section{Response to Sound}

Responses to sound were examined by a number of methods. (i) Behavioural audiograms were conducted to determine to which frequencies the larvae were most sensitive. (ii) Responses to $200 \mathrm{~Hz}$ at all sound intensities were recorded during behavioural audiogram trials, and these data were later analysed to determine the effect that intensity had on the type and number of responses. A "habituation/sensitization" experiment was included to observe the effects of the repeated stimulation on the larvae independent of frequency and sound intensity. A "high-low" experiment was included, to confirm that differences in responses were due to different sound intensities only. (iii) 
High-speed videography in conjunction with laser vibrometry enabled accurate evaluation of various parameters of larval response to a loud $200 \mathrm{~Hz}$ tone, including latency and speed of flicks and contractions, and flick angle.

\section{(i) Behavioural Audiograms \& Acoustic Stimulus:}

Audiogram trials were conducted to determine the sound frequencies to which the larvae are most responsive. An individual larva was selected for each audiogram trial, and placed on a potted Asclepias plant placed $200 \mathrm{~mm}$ away from a woofer (Sammi Sound, model CWR 200B50, range 24 Hz-4 kHz; Samut Pakarn, Thailand). The woofer and Asclepias plant were enclosed in a Faraday cage lined with acoustic foam, which had one side unobstructed to allow observation and recording with a video camera (Fig. 2.1). Pure tones ( $1 \mathrm{~s}$ duration, $25 \mathrm{~ms}$ rise/fall, linear ramp) between 100 and $1200 \mathrm{~Hz}$ were generated by a Tucker Davis Technologies digital signal processor (RX6 multifunction processor; Alachua, FL) and shaped using a PC with Tucker Davis software (RPvdsEx, v. 5.4). The first sound pulse of each frequency was delivered at a subthreshold intensity and each successive pulse of the same frequency was increased in $3 \mathrm{~dB}$ steps. Ten second intervals of silence sseparated each pulse of increasing intensity. Subsequent frequencies were presented at 50 or $100 \mathrm{~Hz}$ intervals, which were played in random order, with three minute intervals of silence between frequencies. Audiograms were generated in this manner for a total of 32 larvae. A greater number of audiogram trials were performed at lower sound frequencies to obtain higher resolution in this range, which appeared to be more important to the larvae. All trials were videotaped using one of three video cameras: Sony HDR-HC7 MiniDV, DCR-HC85 MiniDV, or DCR-TRV140 Digital8 Handycam (Tokyo, Japan), and videos were transferred to a computer for analysis (described below), 

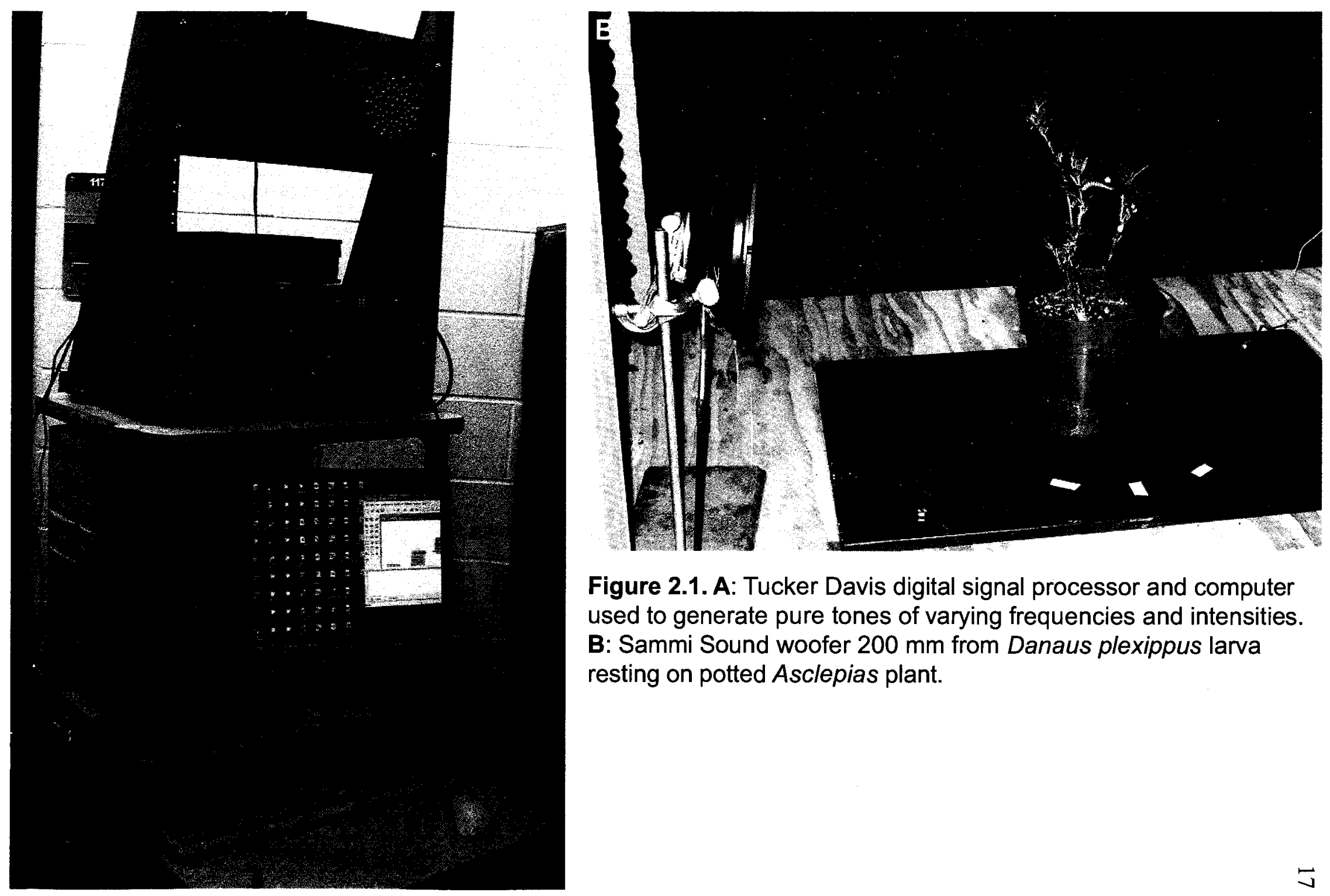

Figure 2.1. A: Tucker Davis digital signal processor and computer used to generate pure tones of varying frequencies and intensities. B: Sammi Sound woofer $200 \mathrm{~mm}$ from Danaus plexippus larva resting on potted Asclepias plant. 
using either iMovie (v. 6.0, Apple Inc.; Cupertino, CA) or KinoDV video editor (v. 1.3, Gnu General Public License). Further analysis of these tapes is discussed in the next section. Humming at or blowing on the larvae was also occasionally used to test responsiveness to these stimuli, but no specific procedure was followed, and trials involving these stimuli were not usually videotaped.

Behaviours were scored by watching the videos at a later date, with reference to the individual, frequency of the sound, and intensity of the sound. Flicks were subcategorized as either "partial" or "full," to establish an approximation that was crudely indicative of flick magnitude. Partial flicks described motions larvae made when their thoracic legs remained attached to the substrate so that they did not actually raise their bodies from the substrate. If the larvae flicked more vigorously, they reached a full flick, where the thoracic legs were distinctly raised from the substrate. This distinction was easily identified during video analysis, and was clearly visible from most viewing angles. Thus, freezing, contractions, and the number of full and partial flicks were recorded, and each behaviour was considered a response to sound if it began within $1 \mathrm{~s}$ from the onset of the sound pulse.

One behavioural audiogram was constructed that considered the threshold values at each frequency to be the minimum intensity at which any response to sound (i.e. flicking, contracting, or freezing) was observed. Threshold values obtained for this data set were also plotted on particle velocity $(\mathrm{m} / \mathrm{s})$ and particle displacement $(\mu \mathrm{m})$ curves (see below). Another behavioural audiogram was compiled using a subset of the same data, which only calculated threshold values as the lowest intensity where flicks occurred.

The intensity of the sound ( $\mathrm{dB}_{\mathrm{SPL}}, \mathrm{C}$-weighting) was calibrated for all frequencies using Brüel \& Kjær Type 2239A sound level meter (Naerum, Denmark), and best fit lines 


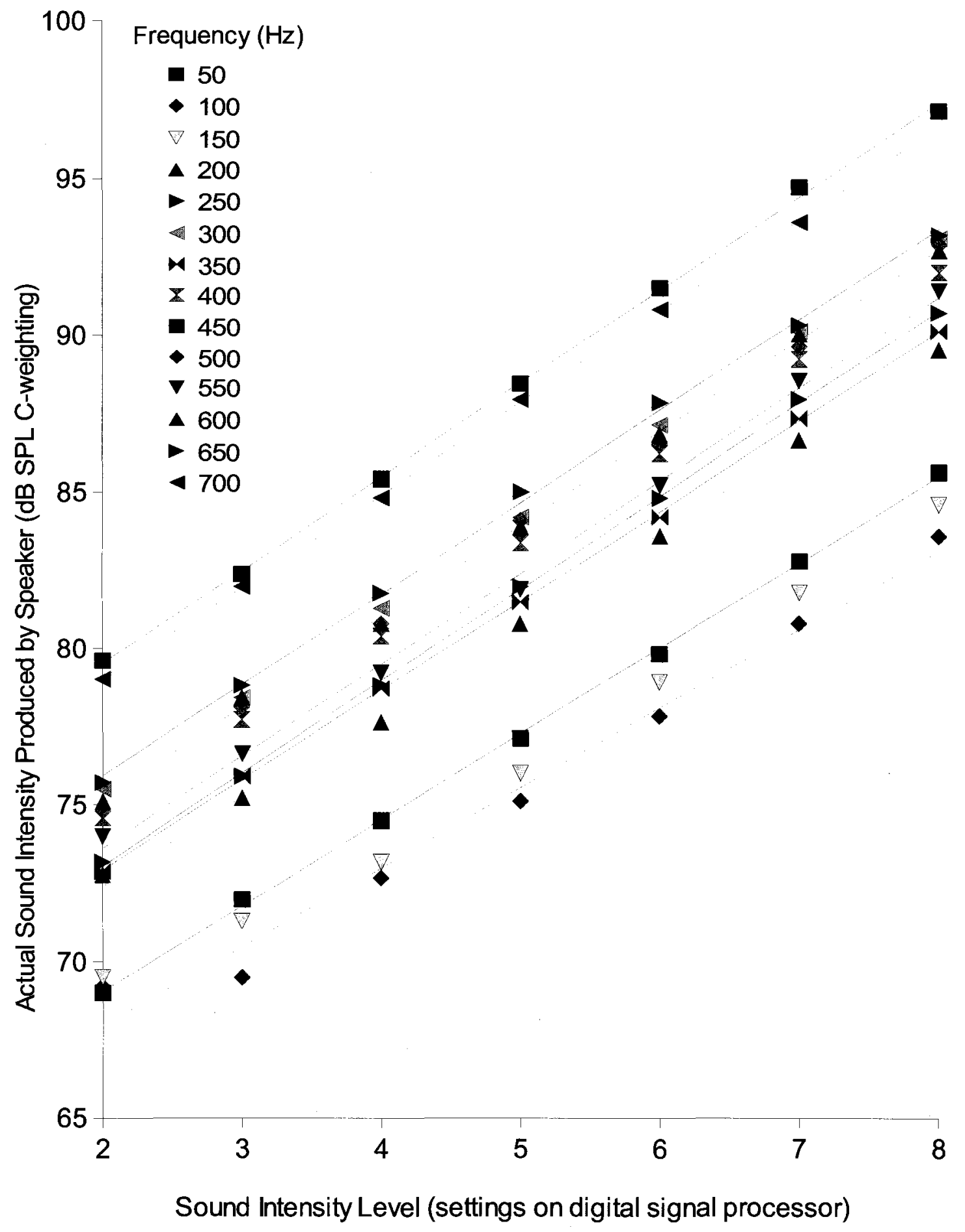

Figure 2.2. Speaker calibration curves for Sammi Sound woofer, over 50-700 $\mathrm{Hz}$. Functions obtained from best fit lines of these curves were used to calculate actual sound pressure level (dB SPL, C-weighted) values from the arbitrary intensity levels that were recorded during data analysis. 
were generated for each frequency using linear regression (Fig. 2.2). Intensities at the highest attenuation setting on the Tucker Davis digital signal processor were ignored, because the sound level obtained at this setting were discrepant. Actual sound level $\left(\mathrm{dB}_{\mathrm{SPL}}\right)$ was calculated for each measured frequency and intensity, using equations derived from the best fit lines (Fig. 2.2).

Although sound pressure is presumably not important to larval Lepidoptera, behavioural audiograms plotted against sound pressure level were included in the results for two reasons. Firstly, because they were measured at the same distance from the sound source, they provide information on the relative sensitivity to different frequencies of sound. Secondly, they provide context that relates near-field sound to the human perception of far-field sound. However, it should be noted that since these values were measured with $\mathrm{C}$-weighting, this means that the decibel level is proportional to the actual power of the sound pressure waves for all frequencies measured. The A-weighted curve is intended to more closely match the human experience of loudness at different frequencies, but it does not accurately represent sound pressure levels (Smith, 1999). Since humans are less sensitive to low frequency $(<200 \mathrm{~Hz})$ sounds, the decibel values presented may seem high compared to how a human would actually experience the sound.

Sounds were measured in sound pressure level, but larval Lepidoptera have been shown to hear near-field sound, so measurements in decibels were converted to particle velocity $(v)$ and particle displacement $(\xi)$ in several steps. Particle velocity is proportional to sound pressure, but particle displacement is dependent on frequency of the sound and distance from the sound source (Beranek, 1954). The speaker was considered a monopole for the purposes of analysis, but this was only an approximation (Beranek, 1954; Tautz, 
1977). First, the sound pressure $p_{r m s}$ in Pascals was determined from sound pressure level $L_{p}$ where $p_{r e f}$ is $20 \mu \mathrm{Pa}\left(0 \mathrm{~dB}_{\mathrm{SPL}}\right.$, human threshold of hearing) using the following equation:

$p_{r m s}=p_{r e f} \cdot 10^{\frac{L p}{20}}$

Particle velocity $v$ and displacement $\xi$ were calculated from the following equations ( $P=$ sound pressure obtained from the above equation; $\rho$ : density of air at 20 ${ }^{\circ} \mathrm{C}\left(1.204 \mathrm{~kg} / \mathrm{m}^{3}\right), c$ : velocity of sound at $20{ }^{\circ} \mathrm{C}(343.2 \mathrm{~m} / \mathrm{s}) ; f$ : frequency $(\mathrm{Hz}) ; r$ : distance from sound source $(200 \mathrm{~mm}) ; \lambda$ : wavelength of the sound that was measured; $\gamma$ : phase angle between $\xi$ and $\xi_{\mathrm{F}}$ ):

$\nu=\frac{p}{\rho \cdot c}$ and $\xi_{F}=\frac{p}{\rho \cdot c \cdot 2 \cdot \pi \cdot f}$

$\xi$ was corrected by $\quad \xi=\frac{\xi_{F}}{\cos (\gamma)}$ where: $\tan |\gamma|=\frac{\lambda}{2 \cdot \pi \cdot r}$

because $r<\lambda$ for all frequencies tested (Tautz, 1979).

All raw data were converted to particle velocity or displacement values prior to further analysis; means, maxima and minima, standard deviations, and $95 \%$ confidence intervals were re-calculated from this modified data set. Threshold values for flicks only and all responses were each plotted against particle velocity and particle displacement. Particle velocity was plotted on a logarithmic scale.

(ii) Behavioural responses related to sound intensity from audiogram videos at $200 \mathrm{~Hz}$

Audiogram data from video recordings of 32 audiogram trials (described above) were used to determine relationships between the types and numbers of behavioural responses and the sound stimulus intensity. Responses to $200 \mathrm{~Hz}$ tones were used for this 
analysis because this was the best response frequency with the largest data set. The number of larvae that responded to a $200 \mathrm{~Hz}$ tone by flicking or contracting was compared between each of the 8 sound intensities investigated. The mean numbers of times each caterpillar flicked, of those that responded by flicking, was also compared. Additionally, the relationship between flick magnitude and sound intensity was also examined, by comparing the mean number of full and partial flicks reported at each intensity of the $200 \mathrm{~Hz}$ tone.

A separate habituation/sensitization experiment was conducted to examine any possible effects of decreasing or increasing responsiveness that repeated stimulation might have on the larvae. One-second long tones of a single frequency were played repeatedly, at ten second intervals, in a manner identical to the audiogram experiments (see above), except that the intensity of the sound was kept constant, instead of slowly increasing. A tone with a frequency of $200 \mathrm{~Hz}$ was was played at $92 \mathrm{~dB}_{\mathrm{SPL}}$ (which corresponds to the loudest setting used in the audiograms) to elicit the largest number of flicks possible, and was repeated until each larva stopped responding. The number of flicks at each nth tone was recorded in this fashion for six larvae.

A "high-low" experiment was conducted separately from audiogram trials, to confirm that the differences in responsiveness observed between different intensities of sound were accurately reflective of the effect of differing sound intensity on the behaviour of the larvae. Pauses of ten seconds between stimuli that occurred during the audiogram trials may have been insufficient to eliminate any effects caused by habituation or sensitization. Thus, this second experiment involved playing each of several larvae a relatively quiet and loud stimulus, with a much longer period of time between stimuli. Single one second tones of $200 \mathrm{~Hz}$ played at $84 \mathrm{~dB}_{\mathrm{SPL}}$ and $92 \mathrm{~dB}_{\mathrm{SPL}}$ 
(corresponding to the fifth highest and highest sound intensity settings used in the audiograms, respectively) were presented to each of 17 larvae, with five minutes of silence between stimuli. Additionally, audiogram trials were always performed in the order of increasing intensity, so the order in which the stimuli were presented in this experiment was randomized such that approximately half received the high intensity stimulus first. The number of flicks that each individual performed at each stimulus was recorded, and any individual that did not respond by flicking to either of the stimuli was not included in analysis. A paired t-test was used to determine if the number of flicks was significantly different between the two sound intensities.

\section{(iii) High speed video and laser vibrometry}

Precise measurements of response latencies and temporal relationships of movement patterns were not obtainable with regular video recordings, and observations at a higher number of frames per second were required. Visual representation of stimulus onset and an accurate graphical display of vibrational disturbances caused by caterpillar movement enabled us to temporally describe a larva's motion with greater accuracy. This was achieved by simultaneously recording data from a microphone, high speed camera, and laser vibrometer (Fig. 2.3). Contractions and flicks were captured with high speed videography and laser vibrometry; freezing was not observed. Stimulus start time, incidence and cessation of contractions and flicks were recorded, so that latency, duration, and intervals of each movement could be calculated. The decrease in body length during each contraction and the angle to which larvae flicked was also measured. Late instar larvae were tested in a natural resting position on a potted Asclepias plant, which was illuminated with a halogen lamp during high speed recordings. Sounds 


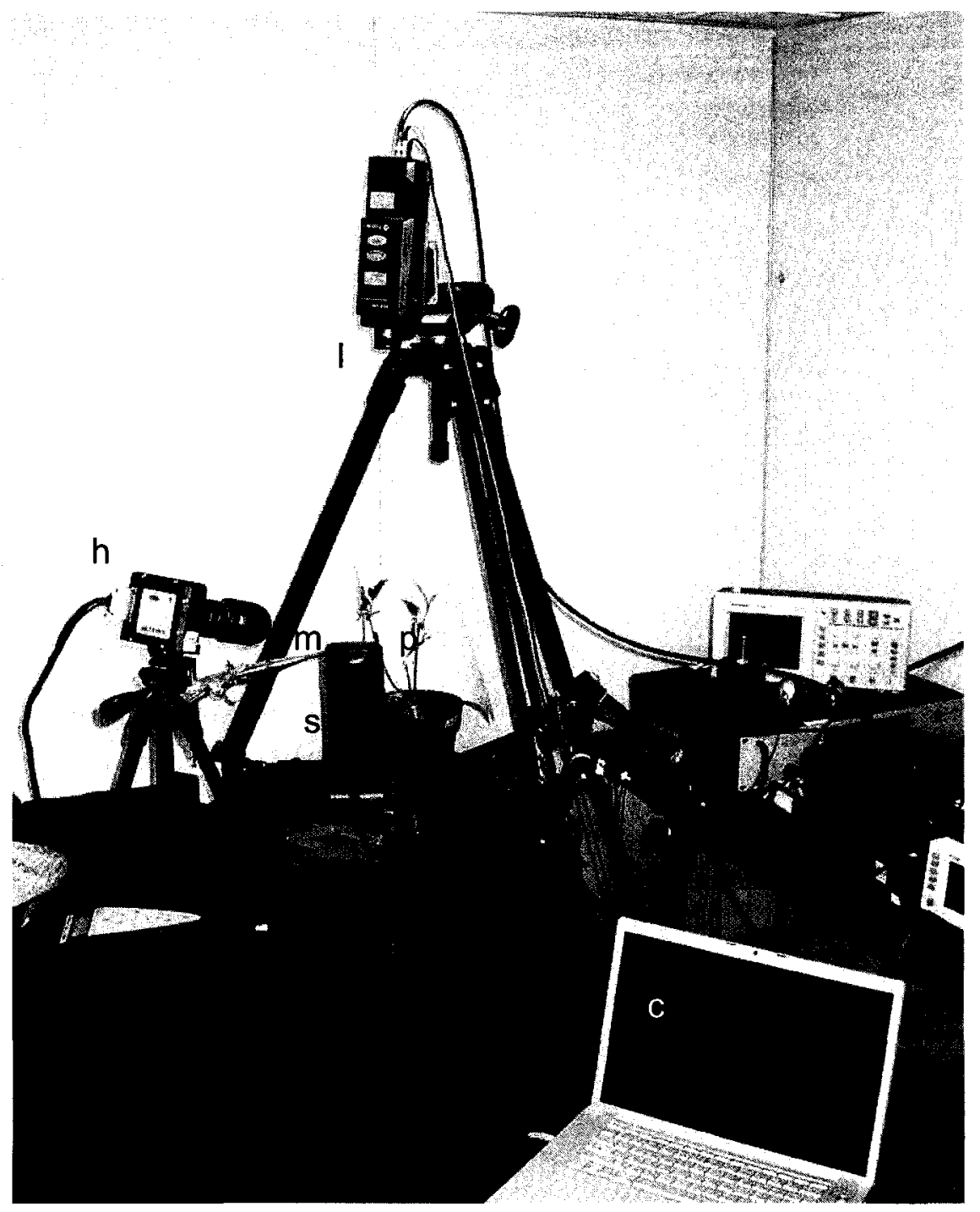

Figure 2.3. High speed videography set-up. Raven on MacBook laptop played $200 \mathrm{~Hz}$ tones through speakers (s). Microphone $(\mathrm{m})$, high speed camera $(\mathrm{h})$, and laser vibrometer (I) recorded sound, video, and vibration data from Danaus plexippus transmitted through Asclepias sp. plant (p) onto MiDAS analysis software (not shown). 
presented to caterpillars during the high speed video trials were $200 \mathrm{~Hz}$ tones, one second in duration, of intensities determined to be either approximately 95 or $99 \mathrm{~dB}_{\mathrm{SPL}}$. Longer tones were used during a limited number of additional trials, but videos obtained from these trials were not included in quantitative data analysis. These parameters were chosen because they were previously demonstrated from the audiogram experiments (described above) to be most effective at eliciting a response from larvae.

Sounds were generated using Raven Pro v. 1.3 interactive sound analysis software (Cornell Lab of Ornithology; Ithaca, NY) on a MacBook Pro (Apple, Inc.; Cupertino, CA) computer and played through Logitech R10 (Romanel-sur-Morges, Switzerland) speakers placed $300 \mathrm{~mm}$ from the caterpillar. Sounds were recorded using an Earthworks (QTC40; Milford, NH) condenser microphone, which was output through a Fostex Field Memory Recorder (FR-2; Tokyo, Japan) or Marantz Portable Solid State Recorder (PMD671; Kanagawa, Japan) data recorder to provide phantom power. Audio data were sampled at 6250 or $16000 \mathrm{~Hz}$ and recorded onto the high speed camera set-up on an A70 Toshiba Satellite (Tokyo, Japan) notebook computer, which allowed for latency calculations. Laser Doppler vibrometry was used to monitor subtle movements of the caterpillar in response to sound. An adhesive reflective disc (4 $\mathrm{mm}$ diameter) was placed on a nearby leaf to improve resolution for the vibrometer. Vibrations resulting from movements of the caterpillar were recorded using a Polytec, PDV-100 portable digital vibrometer. Laser data were sampled at 6250 or $16000 \mathrm{~Hz}$, and transmitted through MiDAS DA-123 Data Acquisition Module (Cambridge, MA) to the notebook computer.

A DRS Lightnight RDT (Itronx Imaging Technologies, Westlake Village, CA) high speed camera was used with Xcitec MiDAS software (v. 2.0; Cambridge, MA) to 
capture the video at 250 or 400 frames per second. Caterpillar movements, the sound stimulus and the vibrational response were monitored simultaneously.

Contraction data were analyzed from seven or eight trials with five individuals by measuring latency, duration and body length of the larvae before and during each contraction. Latency of each contraction was calculated by subtracting the time at which the sound began and the start time of the behaviour, as evinced by watching the video and coinciding disturbance in the laser trace. Body length measurements were obtained by analyzing frames before and during each contraction from the high speed video in ImageJ image processing and analysis software (v. 1.38; U.S. National Institutes of Health, Bethesda, MD).

Data for flick responses were calculated for up to 45 flicks over 18 trials with 13 individuals. The rise time of a flick was defined as the time it takes the caterpillar to reach the peak position of a flick from resting position, and the fall time was the amount of time it took to return to its resting position. These values were obtained from a combination of the laser and video data, which usually clearly indicated where a flick began and ended. Flick latency was calculated in the same manner as contractions (see above). Flick angles were calculated by measuring the angle between the portion of the caterpillar's body lifted from the substrate and that which was still attached, which usually meant that the fulcrum was located just anterior of the first pair of prolegs. Sometimes the larvae were resting such that their bodies were not positioned in a straight line, so to calculate flick angle, the angle that their bodies made before the flick was subtracted from the angle it made following the flick. Flick angles were measured using ImageJ software (see above).

Means, minima, maxima, and $95 \%$ confidence intervals were calculated where 
possible, from contractions and flicks. Data was compared between individuals using unpaired t-tests, ANOVA, or linear regression; paired t-tests were used to compare differences between two parameters among individuals. Statistical significance was interpreted as $\alpha \leq 0.05$. Figures displaying laser and audio data were constructed by exporting data to MATLAB (v. 7.0; The MathWorks, Natick, MA).

\section{Anatomy}

\section{External morphology}

External morphology was examined using light and scanning electron microscopy in order to identify putative receptor organs, and then to measure external characteristics of these organs.

Initial examinations of putative receptors were conducted using an Olympus (Tokyo, Japan) SZX12 stereo microscope. There were a few possible candidates, including filiform sensilla, the prothoracic shield, and tubercles. Research by Minnich (1936) suggests that there may be a diffuse distribution of receptors on the first two thirds of the body of D. plexippus larvae. Following preliminary ablations, and with the guidance of findings from Markl and Tautz (1975), which report that specialized sensilla were used by $M$. brassicae larvae to detect sounds, we eventually focused on particular sensilla for further morphological descriptions (see results). Sensilla from 17 fifth instar larvae fixed in alcohol, glutaraldehyde, or $\mathrm{C} \& \mathrm{C}$ were measured using a stereo microscope (Olympus (Tokyo, Japan) SZX12) equipped with a Zeiss (Oberkochen, Germany) AxioCam MRc5 camera (1.4 megapixels, 1388 x 1040). Larvae were manipulated so that the whole sensillum was usually in focus at once, to ensure accurate measurement. This was not always possible, as occasionally tubercles or wrinkles in the body that had 
been fixed in position interfered with the ideal view of the sensilla. Lengths of sensilla were measured using AxioVision (v. 4.6) software. Head capsules were photographed and later measured to determine to which instar the larvae belonged (Oberhauser and Kuda, 1997).

\section{Scanning electron microscopy}

Scanning electron micrographs were taken of several sensilla, as well as the prothoracic shield and tubercles. Seven larvae were injected with, and placed in, $70 \%$ ethanol and stored until two days prior to critical point drying. In preparation for critical point drying, each larva was severed between the thorax and abdomen, and between abdominal segments 9 and 10 to. The anterior and posterior portions were reserved for electron microscopy. Two days before critical point drying, the tissue was transferred to $95 \%$ ethanol for 8 hours, and then into $100 \%$ ethanol for 16 hours. The specimens were critical point dried using a Polaron Critical Point Drying Apparatus (E3100 Jumbo Series II; Hertfordshire, England) for two hours, with a liquid carbon dioxide change every 15 minutes. The dried specimens were mounted on aluminum stubs, and sputter-coated with gold-palladium. The tissue was then examined using a JEOL (Tokyo, Japan) JSM-6400 scanning electron microscope.

\section{Paraffin section histology}

Larvae were injected with, and fixed in, $3 \%$ glutaraldehyde in $0.2 \mathrm{M}$ dibasic phosphate buffer (Humason, 1997) or C\&C (Chauthani and Callahan, 1966) and stored at $4{ }^{\circ} \mathrm{C}$ until required. Tissue containing either sensilla, tubercles or the prothoracic shield was excised from individuals, dehydrated in an ethanol series $(50,70,80$, and $95 \%$ for 30 min. each, then three changes of $100 \%$ for $20 \mathrm{~min}$. each), and transferred to two changes 
of xylene or Histo-Clear clearing agent (National Diagnostics, Atlanta, GA). The cleared tissue was infiltrated with two changes of Paraplast X-tra paraffin (McCormick Scientific, St. Louis, MO) at $60^{\circ} \mathrm{C}$ for 30 minutes, then embedded in the same and immediately stored at $4{ }^{\circ} \mathrm{C}$ until required. Paraffin moulds were trimmed using a razor blade, and adhered to wooden blocks. These blocks were allowed to set for fifteen minutes or more before sectioning. Thick $(5-10 \mu \mathrm{m})$ sections were cut with a Leitz 1512 (Wetzlar, Germany) microtome and transferred to Fisherbrand Superfrost/Plus slides, warmed on a Fisher Scientific (Pittsburgh, PA) slide warmer overnight at $40^{\circ} \mathrm{C}$. The following day, they were deparaffinized through a xylene/Histo-Clear and ethanol series, and stained with 3\% Polysciences Multiple Stain Solution (Polysciences, Inc., Warrington, PA). Coverslips were affixed with Permount (Fisher Scientific, Pittsburgh, PA), and slides were observed with a Zeiss Axio Imager M1 compound microscope. Images were captured with a Zeiss AxioCam MRm camera (1.4 megapixels, $1388 \mathrm{x}$ 1040) using AxioVision (v. 4.6.3.0) software.

\section{Experimental Ablations}

Larvae needed to be held still in order to remove the sensilla as well as photograph them under the stereo microscope. Several methods of larval immobilization were attempted before a successful technique was chosen. Placing responsive larvae briefly in the refrigerator or freezer immobilized them temporarily following their removal, but within a minute they had usually regained their mobility. Placing them on top of an ice pack was similarly ineffective. As they regained mobility, they moved slowly or in isolated jerky motions, but this unpredictability prevented satisfactory photography, and increased the risk of injury from forceps used to depilate the sensilla. 
Carbon dioxide, which is commonly used as a short-term insect anaesthetic (Nicolas and Sillans, 1989), was effective at completely immobilizing the larvae temporarily. Rather than just slow them down, it relaxed their muscles. The larvae reacted violently to the gas at first, and usually regurgitated and defecated before they lost the ability to move. However, within five minutes after the flow of carbon dioxide ceased, the larvae regained enough mobility to crawl back onto an Asclepias plant, with no apparent lasting adverse effects on their behaviour or physiology. Following ablations, both experimental and control larvae appeared unharmed, and behaved normally.

The larvae were examined in gross detail before proceeding with ablations to identify candidates for near-field receptors, and three pairs of long sensilla were singled out as putative receptors. Ablation experiments were carried out to determine if these sensilla were indeed responsible for sound reception. Larvae were chosen for experimentation if they responded by flicking to a $1 \mathrm{~s} 200 \mathrm{~Hz}$ tone played at approximately $80 \mathrm{~dB}_{\text {SPL. }}$ Larvae that responded were randomly distributed into different experimental groups. To immobilize the caterpillars, they were anaesthetized with the minimum amount of carbon dioxide gas required to keep them immobile, and a stereo microscope was used to locate the sensilla. Removal of all six sensilla took approximately three minutes. Caterpillars chosen as experimental controls were also anaesthetized for the same amount of time, and kept immobile with carbon dioxide. Controls were examined during this time to ensure that all pairs of sensilla on the thorax and tenth abdominal segment were present and intact, which served the dual purpose of exposing the caterpillars to the same gentle manipulation that the experimental caterpillars experienced.

First, it was determined whether or not any of the aforementioned three pairs of 
sensilla were involved with hearing. Each of the two pairs of sensilla on the thorax and single pair of sensilla on the abdomen were simply plucked out using a pair of forceps. All six putative receptors were removed in this fashion from 27 larvae. The pair of sensilla on the tenth abdominal segment, both front pairs of sensilla, or the upper or lower pairs of front sensilla were removed from another 10 caterpillars for each experimental group. Another 15 larvae were chosen as controls for all ablation experiments. Ablations were carried out over a period of several weeks, and each time ablations were performed, at least one caterpillar was anaesthetized as a control, to account for any response variability. The type of treatment that the larvae received was recorded on video and the larvae were painted with different colours of fluorescent entomological grade paint (Shannon Luminous Materials, Inc., Santa Ana, CA) to identify which individuals had received which treatment. As soon as they regained mobility, larvae were placed back on an Asclepias plant, and soon after (5-30 minutes) played a series of $1 \mathrm{~s}$ sound pulses, again at approximately $80 \mathrm{~dB}$ SPL, at 200 and $300 \mathrm{~Hz}$. Loud humming was also used to attempt to induce the larvae to respond. The larvae that did not respond immediately were tested again in 15-30 minutes, and then twice each following day until they moulted or responded. Proportions of ablated and control larvae were compared with chi-square tests. Individuals that responded the day following the ablation were noted as well, but there was a high variability in larval response between days, and many of the larvae had moulted by this time. These complications necessitated that only the data for the first day were included in chi square analysis.

Five of the individuals used in full ablations were third instar larvae that were isolated and observed until following their next moult. At this time, they were once again presented with a stimulus, and it was recorded if they responded. Following this, they 
were observed with the stereo microscope to confirm that they had regrown the sensilla that were removed.

Two additional responsive larvae were tested to ensure that neither the prothoracic shield nor the tubercles were in any way involved in audition. One larva was anaesthetized with carbon dioxide and a human hair was used to ligature the two front tubercles at their base. With dissection scissors, both anterior tubercles were carefully removed. The two rear tubercles were also later removed in the same fashion. The second caterpillar was observed with a stereo microscope and a small globule of entomological paint was daubed onto the prothoracic shield, covering the setae on it, to prevent any from oscillating in response to sound. These larvae were tested again to see if they still responded to sound (see above). 


\section{RESULTS}

\section{Response to Sound}

Generally, monarch larvae responded to sound by exhibiting up to three different behaviours: freezing, which comprised an abrupt cessation of movement; contraction, where the caterpillar slightly contracted the anterior portion of its body; and flicking of the anterior thorax, whereby the caterpillar rapidly lifts the anterior portion of its body up and down in a flicking or jerking motion. These behaviours may not be entirely distinct from one another, since in order to contract, the caterpillar must first cease any other activities, and when it flicks, the head is tucked into the head collar region, as it does during a contraction. Therefore freezes, contractions, and flicks may simply be different magnitudes of the same basic behaviour. However, it was still possible to observe freezes and flicks as discrete events when they occurred in isolation, which they often did. Larvae responded by flicking or contracting to humming, but did not respond in the same manner to sustained air flow, indicating that it was only sound to which they were sensitive. The following results describe first the relationship between different behaviours and the sound frequency and intensity, followed by a more detailed analysis of the characteristics of each behaviour, and finally an analysis of the structures used to detect sounds.

\section{Behavioural Audiograms}

Danaus plexippus larvae responded to pure tones between 50 and $900 \mathrm{~Hz}$, although at higher frequencies, very few larvae responded, and only at high intensities (> $100 \mathrm{~dB}_{\mathrm{SPL}}$ ) (Fig. 2.4). When particle velocity values were calculated using the same data used to create Figure 2.4, a very similarly shaped graph was produced (Fig. 2.5). Thus, 


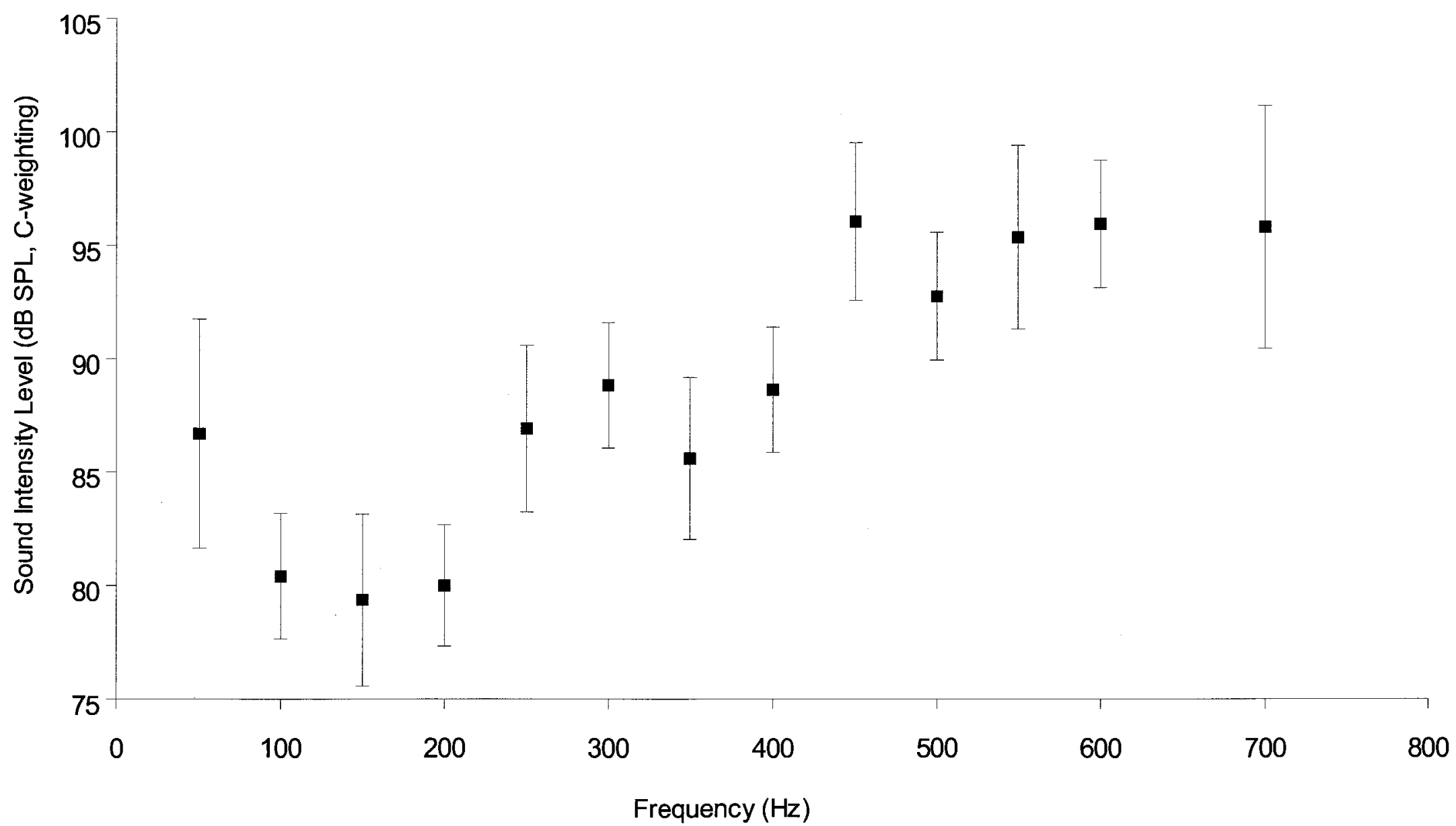

Figure 2.4. Behavioural audiogram for Danaus plexippus larvae, including all responses $(n=32)$.

Where no behavioural response was observed, thresholds were assigned arbitrary values one step $(\sim 3$ $\mathrm{dB}$ SPL, see Fig. 2.2) higher than the highest sound intensity measured for that frequency. Error bars indicate $95 \%$ Confidence Interval of the mean for each frequency. 


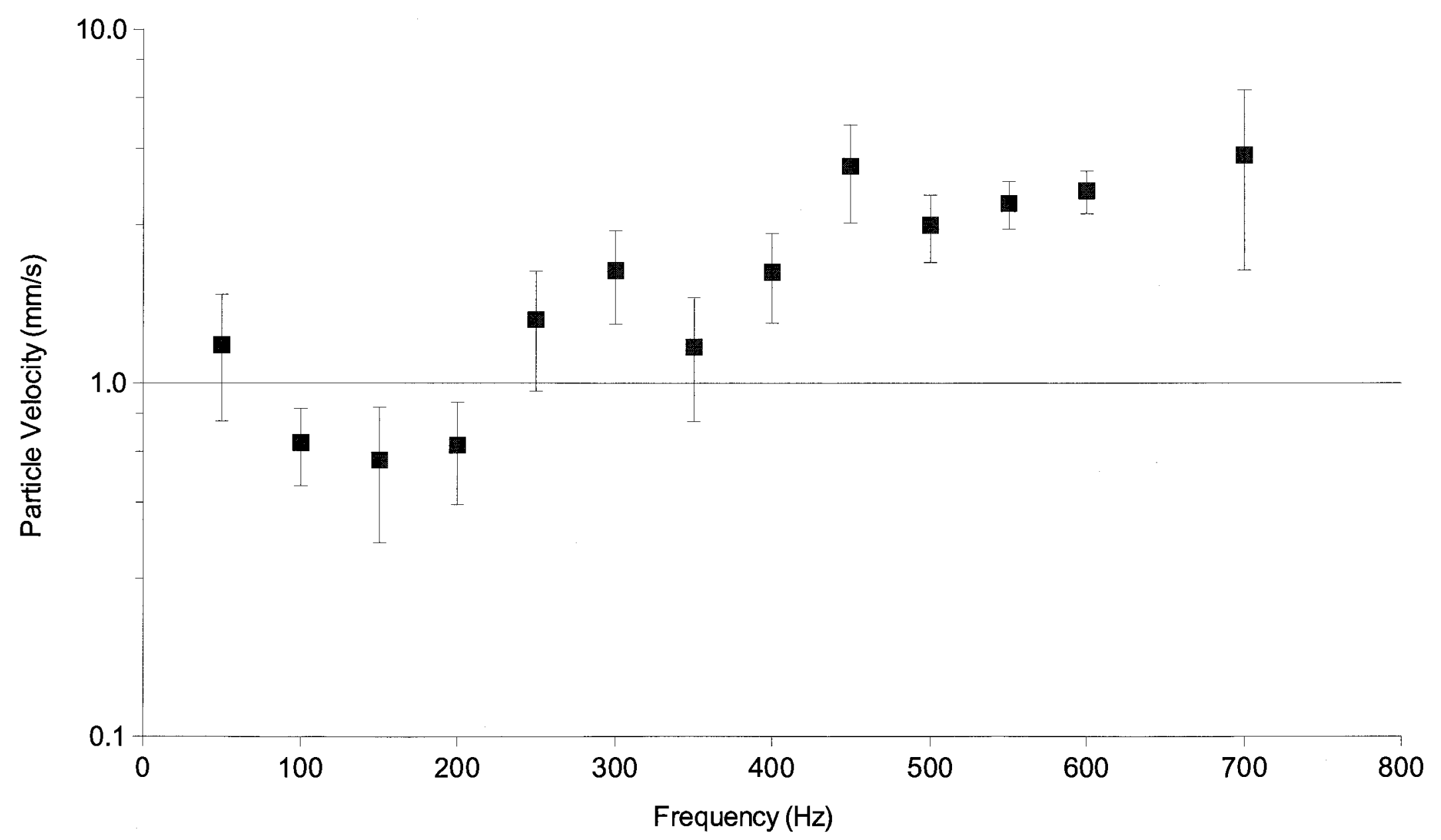

Figure 2.5. Behavioural audiogram for Danaus plexippus larvae, including all responses $(n=32)$. Data used to create Fig. 2.4 recalculated to yield particle velocity. Error bars indicate $95 \%$ Confidence Interval of the mean for each frequency. 
corresponding particle velocity values from Figure 2.5 are included in parentheses in the following description. The audiograms show that the larvae are most sensitive to lowfrequency sounds between 100 and $200 \mathrm{~Hz}$. The median value over all frequencies was $88 \mathrm{~dB}_{\mathrm{SPL}}(1.42 \mathrm{~mm} / \mathrm{s})$, and the minimum threshold for an individual was $68 \mathrm{~dB}$ SPL $(202$ $\mu \mathrm{m} / \mathrm{s})$ at $100 \mathrm{~Hz}$. The lowest mean threshold value was $79 \mathrm{~dB}$ SPL $(605 \mu \mathrm{m} / \mathrm{s})$ at $150 \mathrm{~Hz}$, but this threshold value was not significantly different for thresholds at $100 \mathrm{~Hz}(80 \mathrm{~dB}$ SPL or $679 \mu \mathrm{m} / \mathrm{s}$; unpaired t-test, $\mathrm{t}=0.468, \mathrm{P}=0.642, \mathrm{n}=46)$ or $200 \mathrm{~Hz}(80 \mathrm{~dB}$ SPL or $668 \mu \mathrm{m} /$ $\mathrm{s}$; unpaired $\mathrm{t}$-test, $\mathrm{t}=0.303, \mathrm{P}=0.763$, 48) (Fig. 2.4).

A behavioural audiogram was conducted using the same data as for Figure 2.4, but recalculated to yield particle displacement (Fig. 2.6). Data here shows that particle displacement was highest at $50 \mathrm{~Hz}(22.7 \mu \mathrm{m})$, but remained approximately constant between 150 and $700 \mathrm{~Hz}$, at approximately $1.12 \mu \mathrm{m}$.

A second behavioural audiogram was constructed that considered only flicks as responses (Fig. 2.7). The shape of the curve was the same as Figure 2.4, but with higher thresholds. Danaus plexippus larvae responded by flicking at frequencies between 50 and $700 \mathrm{~Hz}$. Again, the best frequency range was between $100 \mathrm{~Hz}$ and $200 \mathrm{~Hz}$, and the lowest mean threshold value was $81 \mathrm{~dB}$ sPt, at $150 \mathrm{~Hz}$. Differences in threshold values between 100,150 , and $200 \mathrm{~Hz}$ were slightly more pronounced, but still not significantly different from one another (Fig. 2.7). The median value over all frequencies was 90 $\mathrm{dB}_{\mathrm{SPL}}$, and the minimum threshold for an individual was was $69 \mathrm{~dB}$ SPL at $150 \mathrm{~Hz}$.

Results of the habituation/sensitization experiment demonstrate the effect of repeated $200 \mathrm{~Hz}$ stimulus in ten second intervals at a constant intensity (92 dB BPL $)$ on flicking behaviour of the larvae (Fig. 2.8). Figure 2.8 established that approximately the same number of flicks were observed between the first and sixth tones presented, and 


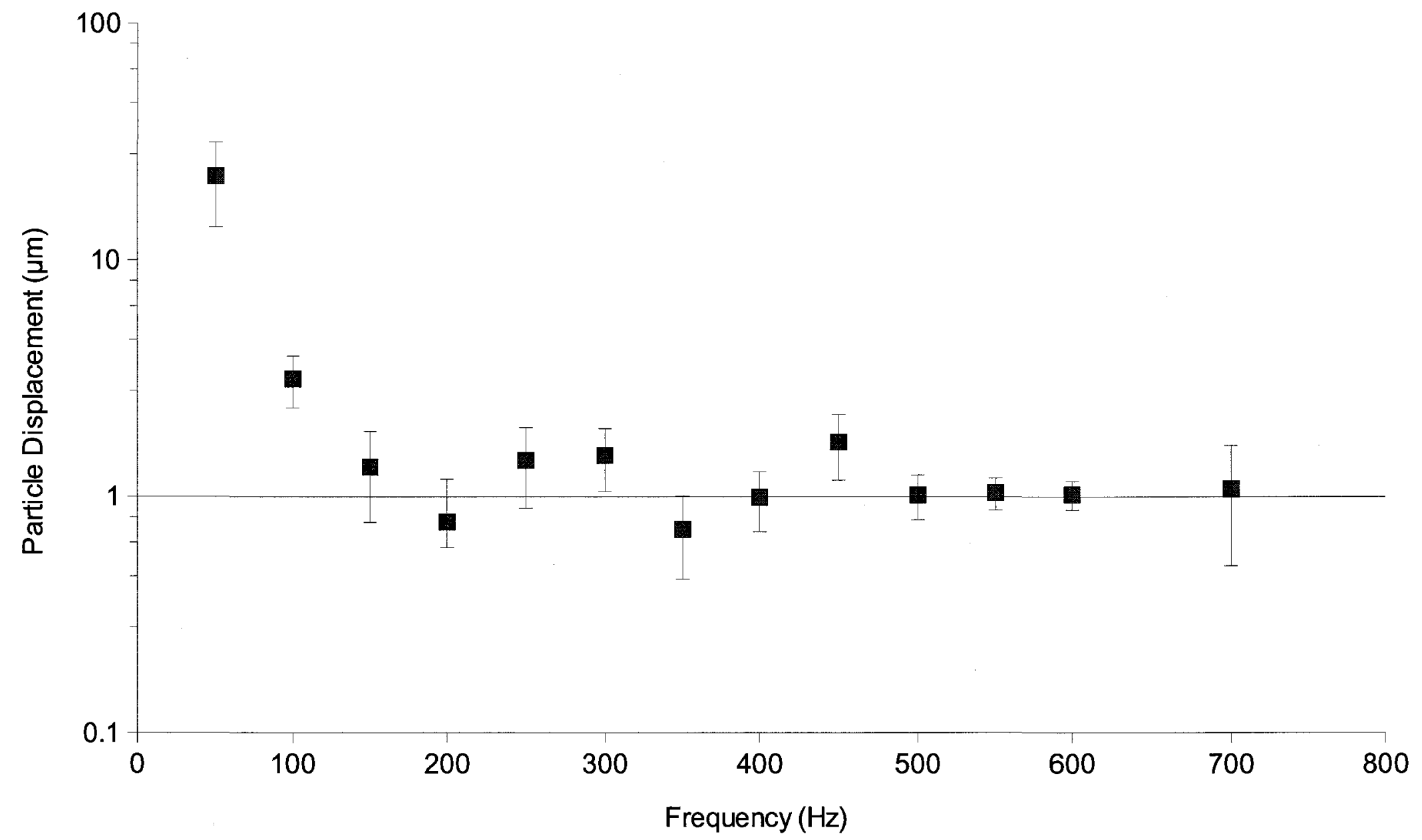

Figure 2.6. Behavioural audiogram for Danaus plexippus larvae, including all responses $(\mathrm{n}=$ 32). Data used to create Fig. 2.4 recalculated to yield particle displacement. Error bars indicate $95 \%$ Confidence Interval of the mean for each frequency. 


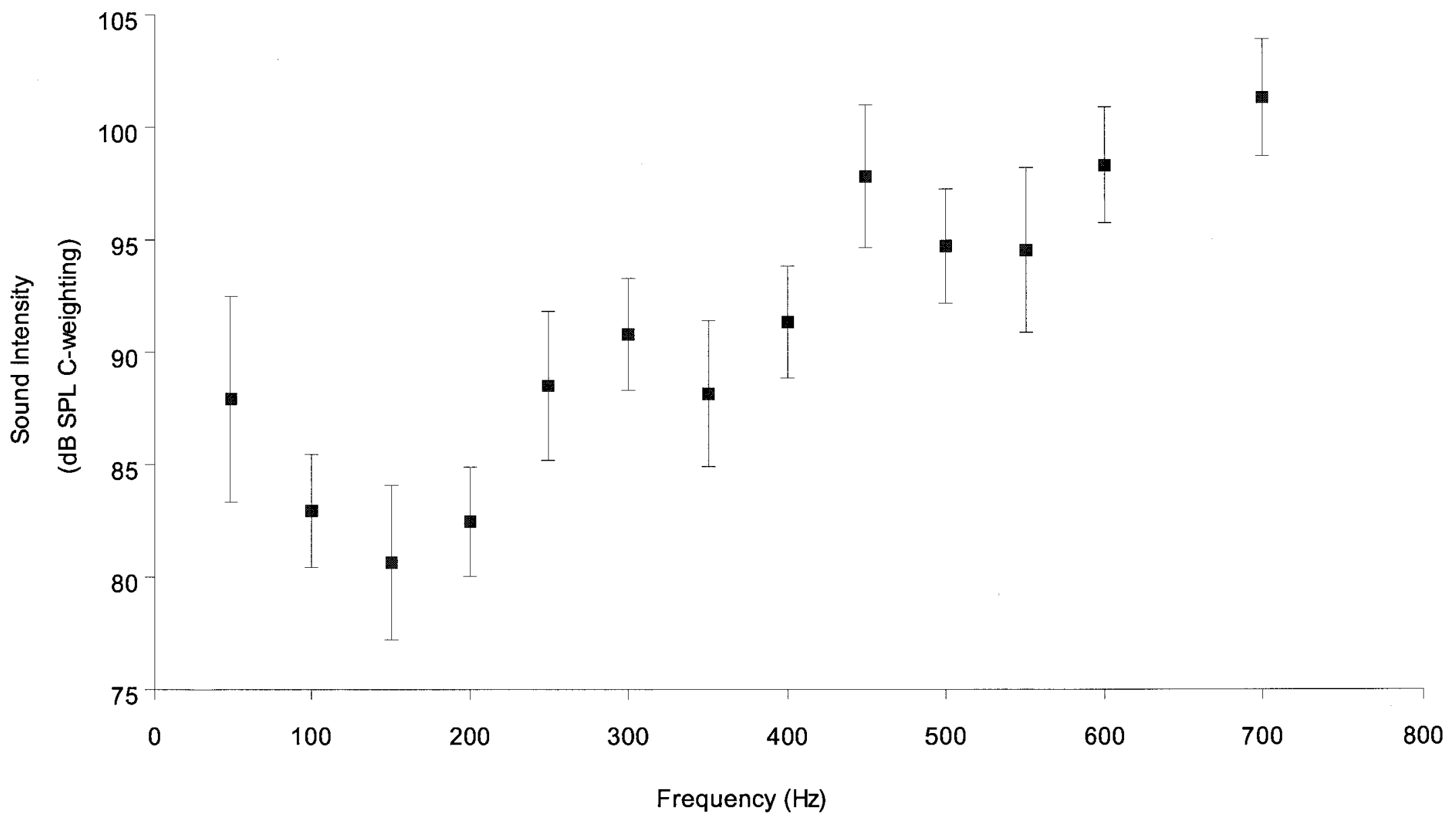

Figure 2.7. Behavioural audiogram for Danaus plexippus larvae, considering flicks only as responses $(n=32)$. Where no behavioural response was observed, thresholds were assigned arbitrary values one step ( $3 \mathrm{~dB}$ SPL, see Fig. 2.2) higher than the highest sound intensity measured for that frequency. Error bars indicate $95 \%$ Confidence Interval of the mean for each frequency. 


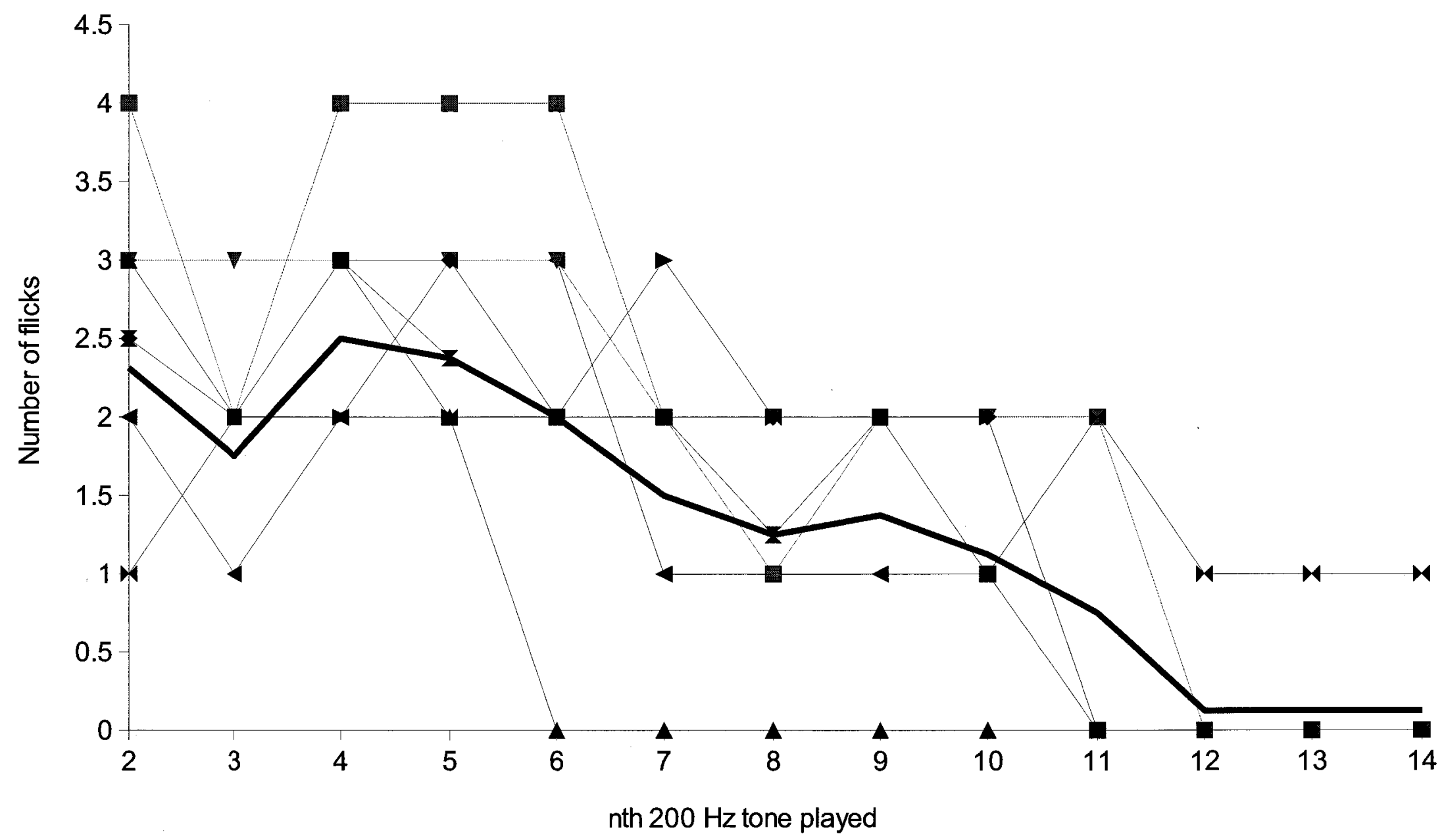

Figure 2.8. Number of times Danaus plexippus larvae flicked in response to the nth number of $200 \mathrm{~Hz}$ tones with a duration of $1 \mathrm{~s}$, played at $92 \mathrm{~dB} S P L(n=8)$. Bold line represents mean over all individuals observed. 
following this, the number of flicks declines with each subsequent tone. Thus, there was likely no sensitization that occurred during the trials with increasing intensity $200 \mathrm{~Hz}$ tones, but after approximately six tones, habituation begins.

\section{Description of Behaviours}

Freezing

Freezing occurred only rarely during audiogram trials, and was defined as the cessation of all movement, which was sustained for a widely variable period of time, ranging from approximately one second to one minute. The nature of this type of response was such that it was only observable when the caterpillar was already engaged in some sort of movement, such as feeding, walking, or laying silk. Cessation of other activities was also necessary to engage in contractions and flicks, but freezing was only recorded as a response when it occurred in isolation. During audiogram trials, it was difficult to determine how long freezing lasted, because another stimulus followed the last ten seconds later. Too few examples of freezing were observed in audiogram trials to draw any conclusions about a possible relationship this behaviour may have with sound frequency, although this behaviour was sometimes observed at either lower intensity sounds that were insufficiently loud to elicit a full contraction or flick, or following many repetitive stimuli, after habituation had occurred. Because of the difficulty in recognizing this behaviour, freezes were observed only for the purpose of making qualitative observations, and were not used in quantitative analysis.

\section{Contraction}

A contraction is the simultaneous cessation of movement and contraction of longitudinal muscles, resulting in a small decrease in body length. Most of this reduction 
in length is a result of the head retracting slightly into the headcollar region. Often the legs lifted off the substrate, and the tubercles moved backwards (Fig. 2.9).

High speed video trials used two different intensities (95 and $99 \mathrm{~dB}_{\text {SPL }}$ ) of a 200 $\mathrm{Hz}$ tone, so before amalgamating data obtained in response to both sound intensities, the data sets were compared to determine if there was a significant difference between them. Analysis of contraction data showed that there was no significant difference between contraction duration at the two different sound intensities (unpaired t-test, $\mathrm{t}=1.1157, \mathrm{P}=$ $0.315, \mathrm{n}=7$ ), change in body length (unpaired $\mathrm{t}$-test, $\mathrm{t}=0.936, \mathrm{P}=0.403, \mathrm{n}=6$ ), or response latency (unpaired t-test, $t=0.426, P=0.688, n=7$ ). Therefore, both sets of contraction data were analyzed together.

Contractions in response to a $200 \mathrm{~Hz}$ tone at 95 or $99 \mathrm{~dB}$ SPL, observed from high speed videography trials, resulted in a small (1.88\%) but significant decrease in body length (paired t-test, $\mathrm{t}=3.97, \mathrm{P}=0.0106, \mathrm{n}=6$ ). Data from the same high speed trials indicated that the mean latency of contracting was $580 \mathrm{~ms}$ (95\% CI: 71.5-1090 ms, min. $40 \mathrm{~ms}$, max. $1.51 \mathrm{~s}, \mathrm{n}=7$ ) with respect to incidence of the sound stimulus, and the time it took to reach a contracted position was $78.6 \mathrm{~ms}(95 \% \mathrm{CI}: 10.9-147 \mathrm{~ms}$, $\mathrm{min} .35 .8 \mathrm{~ms}$, max. $240 \mathrm{~ms}, \mathrm{n}=7$ ). Behavioural audiogram videos demonstrated that contractions comprised a greater proportion of responses at lower sound intensities and frequencies to which the caterpillars were less responsive. Although the number of individuals that contracted in response to a $200 \mathrm{~Hz}$ tone during behavioural audiograms changed little among different intensities, contractions composed a much smaller proportion of responses at higher intensities compared to lower intensities (Fig. 2.10). 
A

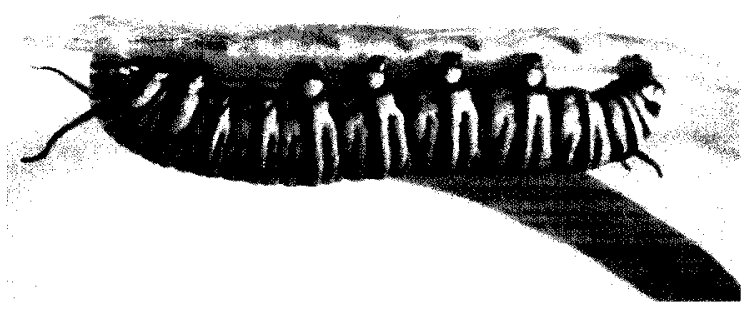

B

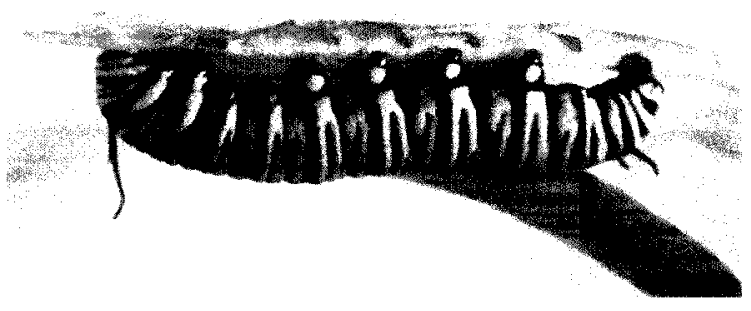

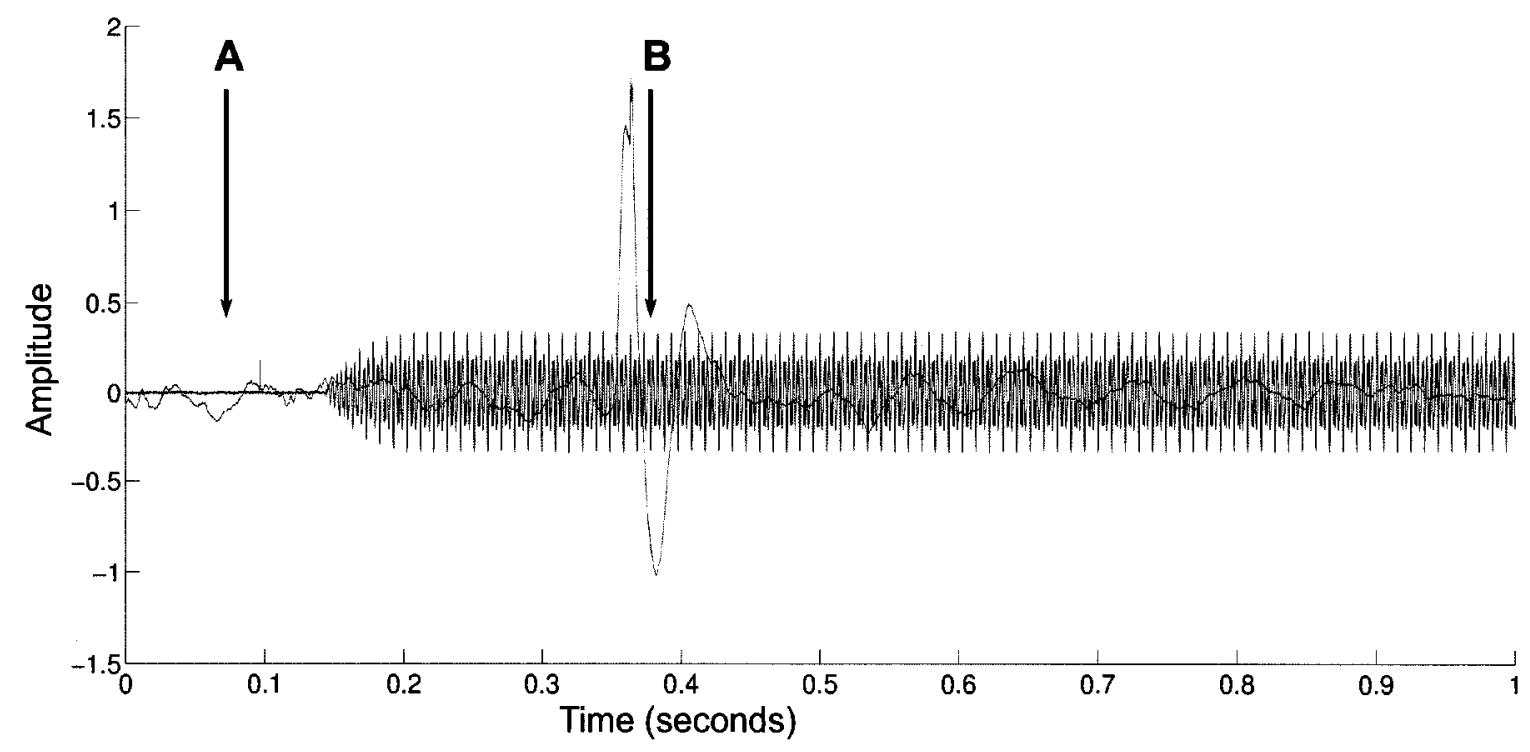

Figure 2.9. Danaus plexippus larva contracts in response to sound. Laser vibrometer output (pink line) measures vibration caused by larva contracting, and microphone output (blue line) measures one second, $200 \mathrm{~Hz}$ sound stimulus at $95 \mathrm{~dB}$ SPL. High speed camera captured A: position of resting larva, before introduction of sound, and B: larva in a contracted position. 


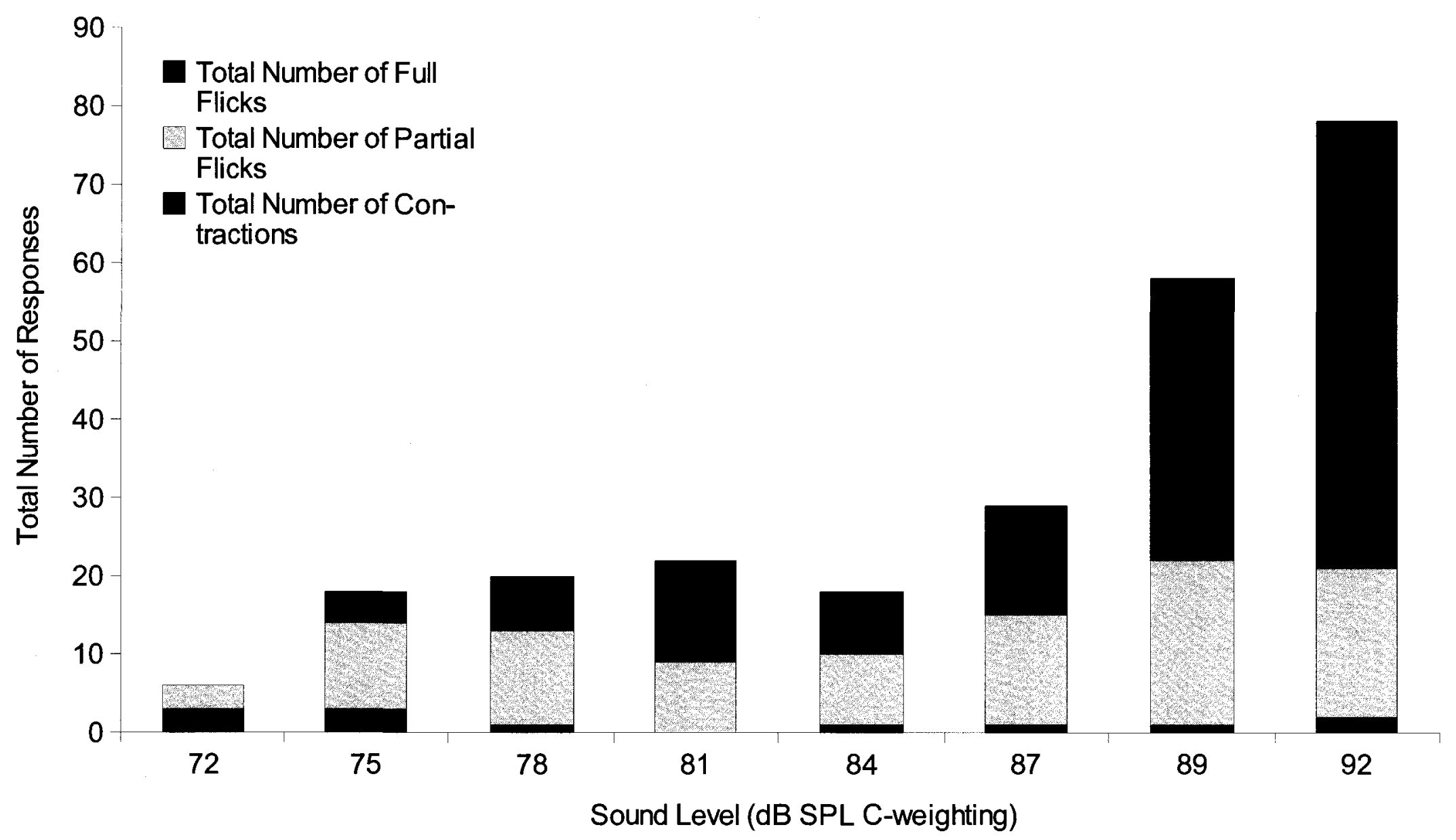

Figure 2.10. The effect of sound level (dB SPL) on type and number of responses (contractions and flicking) of Danaus plexippus larvae in response to a $200 \mathrm{~Hz}$ tone $(n=32)$. Total number of flicks is divided into partial and full flicks. 
Flick

General Description:

Flicks occurred in isolation, or in trains of up to 13 consecutive flicks (Fig. 2.11). During a flick, the larvae normally released their thoracic legs from the substrate, and rapidly raised the anterior portion of their bodies (Fig. 2.12). As they began to lower their bodies, they often retracted their head and curled downwards (Fig. 2.13). A single flick was completed when the anterior portion of the body lowered back to the substrate so that the thoracic legs were nearly touching it. However, depending on the intensity of the response, sometimes not all legs were released from the substrate as in a partial flick, so flicks were defined by the fact that the motion was more rapid than during a contraction. Conversely, sometimes a caterpillar would flick so vigorously that it would release one or two of its anterior prolegs from the substrate.

High speed video trials used two different intensities, so flick data were compared to determine if there was a significant difference between the two intensities (see above). Flick angle (unpaired t-test, $\mathrm{t}=0.486, \mathrm{P}=0.630, \mathrm{n}=33$ ) and response latency (unpaired t-test, $\mathrm{t}=0.0813, \mathrm{P}=0.936, \mathrm{n}=17$ ) did not differ between the two sound intensities, so both data sets were analyzed together.

\section{Flick Angle:}

The angle to which larvae raised themselves from the substrate was measured as a method of gauging response magnitude in analysis of high speed video. Larvae raised the anterior portion of their bodies to a mean angle of $26^{\circ}$ from the substrate in response to $200 \mathrm{~Hz}$ tones at 95 or $99 \mathrm{~dB}_{\mathrm{SPL}}\left(95 \% \mathrm{CI}: 17.83-34.91^{\circ}, \mathrm{n}=33\right.$ flicks).

During high speed video trials, in response to $200 \mathrm{~Hz}$ tones of 95 or $99 \mathrm{~dB}$ SPL , if 

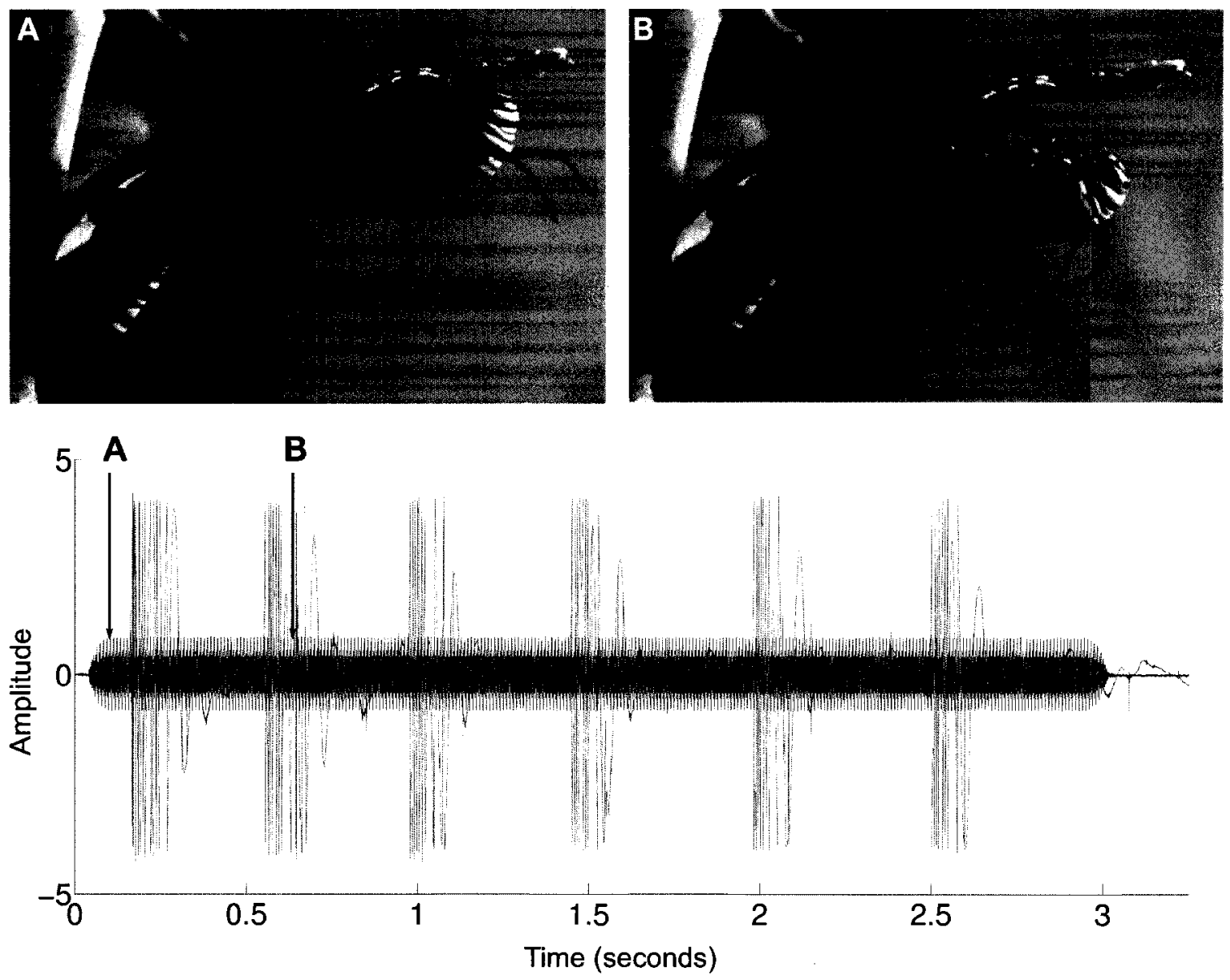

Fig. 2.11. Fifth instar monarch caterpillar response to sound stimulus by flicking. Microphone (blue line) indicates $200 \mathrm{~Hz}$ tone, and laser vibrometer (pink line) measures vibrations caused by movement of the caterpillar. Each of six flicks is visible as a distinct peak. High speed camera frames illustrate the caterpillar A in resting position before introduction of sound, and $\mathbf{B}$ in the peak position of the second flick, at times indicated on the graph. 

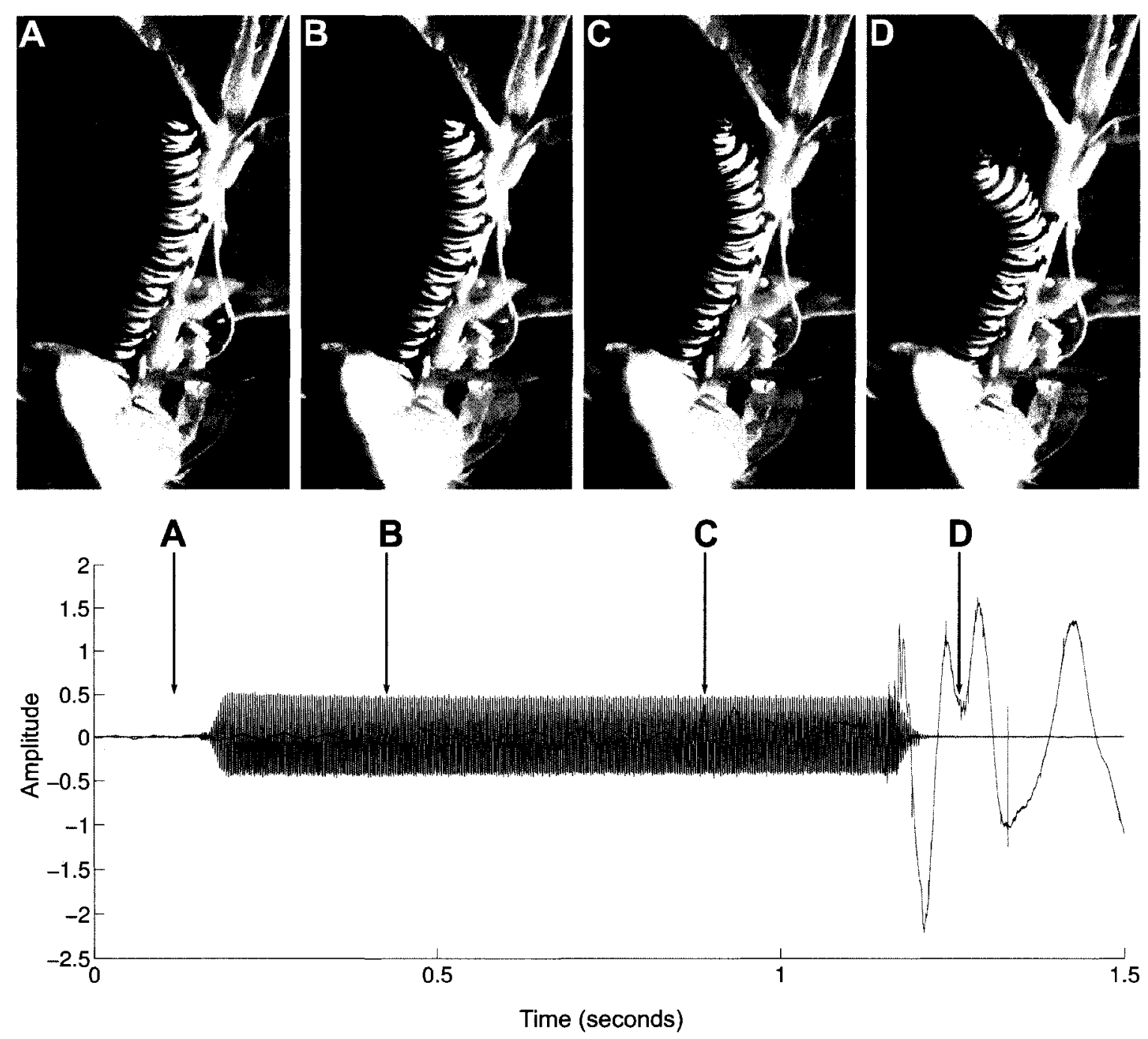

Figure 2.12. Fifth instar Danaus plexippus larva responding to sound stimulus by contracting then flicking. Microphone (blue line) indicates $200 \mathrm{~Hz}$ tone, and laser vibrometer (pink line) measures vibrations caused by movement of the caterpillar. High speed camera frames illustrate the caterpillar A: in resting position before introduction of sound, $\mathbf{B}$ : in contracted position, $\mathbf{C}$ : in peak position of a small flick, and $\mathbf{D}$ : in peak position of a more vigorous flick. This pattern of a smaller initial flick followed by a more vigorous flick in response to a single stimulus was commonly observed. 

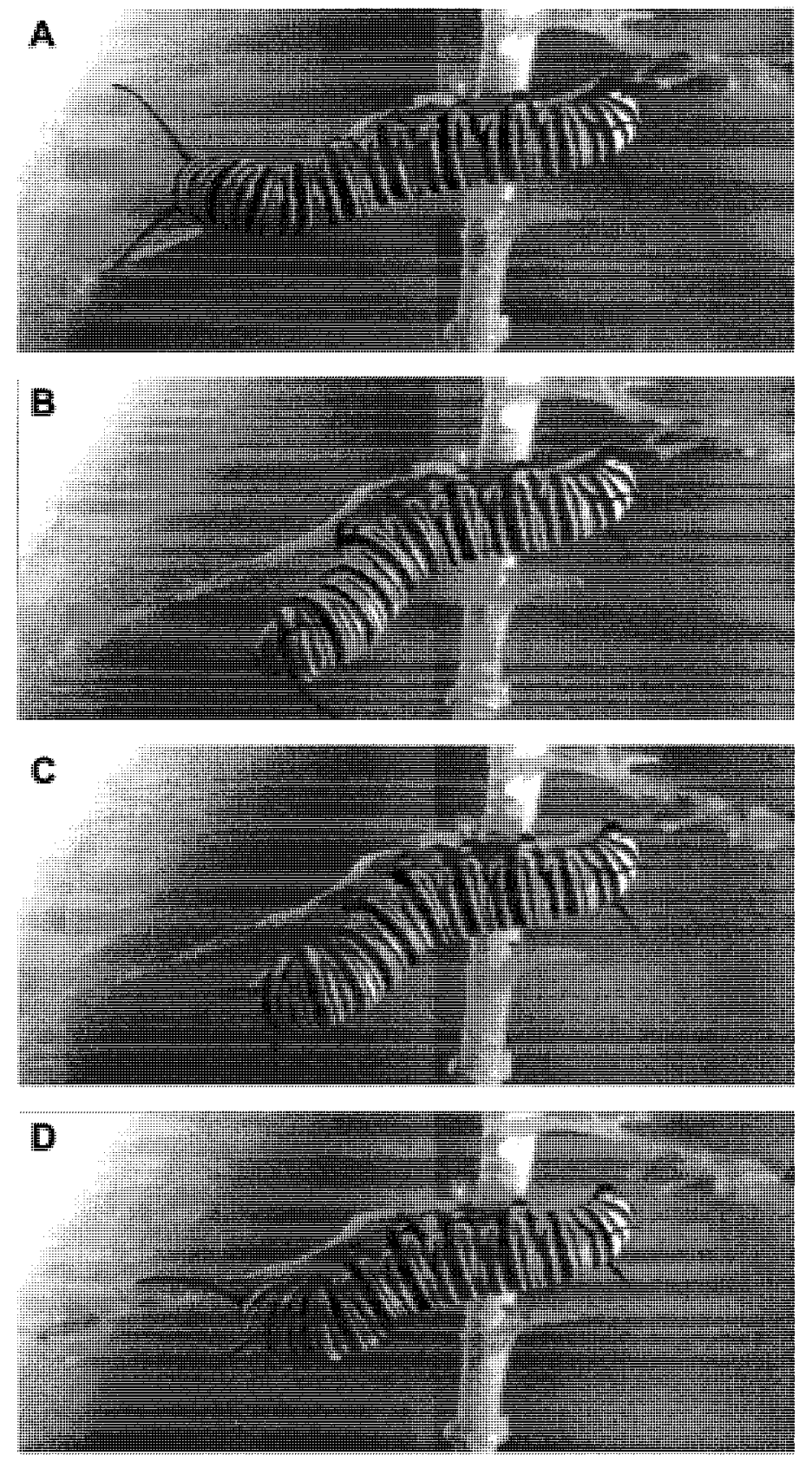

Figure 2.13. Succession of frames from high speed video showing Danaus plexippus larva flicking dorsally and contracting during mid-flick. A: Larva resting until $120 \mathrm{~ms}$ following tone $(300 \mathrm{~Hz}, 95 \mathrm{~dB} \mathrm{SPL})$. B: Larva at peak of second flick (first flick not shown), $340 \mathrm{~ms}$ following tone. C: Larva retracting its head and curling downwards as it returns to the branch, $380 \mathrm{~ms}$ following tone. D: Larva returned to branch, with head retracted and curled downwards, $470 \mathrm{~ms}$ following tone. 
larvae consecutively flicked more than once in response to one stimulus, their bodies extended an average of $12.1^{\circ}$ further during second flicks than first flicks (unpaired t-test, $\mathrm{t}=2.70, \mathrm{P}=0.0151, \mathrm{n}=19)$. There appeared to be a trend developing between flick order and flick angle, whereby flick angle increased from first to second and third flick, remained steady for the fourth flick, and decreased for the fifth flicks (Fig. 2.14). However, this variation was not significantly different when all flick numbers were compared (ANOVA, $\mathrm{f}=2.34, \mathrm{P}=0.08, \mathrm{n}=33$ ).

Some larvae flicked so vigorously that they lost their grip with all prolegs from the leaf or branch to which they were attached. These larvae fell to the ground, curled up into a ball, and remained motionless in this position for a minute or more. This behaviour was occasionally observed only in response to loud humming at close proximity. Neither sound level nor frequency of humming was measured, but sound level was likely higher than sound produced by speakers. This falling behaviour was observed only in what were likely third or early fourth instar larvae.

\section{Latency/Duration from High Speed:}

Analysis of high speed videos demonstrated that mean latency between introduction of $200 \mathrm{~Hz}$ tones at 95 or $99 \mathrm{~dB}_{\mathrm{SPL}}$ sound and the first perceptible movement of a flick was $471 \mathrm{~ms}(95 \% \mathrm{CI}: 305-637 \mathrm{~ms}$, min. $100 \mathrm{~ms}$, max. $1526 \mathrm{~ms}, \mathrm{n}=23$ ) when all trials and individuals were analyzed, or $290 \mathrm{~ms}$ (95\% CI: 152-427 ms, $\min .100 \mathrm{ms,}$ max. $729 \mathrm{~ms}, \mathrm{~N}=12$ ) when the fastest trial of each individual was measured. The upward stroke of a flick in response to $200 \mathrm{~Hz}$ tones at 95 or $99 \mathrm{~dB}$ SPL was the fastest movement, taking a mean of $42.6 \mathrm{~ms}$ to complete, significantly shorter than the $73.4 \mathrm{~ms}$ duration of the downward stroke (paired t-test, $\mathrm{t}=6.93, \mathrm{P}<0.0001, \mathrm{~N}=45$ ). 


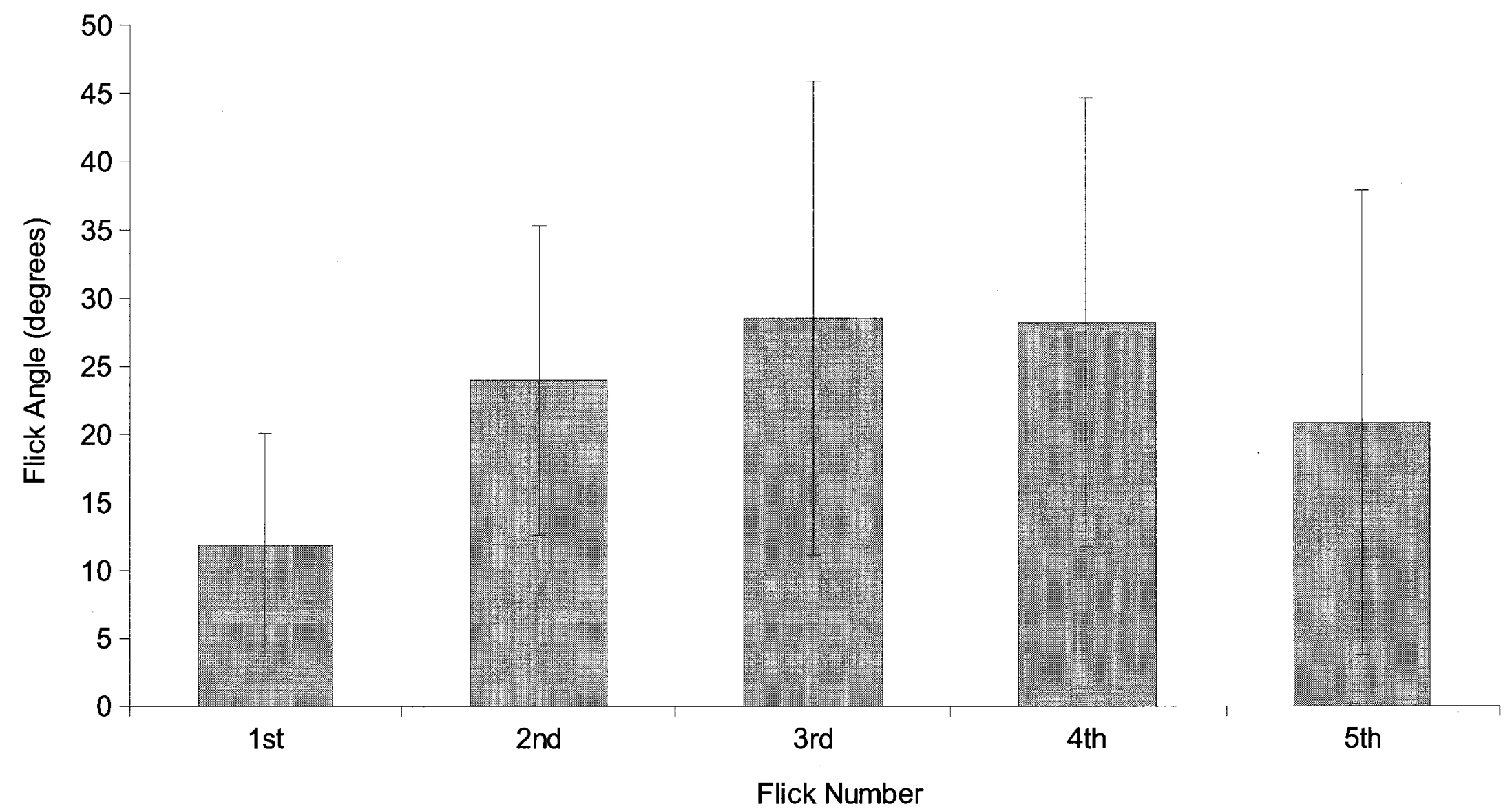

Figure 2.14. Relationship between flick number and flick angle of Danaus plexippus larvae. Angles measured from stills obtained from high speed videography, obtained in responses to a $200 \mathrm{~Hz}$ tone at 95 or $99 \mathrm{~dB}$ SPL. Error bars indicate standard deviation of the mean for each flick number. Mean angle difference between flick numbers 1 and 2 is statistically significant $(P=0.0151)$. 1st $(n=11), 2 n d(n=8)$ 3 rd $(n=6)$, 4th $(n=5)$, and 5 th $(n=3)$. 
Flicking responses relative to sound intensity from audiogram videos:

The relationship between sound level $\left(\mathrm{dB}_{\mathrm{SPL}}\right)$ and flicking response was examined within one of the best frequencies, $200 \mathrm{~Hz}$ (Fig. 2.15), using data obtained from behavioural audiogram videos. The total number of individuals that respond by flicking steadily increased from six responders at sound levels of $72 \mathrm{~dB}$ sPL, to 23 responders at 92 $\mathrm{dB}_{\mathrm{SPL}}$. Considering only those individuals that responded by flicking, the number of times an individual flicked also increased with higher sound intensities (Fig. 2.15). Responding larvae flicked only once at $72 \mathrm{~dB}_{\mathrm{SPL}}$, and an average of 3.22 times at 92 $\mathrm{dB}_{\text {SPL. }}$.

The high-low experiment was conducted to confirm that there was a significant difference between the number of times that larvae flicked in response to two different intensities of sound, and that differences among intensities observed in Figure 2.15 were not simply due to sensitization caused by repeated stimulation. The $200 \mathrm{~Hz}$ high (92 $\left.\mathrm{dB}_{\mathrm{SPL}}\right)$ and low $\left(84 \mathrm{~dB}_{\mathrm{SPL}}\right)$ frequencies were played five minutes apart, and in a random order, to control for any effects that repeated tones of increasing intensity might have had on the response of the larvae during audiogram trials. The results of this experiment demonstrate that the number of times an individual flicked in response to a $200 \mathrm{~Hz}$ tone played at $92 \mathrm{~dB}_{\text {SPL }}$ was significantly higher than when the same tone was played at 84 $\mathrm{dB}_{\text {SPL }}$ (paired t-test, $\left.\mathrm{t}=4.34, \mathrm{P}=0.0005, \mathrm{~N}=17\right)($ Table 2.1).

Further analysis was conducted using data obtained in response to $200 \mathrm{~Hz}$ tones during audiogram trials, to establish the relationship between sound intensity and the vigorousness of flicking responses. Figure 2.10 demonstrates that the magnitude with which larvae flicked was also positively associated with sound intensity; a higher number of full flicks were observed at higher sound levels of a $200 \mathrm{~Hz}$ tone. There were no full 


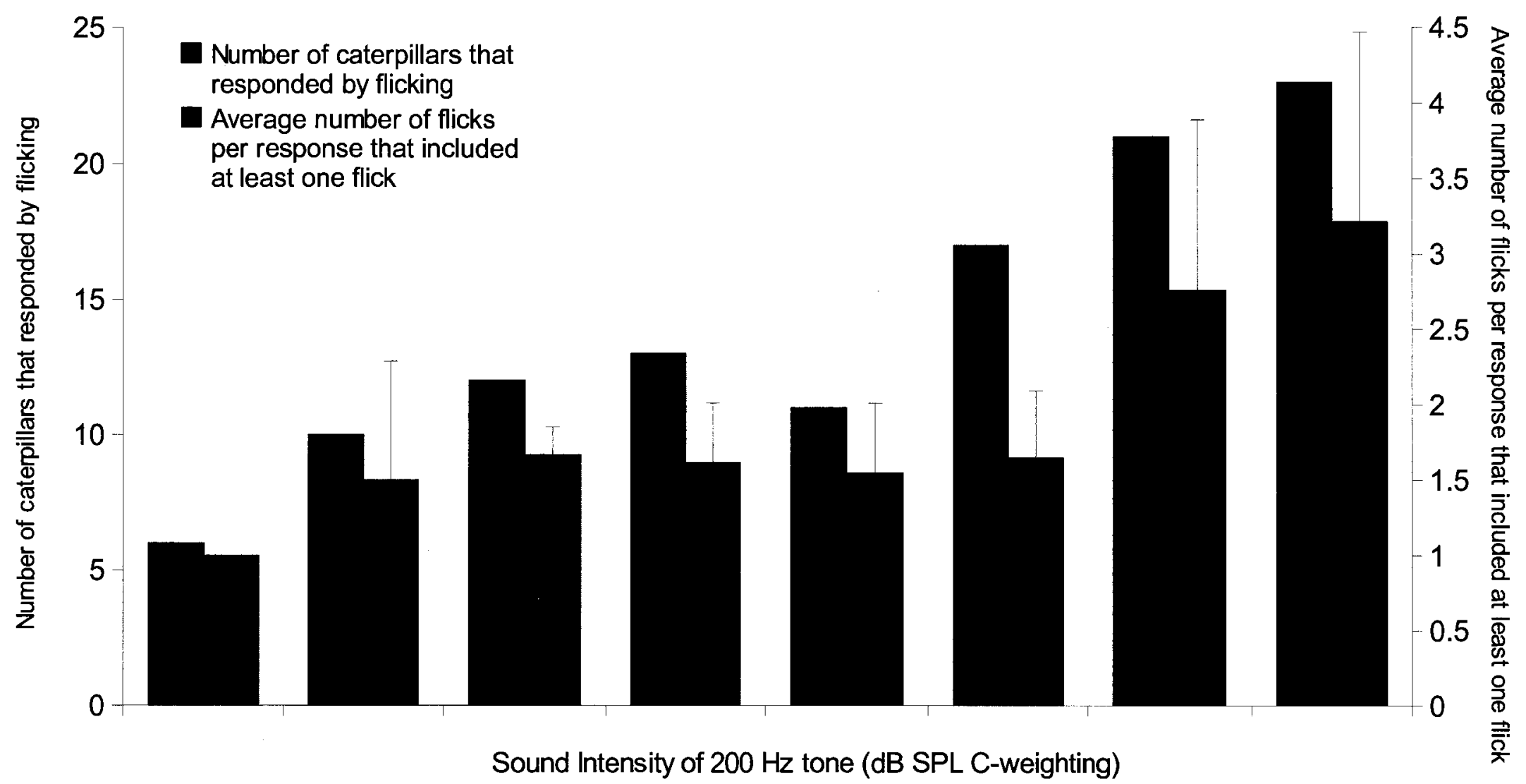

Figure 2.15. Distribution of flicks over increasing sound intensity of $200 \mathrm{~Hz}$ tones. The left axis indicates number of individuals that responded at each intensity of the $200 \mathrm{~Hz}$ tones $(n=32)$. The right axis indicates the average number of flicks per caterpillar at each sound intensity. These data demonstrate that the number of individuals that respond by flicking increases with sound intensity and the average number times each individual flicks also increases with sound intensity. Error bars represent $95 \%$ Confidence Interval of each sound intensity. 
flicks observed at $72 \mathrm{~Hz}$, and full flicks comprised no more than approximately half of all responses from 75 to $87 \mathrm{~dB}_{\text {SPL }}$ (Fig. 2.10). When the sound level was increased to 89 and $92 \mathrm{~dB}_{\mathrm{SPL}}$, however, the numbers of full flicks observed were two to three times the number of partial flicks observed (Fig. 2.10). Thus, larvae flicked more vigorously in response to louder sounds.

\section{Anatomy}

\section{General:}

Larvae were carefully examined by multiple methods for structures that might possess near-field receptors. Scanning electron microscopy provided visual contrast, and gave a better perspective of the depth of the external anatomy of the larvae, especially setae. Despite appearing hairless without magnification, under a stereo microscope all larvae examined in their second instar and older were covered in short and stout setae (Fig. 2.16A), and several longer setae near the head, legs, and prolegs. However, these setae were all far thicker than any near-field receptor previously described (Tautz, 1979; Barth, 2004). The numerous setae that covered the larvae's body were approximately 30 $\mu \mathrm{m}$ long and 3-5 $\mu \mathrm{m}$ thick at the base. These setae tapered gradually toward the ends, which were round and blunt, and the sockets of these shorter setae were approximately conical. Sections of tissue containing these setae were stained and examined under a microscope, and it was found that each of these setae appeared to be innervated by a single sensory cell (Fig. 2.16B). 
Table 2.1. High-Low Experiment: Number of

\begin{tabular}{ccc}
\multicolumn{3}{c}{$\begin{array}{c}\text { flicks in response to } 20 \mathrm{~Hz} \text { tone at high or low } \\
\text { intensities }\end{array}$} \\
\hline Individual & Low (84 dB) & High (92 dB) \\
\hline 1 & 4 & 4 \\
2 & 3 & 3 \\
3 & 1 & 3 \\
4 & 1 & 1 \\
5 & 3 & 4 \\
6 & 2 & 3 \\
7 & 4 & 9 \\
8 & 2 & 2 \\
9 & 4 & 5 \\
10 & 11 & 10 \\
11 & 4 & 8 \\
12 & 2 & 6 \\
13 & 5 & 9 \\
14 & 4 & 9 \\
15 & 10 & 15 \\
16 & 3 & 9 \\
17 & 2 & 6 \\
Sum & 65 & 106 \\
\hline
\end{tabular}



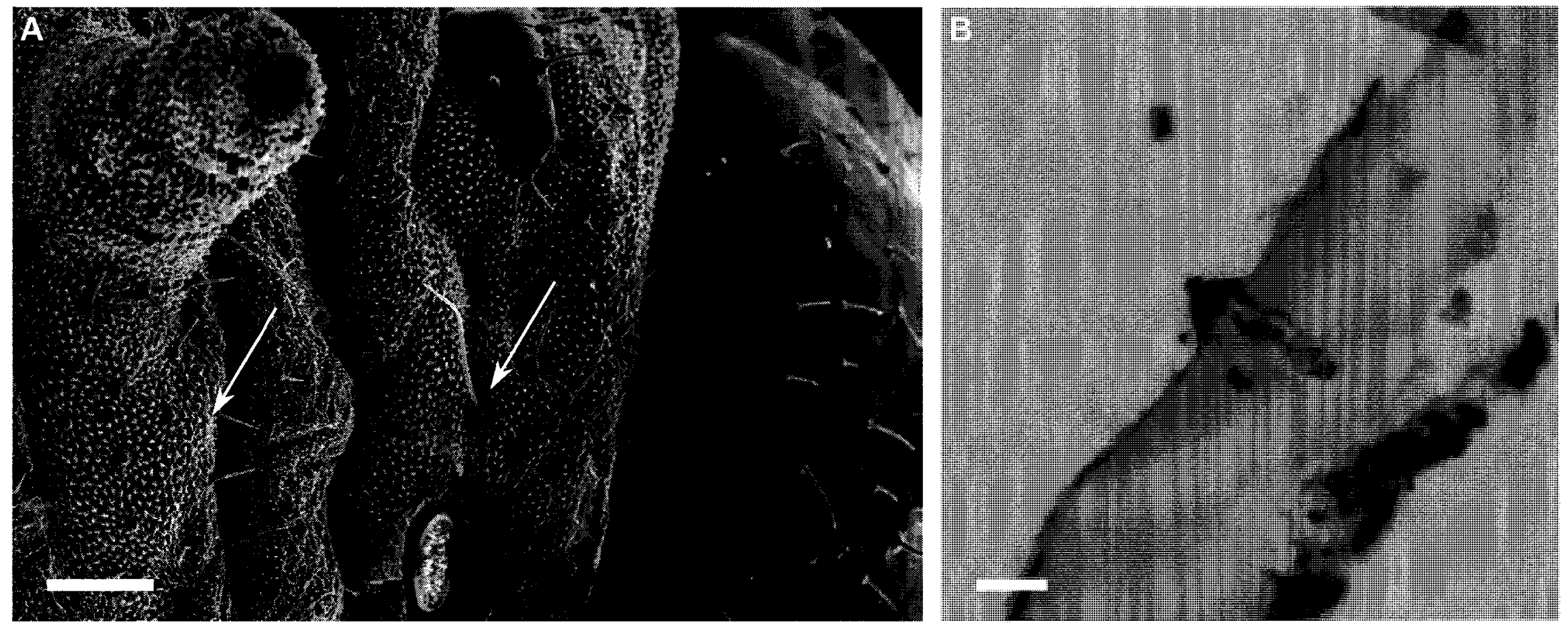

Figure 2.16. Setae cover the body of Danaus plexippus larvae. A: SEM showing typical seta (e.g. left arrow) on body of third instar larva, with filiform sensillum (right arrow) for comparison. Scale bar: $100 \mu \mathrm{m}$. B: $5 \mu \mathrm{m}$ section through a seta clearly showing single mechanosensory neuron. Scale bar: $10 \mu \mathrm{m}$ 


\section{Tubercles}

Long, fleshy appendages called tubercles were located on the second thoracic segment and eleventh abdominal segment. Tubercles were examined along their lengths and at their tips using scanning electron microscopy, and were found to be covered with many short setae $\sim 20 \mu \mathrm{m}$ in length (Fig. 2.17A, B, C). Most of these were erected perpendicular to the tubercle, except near the tubercle's tip, where they aligned toward the tip (Fig. 2.17B). Abdominal tubercles were similar to the thoracic tubercles, except they appeared shorter, and were covered in longer setae (Fig. 2.17D). Histology of the tubercles revealed a thick layer of muscle under the cuticle. Below this layer was an apparently empty cavity, where no tissue or cells were observed (2.17E, F). Epithelial cells near the centre of the tubercle seemed to isolate this region from haemolymph (Fig. 2.17F). Beneath the layer of epithelial cells, a network of neurons was visible, which were probably suspended in haemolymph (Fig. 2.17E, F). Several muscles inserted into a location near the base of the tubercles. (Fig. 2.17F).

A pair of prothoracic shields was observed on the dorsal side of first thoracic segment of all instars, superior to the sensilla and roughly anterior to the tubercle on the same side (Fig. 2.18). These were more heavily sclerotized than the surrounding cuticle. Visual inspection of scanning electron micrographs of the prothoracic shield confirmed that it was more or less smooth in texture, similar to cuticle of the head capsule, with the exception of several grooves or pockets that may have been artifacts of critical point drying. The prothoracic shield also had six thick tapered setae $(\sim 26-60 \mu \mathrm{m}$ long in second and third instars) originating from it (Fig. 2.18). 

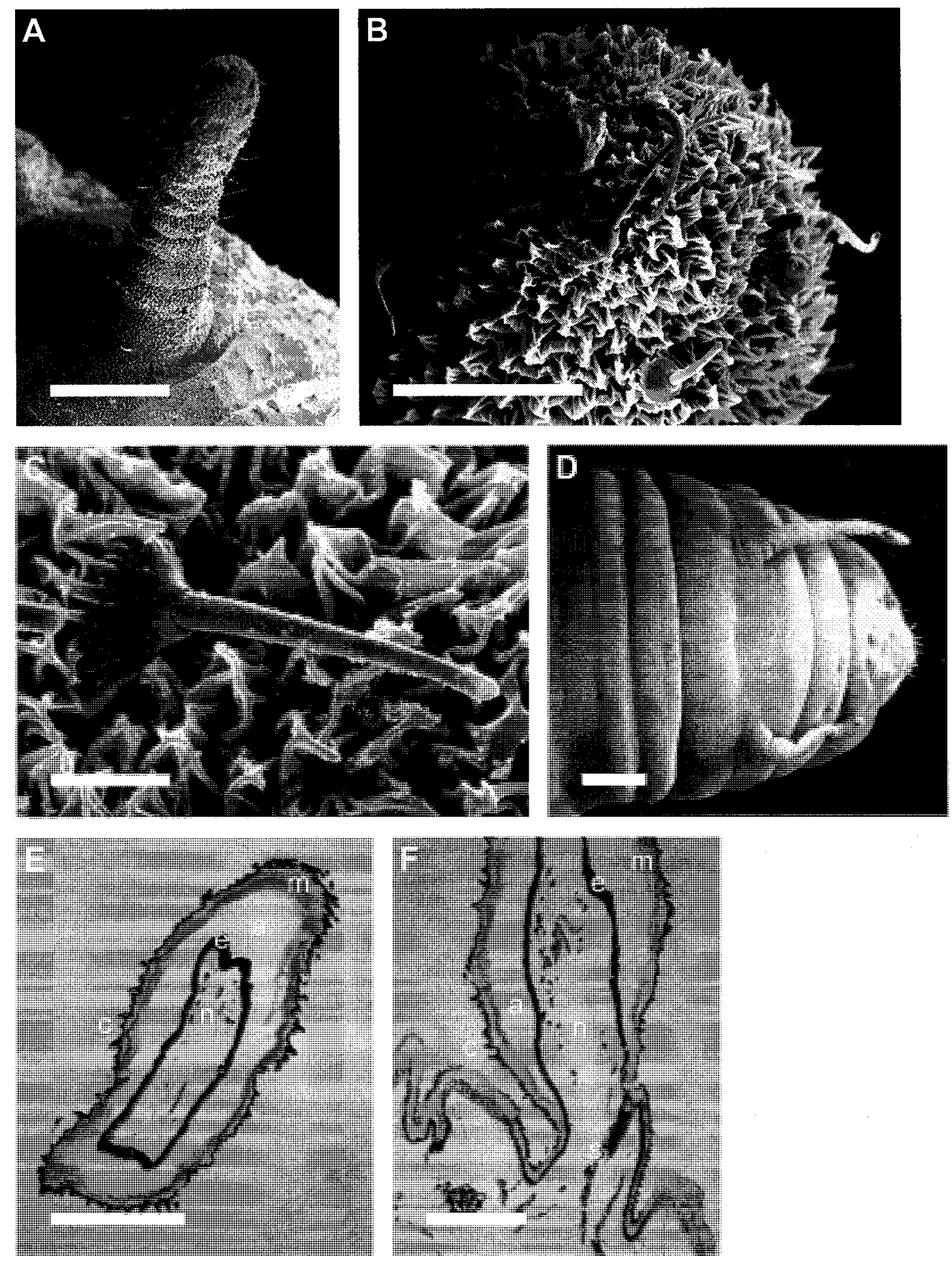

Figure 2.17. Tubercles of Danaus plexippus. A: Scanning Electron Micrograph (SEM) of whole anterior tubercle of third instar larva. Scale bar: $100 \mu \mathrm{m}$. B: Tip of anterior tubercle of same third instar larva. Scale bar: $50 \mu \mathrm{m}$. C: One of many setae that cover tubercles. Scale bar: $10 \mu \mathrm{m}$. D: Rear tubercle of fifth instar larva. Scale bar: $1 \mathrm{~mm}$. E: Cross section of anterior tubercle. Cuticle (c), muscle (m), epithelium (e), cavity (a), and neurons (n). Scale bar: $50 \mu \mathrm{m}$. F: Longitudinal section near base of tubercle showing partitioning by epithelial layer. Striated muscle (s) attach near tubercle base. Scale bar: $50 \mu \mathrm{m}$. 


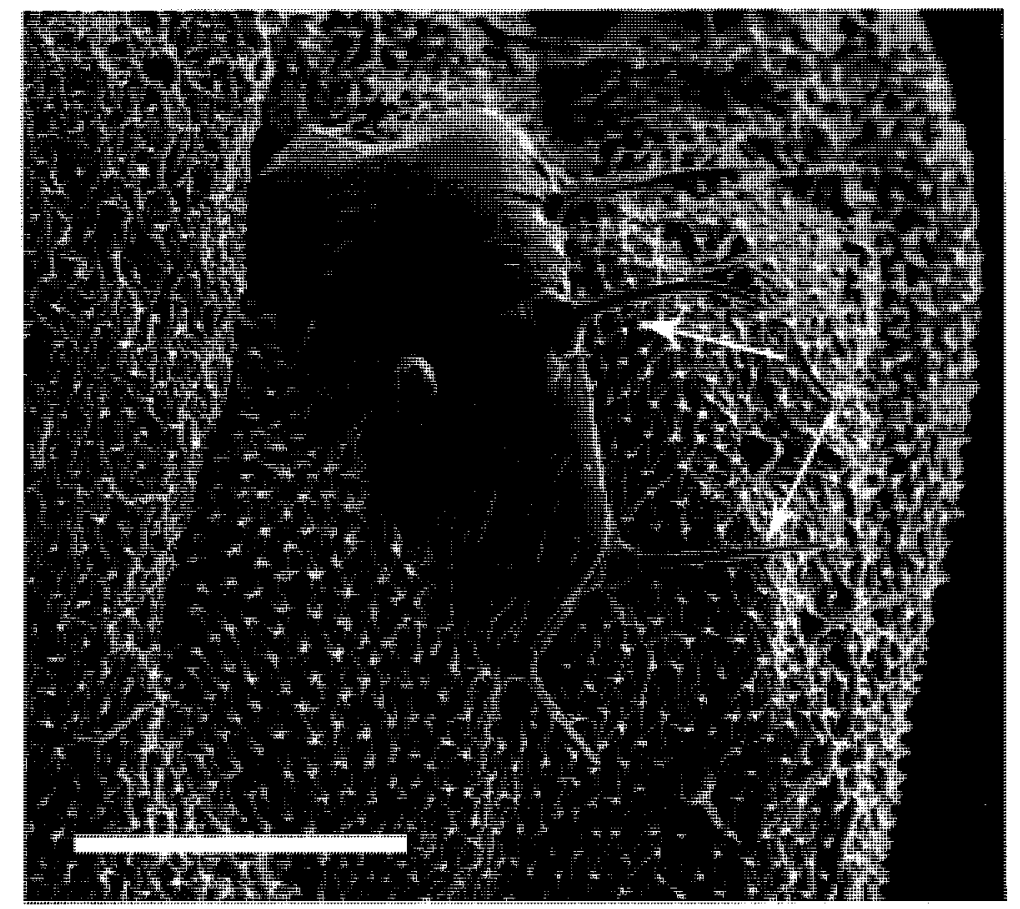

Figure 2.18. SEM of right prothoracic shield of third instar of Danaus plexippus larva. Arrows point to two of the thick setae on prothoracic shield. Scale bar: $100 \mu \mathrm{m}$. 


\section{Filiform Sensilla}

Two pairs of long filiform sensilla were located on the prothoracic segment, and one pair was on the tenth abdominal segment, behind the rear tubercles (Fig. 2.19A). There were also up to four pairs on each of the four segments bearing prolegs, located below the spiracle, although the presence of these sensilla was not consistent. The two thoracic sensilla were located roughly along the lateral midline of the larva, with one positioned directly above the other. The lower anterior sensilla were positioned just anterior to the spiracle on the same segment, while the upper anterior sensilla were located in line with the base of the tubercles (Fig. 2.19B). There was a slight curvature to each of the sensilla as well; the upper anterior setae are curved slightly upwards and anteriorly, while the lower anterior sensilla were curved slightly downwards and anteriorly. The posterior sensilla were curved slightly downwards and posteriorly, and each of the abdominal sensilla curved downwards.

Sensilla from fifth instar larvae were measured, and the mean length of the upper anterior sensilla was $452 \mu \mathrm{m}$ (95\% CI: 413-492 $\mu \mathrm{m}$, min. $343 \mu \mathrm{m}, \max .551 \mu \mathrm{m}, \mathrm{n}=10)$. These sensilla were were $112 \mu \mathrm{m}$ longer (unpaired t-test, $\mathrm{t}=5.72, \mathrm{P}<0.0001, \mathrm{n}=21$ ) than the lower front sensilla, which had a mean length of only $340 \mu \mathrm{m}$ (95\% CI: $320-362$ $\mu \mathrm{m}, \min .302 \mu \mathrm{m}, \max .400 \mu \mathrm{m}, \mathrm{n}=11$ ). Posterior sensilla, which had a mean length of $337 \mu \mathrm{m}(95 \%$ CI: $286-387 \mu \mathrm{m}, \min .208 \mu \mathrm{m}, \max .455 \mu \mathrm{m}, \mathrm{n}=10)$, were $115 \mu \mathrm{m}$ shorter than the front upper sensilla (unpaired t-test, $\mathrm{t}=4.06, \mathrm{P}=0.0007, \mathrm{n}=20$ ), but were not significantly shorter than front lower sensilla (unpaired t-test, $\mathrm{t}=0.179, \mathrm{P}=0.860, \mathrm{n}=$ 21). The abdominal sensilla, when present, appeared even shorter than the other sensilla, at approximately $250 \mu \mathrm{m}$ long. 

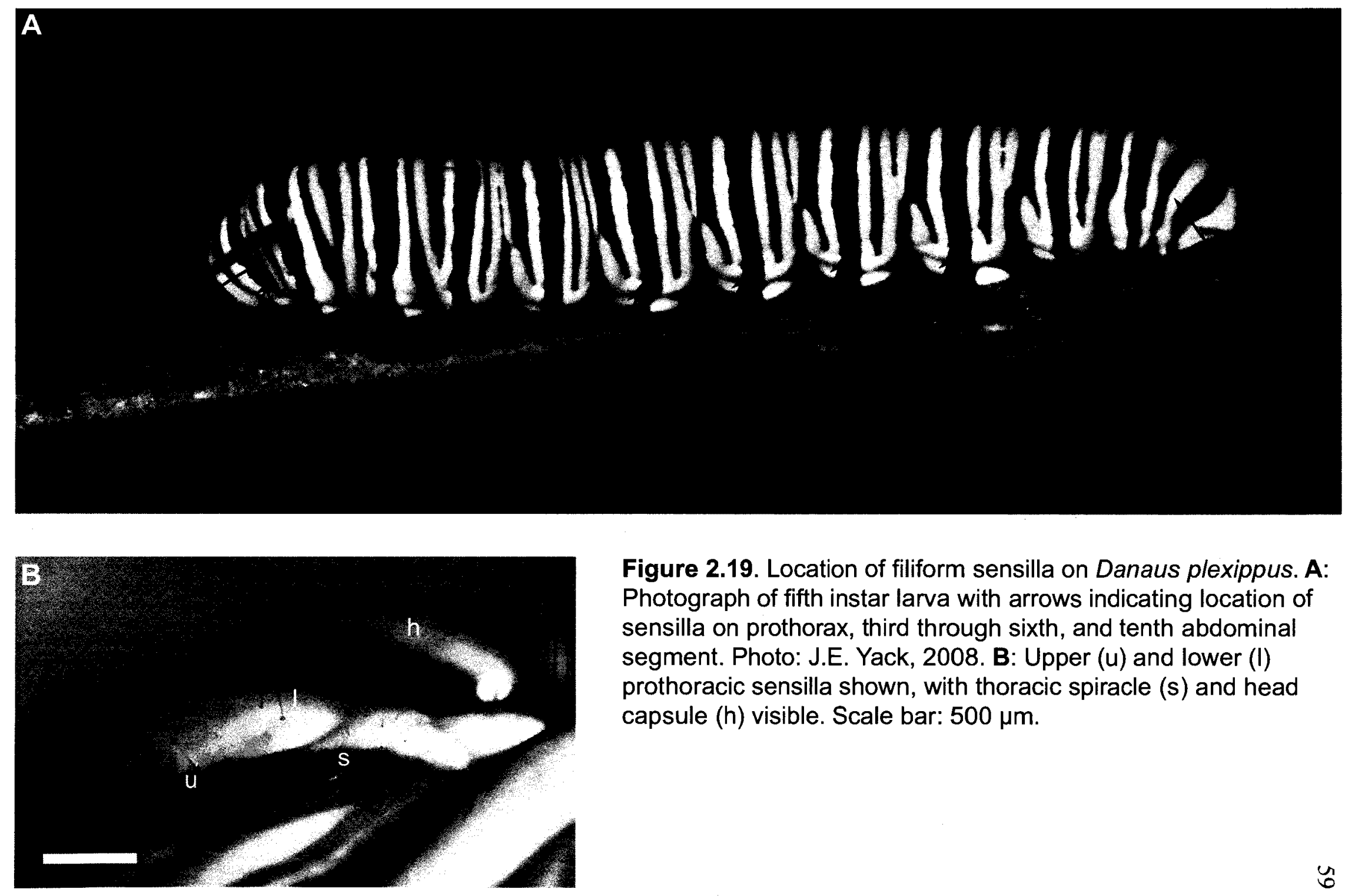

Figure 2.19. Location of filiform sensilla on Danaus plexippus. A: Photograph of fifth instar larva with arrows indicating location of sensilla on prothorax, third through sixth, and tenth abdominal segment. Photo: J.E. Yack, 2008. B: Upper (U) and lower (I) prothoracic sensilla shown, with thoracic spiracle (s) and head capsule (h) visible. Scale bar: $500 \mu \mathrm{m}$. 
Examination of scanning electron micrographs revealed that the filiform sensilla were tapered slightly at both ends, and inserted into a dome shaped socket that was raised above the surface of the cuticle (Fig. 2.20, 2.21, 2.22, 2.23). The diameter of the part of the seta that inserted into the socket was narrower than most of the length of the seta, which tapered again at its tip.

Sensilla were examined using histology to locate and characterize the receptor neurons. Location of the sensilla of interest was complex, yet possible with careful documentation of where the tissue was excised and how it was oriented in the paraffin at time of embedding. The filiform sensilla were recognizable not only because of their location, but also because they were considerably narrower than other sensilla. Sensilla length was not a useful indicator because most were cut off close to the base by the microtome. The socket was also useful for confirming that the sensilla were the putative near-field receptors, because of its different shape (see above). Each of the putative receptors was also clearly innervated by what appeared to be a single mechanosensory neuron (Fig. 2.21 C, Fig. 2.22 C).

\footnotetext{
Ablations

In order to narrow down putative receptor structures, preliminary ablations were performed on the prothoracic shield and tubercles. During removal of tubercles from a larva, a dark red liquid oozed out of each tubercle, but the larva recovered quickly, and responded readily to sound shortly following the procedure. Likewise, the individual with its prothoracic shields obscured by paint also continued to respond to sound, so these were ruled out as putative receptors. Three pairs of sensilla were identified for further investigation, because they were approximately the same length as was observed in $M$.
} 

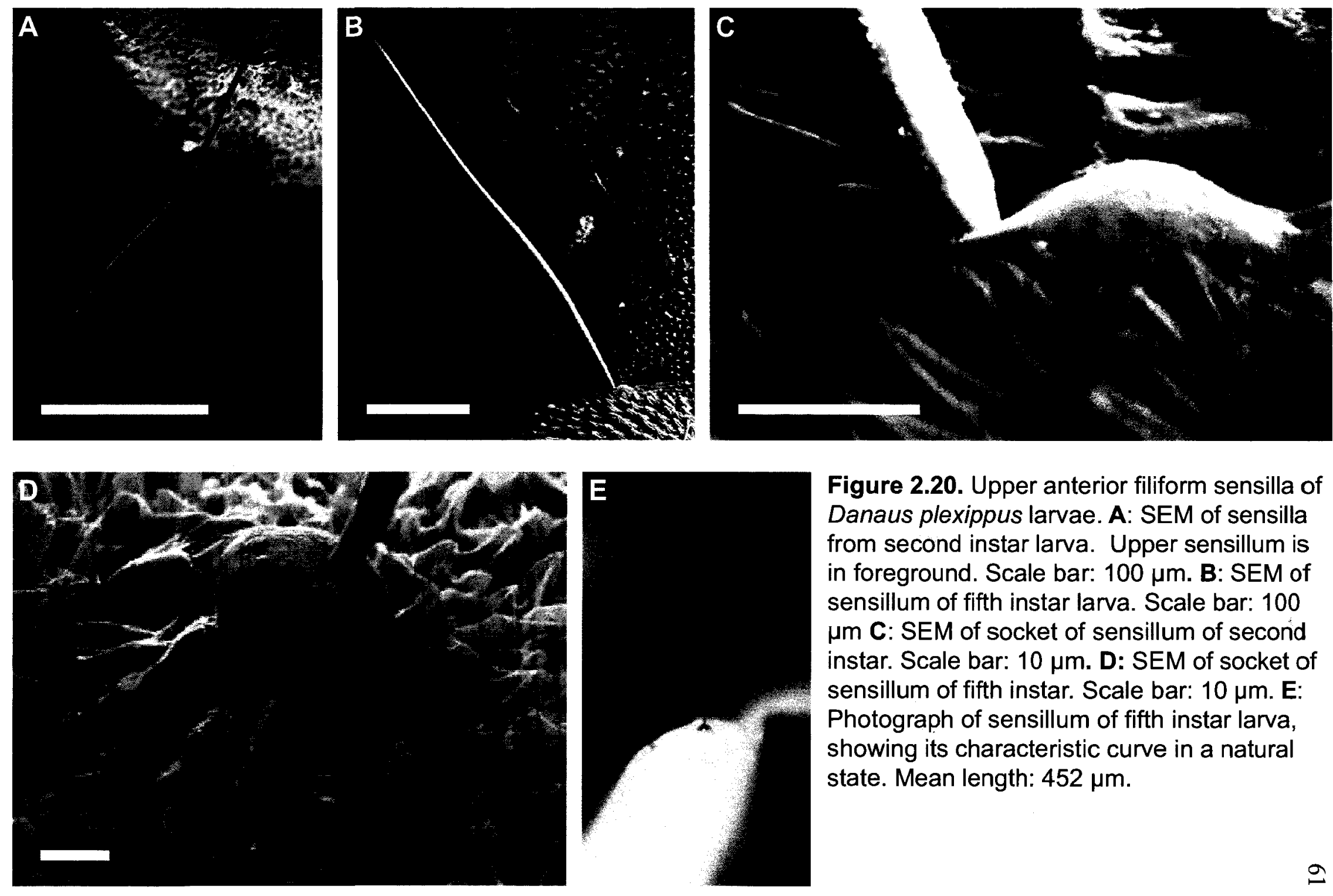

Figure 2.20. Upper anterior filiform sensilla of Danaus plexippus larvae. A: SEM of sensilla from second instar larva. Upper sensillum is in foreground. Scale bar: $100 \mu \mathrm{m}$. B: SEM of sensillum of fifth instar larva. Scale bar: 100 $\mu \mathrm{m}$ C: SEM of socket of sensillum of second instar. Scale bar: $10 \mu \mathrm{m}$. D: SEM of socket of sensillum of fifth instar. Scale bar: $10 \mu \mathrm{m}$. E: Photograph of sensillum of fifth instar larva, showing its characteristic curve in a natural state. Mean length: $452 \mu \mathrm{m}$. 

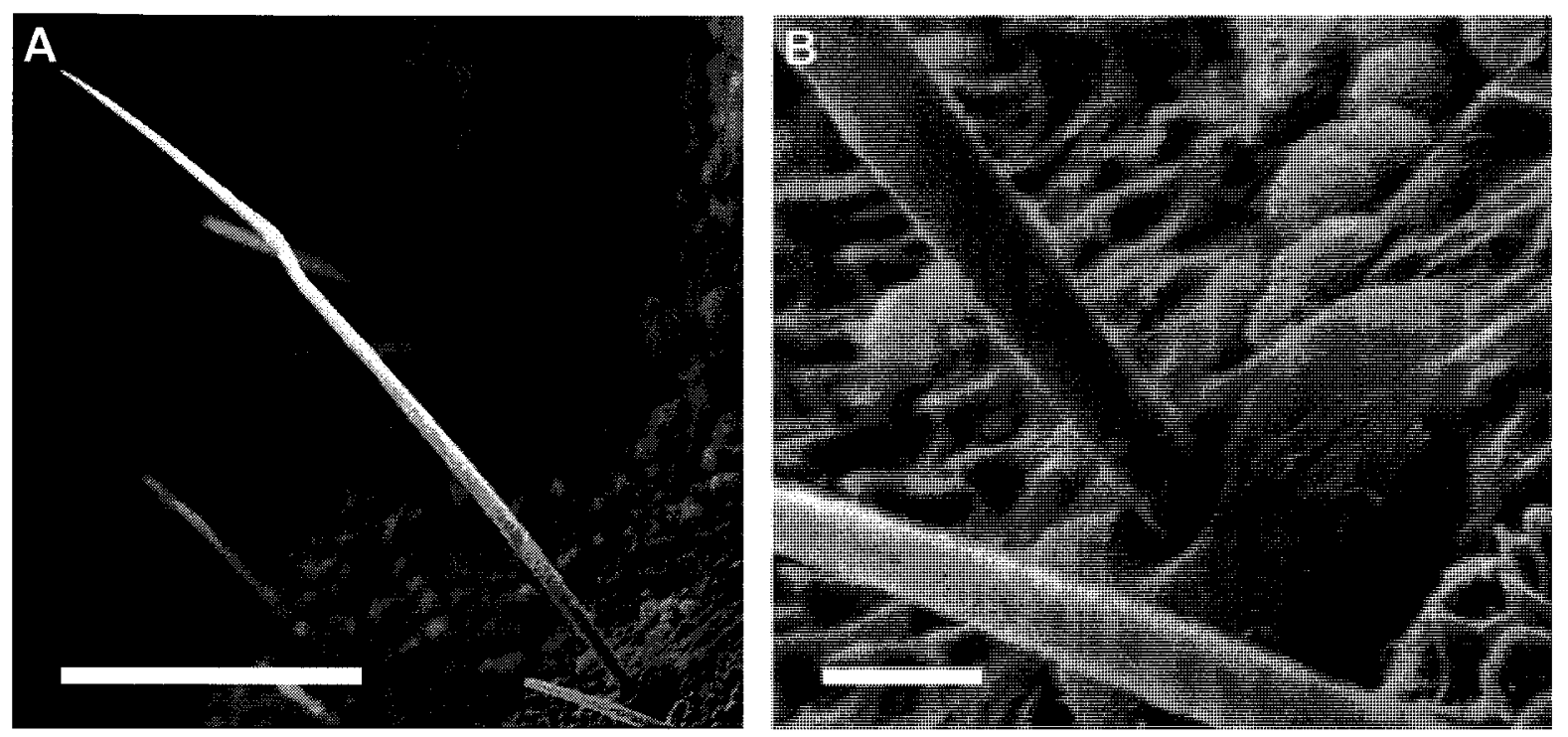

Figure 2.21. Lower anterior filiform sensilla of Danaus plexippus. A: SEM of sensilla from fifth instar larva. Scale bar: $100 \mu \mathrm{m}$. B: SEM of socket of sensillum of fifth instar larva. Scale bar: $10 \mu \mathrm{m} \mathrm{C:}$

Longitudinal thick section. Filiform sensilla and socket (f), spiracle (s), and an axon of probable sensory neuron (d). Scale bar: $100 \mu \mathrm{m}$.

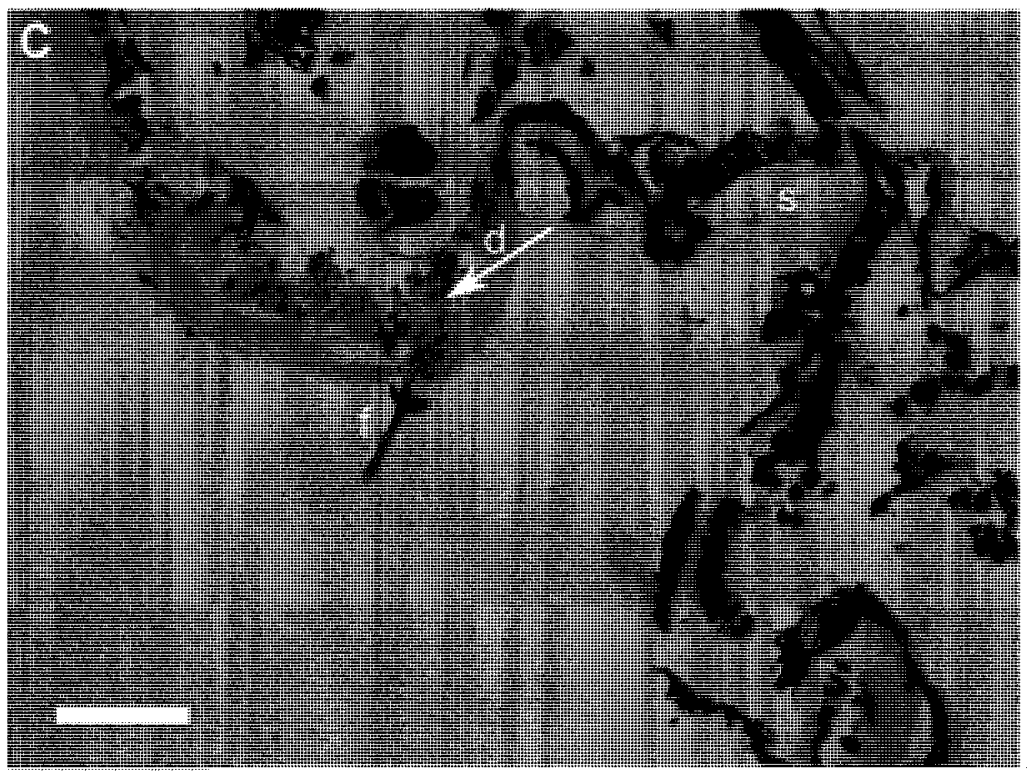



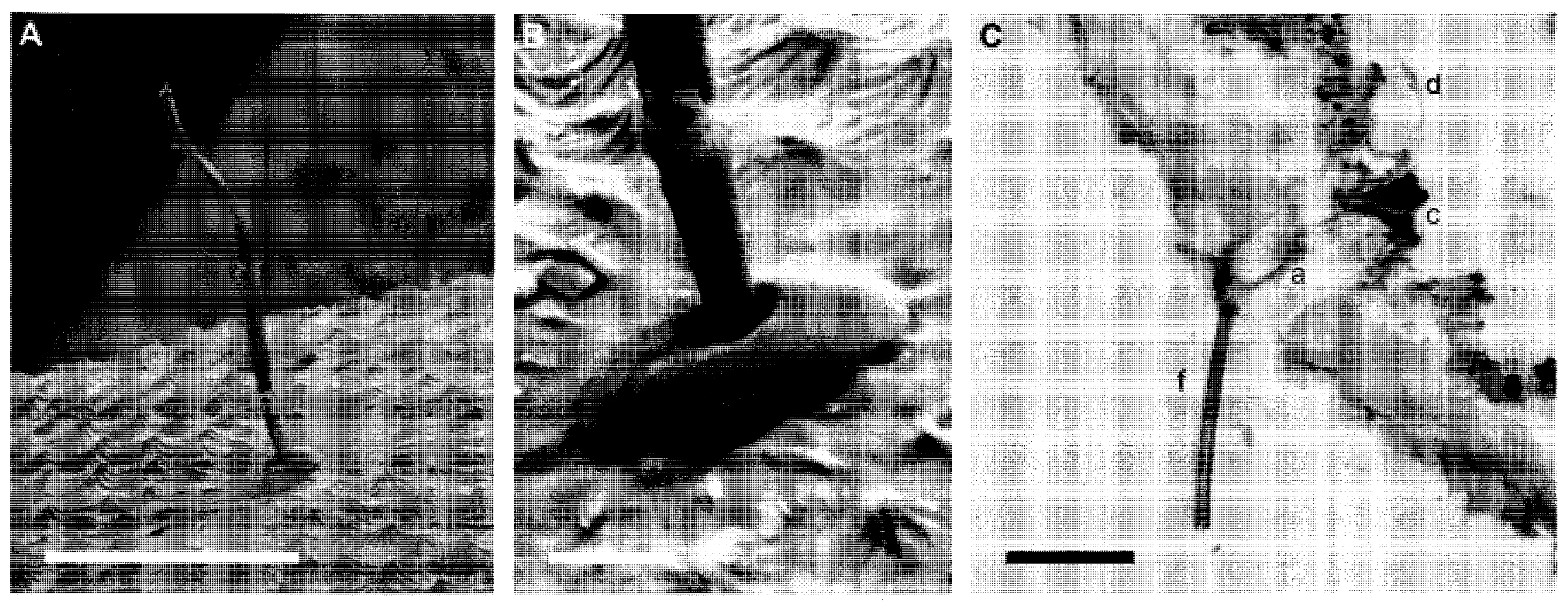

Figure 2.22. Rear filiform sensilla of Danaus plexippus on tenth abdominal segment. A: SEM of sensillum from fifth instar larva. Scale bar: $100 \mu \mathrm{m}$. B: SEM of socket of posterior trichoid sensillum of fifth instar larva. Scale bar: $10 \mu \mathrm{m}$. C: Thick section with sensilla and socket (f), and dendrite (d), cell body (c), and dendrite (d) of sensory cell. Scale bar: $25 \mu \mathrm{m}$. 

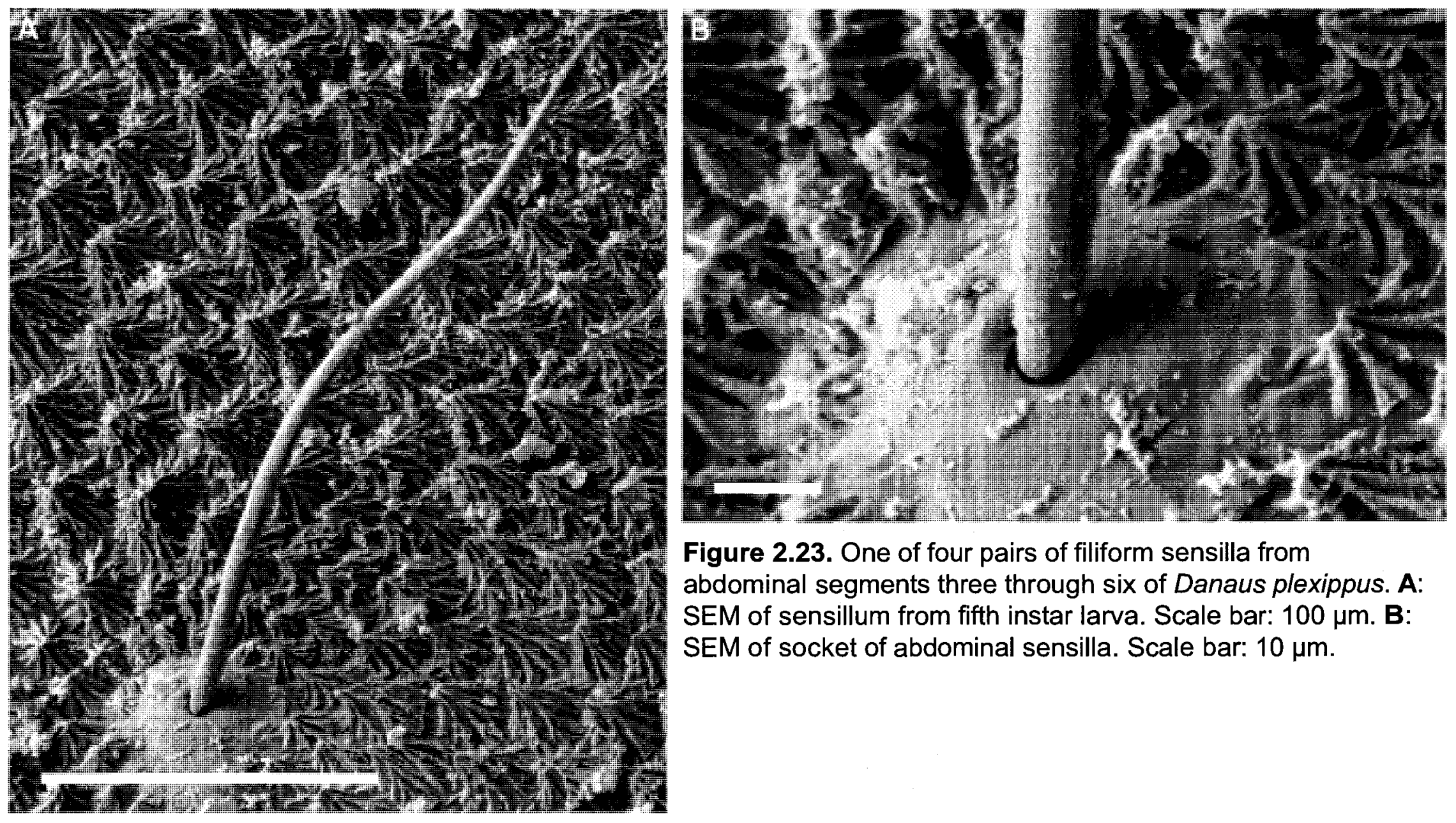

Figure 2.23. One of four pairs of filiform sensilla from abdominal segments three through six of Danaus plexippus. A: SEM of sensillum from fifth instar larva. Scale bar: $100 \mu \mathrm{m}$. B: SEM of socket of abdominal sensilla. Scale bar: $10 \mu \mathrm{m}$. 
brassicae, and because two of them were in a similar location on the thorax (Markl and Tautz, 1975). The four pairs of abdominal sensilla were not investigated further, because they were only half the length of those used by $M$. brassicae to hear, and additionally, initial examination of larvae that responded strongly showed that they mostly lacked these abdominal sensilla, likely having broken off.

Thus, three pairs of sensilla were removed to verify that any were involved in sound reception. In total, 27 individuals were ablated in this manner, and none responded to any stimulus following the procedure (Table 2.2). On the other hand, $93 \%$ of controls responded within an hour of the procedure, and a full $100 \%$ responded within two days. No larvae responded after having both anterior pairs of sensilla removed, and only a single individual responded following removal of its upper anterior sensilla. Both of these findings varied significantly from the expected proportion obtained from the control data (Table 2.2). Removal of either the lower anterior or posterior pair of sensilla had no significant effect on the proportion of larvae that responded (Table 2.2). The five individuals that were isolated following ablations survived until their next moult, and responded strongly once again to acoustic stimuli. When observed with a microscope, it was confirmed that all five larvae had regrown each pair of sensilla. 
Table 2.2. Number and proportion of $D$. plexippus larvae that responded to sound following removal of various filiform sensilla, compared to control (no setae removed).

\begin{tabular}{lcccc}
\hline Setae Removed & N & Responders & Proportion & P-value $^{*}$ \\
\hline All & 27 & 0 & 0 & $<0.0001^{\text {}}$ \\
Both prothoracic & 10 & 0 & 0 & $0.0023^{\star \star}$ \\
Upper prothoracic & 10 & 1 & 0.1 & $0.0084^{\star \star}$ \\
Lower prothoracic & 10 & 8 & 0.8 & 0.73 \\
Rear abdominal & 10 & 9 & 0.9 & 0.93 \\
None (control) & 15 & 14 & 0.93 & - \\
& & & & \\
${ }^{*}$ compared to control & & & & \\
${ }^{\star \star}$ statistically significant & & & & \\
\hline
\end{tabular}




\section{DISCUSSION}

Danaus plexippus was found to be most responsive to low frequency sounds between 100 and $200 \mathrm{~Hz}$, at which their threshold was near $80 \mathrm{~dB}$ SPL or $650 \mu \mathrm{m} / \mathrm{s}$ to pure tones. When larvae responded, they did so by freezing, contracting, or flicking dorsally, and the quality and quantity of responses varied with sound intensity. Sound receptors were identified as mainly a single pair of filiform sensilla on the prothorax. The following discussion will focus on the behavioural response to sound, the functional significance of these behaviours, and the sensory receptors. Comparisons will also be made with Mamestra brassicae, the only other lepidopterous larva in which hearing has been thoroughly studied.

\section{Response to Sound}

\section{Danaus plexippus responds to near-field sound}

Danaus plexippus was confirmed in the present study to respond to sound.

Larvae must be sensitive to the particle displacement component of sound, as opposed to the pressure component, due to the physical properties of the sensilla. Ablation experiments revealed that larvae hear with filiform sensilla, which are not sensitive to changes in pressure, because air pressure is equal around the entire sensilla, and as such cannot exert any force on it (Tautz, 1979). The only other component of sound that such a receptor can respond to is particle displacement. Similar sensilla have also been conclusively shown to be responsive to only the near-field, with experiments conducted in standing wave tubes or boxes (Markl and Tautz, 1975). Although some filiform sensilla respond to wind, such as the cercal filiform sensilla of crickets (Kanou and 
Shimozawa, 1984; Landolfa and Miller, 1995), D. plexippus did not respond to sustained air flow. Danaus plexippus sensory cells are likely similar to those of other species that use filiform hairs used to detect sound, in which the sensory cells do not respond to sustained deflection of the filiform sensilla (Tautz, 1978; Barth and Höller, 1999).

Response latency

Contraction latency was slightly less than flicking latency, although this difference was not significant. This indicates that response latency and flicking were highly variable, at least in the high speed trials, and probably not dependent on the type of response that is observed. Contraction latency in D. plexippus was approximately 40 ms at its shortest value, which is near some previously recorded response thresholds for acoustic startle responses in other species (e.g. Forrest et al., 1995; Fullard, 1982). Very high sound levels were required to elicit responses during high speed trials, so the latency values obtained may be near the shortest that one might encounter, since stimulus intensity is known to affect response time to acoustic stimuli (e.g. Forrest et al., 1995; Triblehorn and Yager, 2005).

Frequency response

The audiograms measured in sound pressure level and particle velocity were very similar, showing that $D$. plexippus was most sensitive to frequencies between 100 and $200 \mathrm{~Hz}$. The similarity of audiograms for all responses (Fig. 2.4) and for only flicks (Fig. 2.7) was expected, simply because the overwhelming majority of responses observed were flicks. The audiogram for all responses represents a true behavioural audiogram, since any response to sound indicates that the sound must have been perceived by the insect. However, if a flick is considered the most effective response to flying predators, 
then Figure 2.7 represents the intensities at which larvae will respond in a way that actually defends themselves, and as such represents a "functional" audiogram.

Although the increase in threshold rises in an approximately linear fashion at frequencies higher than $200 \mathrm{~Hz}$, there are slight decrements in threshold intensity at 350 and $550 \mathrm{~Hz}$ (see Fig. 2.4). These anomalies may be explained by the resonant properties of the sensilla. For example, the sensilla responsible for sound reception likely have a resonant frequency at or near $175 \mathrm{~Hz}$, because this value falls near the middle of the best frequency range. If sensilla resonate at $175 \mathrm{~Hz}$, then they would resonate harmonically at approximately $350 \mathrm{~Hz}$ and $525 \mathrm{~Hz}$, which would cause the sensilla to oscillate at higher intensities, and thus decrease the behavioural response threshold, near these frequencies. Alternatively, these irregularities may be the result of an insufficient sample size (32 trial replications).

\section{Intensity response}

The proportion of larvae responding to sound by flicking increased at higher sound intensities intensities, as did the average number of flicks per response and the proportion of full flicks, compared to partial ones (Fig. 2.10 and 2.15). However, the data used to construct figures 2.10 and 2.15 was taken from behavioural audiogram trials, during which the tones were presented ten seconds apart in increasing intensity. This allowed for the possibility that D. plexippus larvae either sensitized to the sound, or experienced habituation before the trial was complete. Habituation of behavioural responses to stimuli varies depending on many factors (May and Hoy, 1991), and other larvae were reported to habituate quickly following repeated stimulation (Johnson, 1893; Minnich, 1936; Markl and Tautz, 1975). Conversely, sensitization is observed in some 
insect reflex responses, and is often induced by increased levels of octopamine, which is released in response to stress in many invertebrates (e.g. Sombati and Hoyle, 2004). Therefore the habituation/sensitization experiment was conducted to confirm that there was no influence of either of these effects, by repeatedly playing $200 \mathrm{~Hz}$ tone with a constant intensity. The results of this experiment show that D. plexippus larvae do not sensitize over this time period, and do not habituation until the sixth tone (Fig. 2.8). Additionally, the results of the high-low experiment which showed that there was a significant difference between number of flicks in response to high and low intensity sounds, with a much longer waiting time between stimuli. Therefore, it can be concluded with confidence that $D$. plexippus larvae are able to discern different intensities, and that they respond to higher intensities with a more vigorous response Although sensitization was not observed over ten second stimulus intervals, where multiple flicks occurred, larvae commonly flicked to a greater angle during the second flick, which suggests sensitization occurred over a shorter time-scale. This initial sensitization was subjectively observed in behavioural audiogram trials, and was confirmed by measurements from high speed video trials (Fig. 2.14).

\section{Function of Hearing in Danaus plexippus}

In order to support the hypothesis that hearing in $D$. plexippus evolved to detect aerial predator and parasitoid insects, several substantiating criteria should be met. $D$. plexippus should be under selective pressure from predators and parasitoids, in order for these receptors to confer a selective advantage, and flight sounds of these predators and parasitoids should match the frequencies to which $D$. plexippus is most sensitive. Additionally, larvae should respond in a way that effectively defends against attacks from 
these other insects.

Selective pressure from sound producing predators and parasitoids

Danaus plexippus larvae face very high mortality from predators and parasitoids (Oberhauser and Solensky, 2004). Although ants, predatory Hemiptera, and some other terrestrial predators are common, they also face strong mortality from aerial insects (Oberhauser et al., 2007). Lespesia archippivora (Diptera: Tachinidae) is by far the most common parasitoid that attacks monarch larvae in North America (Oberhauser et al., 2007), although twelve species of other tachinid flies and one species of braconid wasp have been reported on D. plexippus as well (Arnaud, 1978). Lespesia archippivora is a generalist, and there have been no reported parasitoids that specialize on D. plexippus (Oberhauser and Solensky, 2004). Parasitism varies widely among geographic area and year (Oberhauser et al, 2007), ranging from 1\% in southern Ontario (Urquhart, 1960) to 43\% in Texas and Louisiana (Lynch and Martin, 1993). One particularly large study of D. plexippus parasitism rates in North America found that an average of $13 \%$ of fourth and fifth instar larvae were parasitized by tachinids, but this number reached up to $90 \%$ for some sites (Oberhauser et al, 2007). Vespid wasps are common aerial predators as well (Oberhauser and Solensky, 2004; personal observation). This shows that there is selective pressure for $D$. plexippus to be able to hear and effectively respond to aerial enemies. However, some parasitoids, particularly tachinids, larviposit near a host, while others lay their eggs on host plants so that the larvae ingest them (Allen et al., 1999; Speight, 1999), and near-field hearing would not be useful against these or any other predators or parasitoids that do not make direct aerial attacks. 
Frequency sensitivity to predators and parasitoids

Danaus plexippus larvae were most sensitive to frequencies that fall within the range of sounds produced by a number of flying insects. Table 2.3 lists the flight sounds of several representatives of Hymenoptera and Diptera of different sizes. These examples were chosen because predators or parasitoids commonly belong to these orders, and species with similar morphology and size produce similar flight sounds (Dudley, 2000). Flight sounds range from $55 \mathrm{~Hz}$ in an ichneumonid parasitoid to $550 \mathrm{~Hz}$ in chironomids (Table 2.3), but most fall into the $150-350 \mathrm{~Hz}$ range, which roughly corresponds to the best frequencies of $D$. plexippus. This suggests that the sound receptors of $D$. plexippus larvae function to detect a relatively broad range of flight sounds produced by aerial insects, although they are not adapted to detect very small parasitoids that produce high frequency flight sounds.

\section{Adaptive significance of behavioural response to sound}

Many parasitoids and predators use visual cues for short-range location of prey (e.g. Nakamatsu and Toshiharu, 2005; Oliai and King, 2000), which suggests that freezing may have a cryptic function. Although D. plexippus is already visually conspicuous with its aposematic colouration, many species of parasitoid require movement, detected either visually or as substrate vibrations, before they will attack a host (Bushbeck and Strausfeld, 1997; Stireman, 2002; Vet and Bakker, 1985). However, while freezing has previously been shown to be effective at avoiding attack by predators (Gross, 1993; Tautz and Markl, 1978), it tends to be an ineffective defense against parasitoids (Hawkins, 1997). Lack of efficacy against parasitoids may explain why $D$. plexippus exhibits other behavioural responses to sound in addition to freezing. 
Table 2.3. Flight sounds of insects. Selected representatitives of Hymenoptera and Diptera with a

\begin{tabular}{|c|c|c|c|c|c|}
\hline Order & Family & Species & $\begin{array}{l}\text { Flight Frequency } \\
(\mathrm{Hz})\end{array}$ & $\begin{array}{c}\text { Approx. } \\
\text { Body Size } \\
\text { (mm) }\end{array}$ & Reference \\
\hline Hymenoptera & Vespidae & $\begin{array}{l}\text { Dolichovespula } \\
\text { media }\end{array}$ & 150 & 20 & $\begin{array}{l}\text { Tautz and Mark } \\
1978\end{array}$ \\
\hline Diptera & Tephritidae & $\begin{array}{l}\text { Anastrepha } \\
\text { suspensa }\end{array}$ & $160-500$ & & $\begin{array}{l}\text { Webb et al. } \\
1976\end{array}$ \\
\hline Hymenoptera & Apidae & Apis mellifera & 250 & 15 & Sotavalta, 1963 \\
\hline Diptera & Muscidae & Musca domestica & $150-200$ & $6-9$ & Sotavalta, 1963 \\
\hline Hymenoptera & Culicidae & $n / a$ & $280-350$ & 10 & Sotavalta, 1963 \\
\hline Diptera & Chironomidae & Chironomus & $440-550$ & $1-10$ & Sotavalta, 1963 \\
\hline Hymenoptera & Vespidae & Vespa vulgaris & 165 & $17-20$ & Sotavalta, 1963 \\
\hline Hymenoptera & Bombidae & Bombus locorum & 150 & 25 & Sotavalta, 1963 \\
\hline Hymenoptera & Ichneumonidae & Ophion luteus & 55 & $10-19$ & Sotavalta, 1963 \\
\hline
\end{tabular}


It is not immediately clear from this research that contracting is an adaptive behaviour, since the movement was subtle and relatively slow, compared to flicking. However, if the behaviour is assumed to be adaptive, I suggest two possible explanations for the function of contractions, with some supporting evidence. One explanation is that this behaviour engages antagonist muscle pairs that are held in an isometric contraction, preventing further movement by the larva. By this hypothesis, the contraction thereby confers the same advantage that freezing does, except it lasts longer. Since a greater proportion of responses at lower sound intensities were contractions (Fig. 2.10), this is suggestive that this behaviour is more adaptive when aerial predators or parasitoids are in the area, but not near enough to risk flicking and drawing attention to the larva's location. Another possibility is that contracting somehow prepares the larva for a flick, by warming up the muscles used in a flick or potentiating neural pathways involved in flicking. As discussed above, the magnitude of a second flick tends to be greater than the first flicks (Fig. 2.14). This is evidence that a previous response, such as a flick or perhaps contraction, can intensify behaviours that shortly follow it.

Flicking likely functions to knock away aerial predators, or prevent oviposition by parasitoids. Observations of other larval Lepidoptera support this hypothesis, as flicking in response to sound or wasps has been experimentally (Tautz and Markl, 1978) or anecdotally reported (Hogue, 1972; Myers and Smith, 1978) to confer protection to the larvae. Some tachinids try to lay the egg on the larva's head capsule, where the larva cannot bite it off (Iwao and Wellington, 1970), and flicking creates a moving target that likely makes oviposition difficult. The upward stroke of a flick was nearly twice as fast as the downward stroke, confirming that upward speed, and thus force, is important, which supports the idea that this behaviour is used to knock a flying insect away. Although $D$. 
plexippus only flicks dorsally in response to sound, lateral flicking behaviour in other larval Lepidoptera has been shown to be an effective defense against some terrestrial predators (Evans, 1982). Less is known about dorsal flicking, but it may be a more effective adaptation to defend against aerial attacks, since lateral flicking is only moderately effective against parasitoids (Hawkins, 1997).

This does not mean that $D$. plexippus larvae are unequipped to defend themselves against terrestrial predators. On the contrary, when gently prodded in the side of the abdomen with forceps, larvae responded by reaching around to grip the forceps with their mandibles, and forcefully flicking to the other side. Biting is usually a very effective defense, because it can seriously injure the attacker (Hawkins, 1997). Thus, D. plexippus larvae display behavioural plasticity based on the type of perceived threat, allowing them to respond more appropriately to different stimuli.

Younger instar larvae are less capable of producing flicks with sufficient force to defend themselves against larger predators or parasitoids, simply because they are smaller (Gross, 1993). It is not surprising then, that younger instar D. plexippus often lost contact with the substrate when they flicked, because evasion by dropping to the ground is a more effective than aggressive defense during these stages (Hawkins, 1997; Gross, 1993).

Another supplementary defense that $D$. plexippus larvae may use in conjunction with flicking is the dispersal of volatile repellent chemicals, which are likely excreted from the head collar region (Rothschild and Bergström, 1997). If these volatiles are released in response to sound, this might partly explain why $D$. plexippus flicks up and down, as opposed to side to side like other larvae (Table 1.1); flicking dorsally would direct the volatiles in the direction of flying predators or parasitoids. However, it has not been confirmed that these volatiles are released in response to sound, and preliminary 
experiments that I conducted were unable to show that wasps (Hymenoptera: Vespidae) groomed themselves more often when placed near larvae that were flicking in response to an auditory stimulus.

Considering that $D$. plexippus larvae are able to detect the flight sounds of parasitoids or predators, and that they have reportedly specialized defenses against terrestrial predators (biting and lateral flicking) and aerial attacks (dorsal flicking, with possible volatile repellents), it may seem surprising that these larvae have such high mortality from predators and parasitoids. It is commonly known that D. plexippus are at lower risk of being consumed by many vertebrate predators, because larvae sequester cardiac glycosides from the hostplant, Asclepias (Oberhauser and Solensky, 2004). These chemicals are harmful to many vertebrate predators, many of which will learn to avoid these unpalatable prey items (e.g. Skelhorn and Rowe, 2006; Trigo, 2000). However, many parasitoids preferentially attack hosts that are likely to be rejected by predators, thus reducing risk of mortality due to predation (Gentry and Dyer, 2002). Other research has established that larvae like $D$. plexippus, which contain unpalatable chemicals are more commonly parasitized (Hawkins 1997).

\section{Sensory Receptors}

\section{Tubercles and prothoracic shields}

Although it is clear that the tubercles are not involved in sound reception, they do appear to be sensory organs. Danaus plexippus larvae slowly and independently moved each anterior tubercle back and forth when exploring their hostplant, in a similar manner that many other insects use their antennae. Tubercles are also covered in sensory setae, 
which supports assertions by some monarch specialists (Dr. Chip Taylor, University of Kansas, personal communication) that tubercles are used for tactile sensation. Neither the tubercles nor the prothoracic shield contained any setae that were appropriate dimensions for receiving near-field sound (Tautz, 1979; Barth, 2004). However, the prothoracic shield in at least one other species, Ahmetia achaja Fruhstorfer (Lepidoptera: Lycaenidae) has been reported to contain a pair of filiform sensilla that the authors state are homologous to one of the pairs of sensilla used for near-field reception in $M$. brassicae (Ballmer and Wright, 2008).

\section{Filiform Sensilla}

One pair of long filiform sensilla located on the upper prothorax were found to be the principal sound receptors of $D$. plexippus larvae. When these sensilla were removed, only a single larva continued to respond, and no larvae responded if both anterior sensilla were removed. Removal of the rear abdominal sensilla had no effect on the proportion of larvae that responded to sound following the ablation, suggesting that they have no primary role in sound reception. Although sensilla on abdominal segments three through six were not removed, their presence or absence had no effect on the strong significance of the impact of the upper prothoracic sensilla, indicating that these likely had no role in audition either.

The principal sound receptors were positioned on the dorsal half of the prothorax, close to the prothoracic ganglia and muscles that must contract during flicking. This proximity would reduce the distance that neural impulses must travel, and thus minimize latency between stimulus and behavioural response. Therefore, the location of the sound receptors is likely adaptive. 
The shape and length of the upper prothoracic sensilla of $D$. plexippus are consistent with known properties of filiform sensilla (Tautz, 1979; Barth, 2004). The physical structure of sensilla in particular is important in determining its resonant properties. A near-field receptor must be sufficiently long to extend past the boundary layer of air around the larva's body at biologically relevant frequencies (Barth, 2004), and this boundary layer ranges between 12.5 and $106 \mu \mathrm{m}$ for the best frequency range of $D$. plexippus (Tautz, 1979). However, it must not be too long such that the displacement angle decreases to the point where the sensory cell is unable transduce the stimulus. Sensilla must also be narrow to be efficiently deflected by oscillations of air particles (Tautz, 1979). A smaller radius at the base of a sensilla increases its maximum theoretical sensitivity (Tautz, 1979), so the fact that the sensilla in D. plexippus are narrower near the socket is likely adaptive, and may be another useful character for identifying near-field receptors. The rear abdominal and lower prothoracic sensilla are shorter than the upper prothoracic pair of sensilla, and four pairs of central abdominal sensilla are shorter still, but they are all still longer than the boundary layer, and the other aforementioned important physical characteristics are very similar and suggestive of a similar function. These other thoracic and abdominal sensilla may contribute additional information if they have different directional sensitivity, such as the different sensilla of M. brassicae (Tautz, 1977). Experiments by Minnich (1936) suggest that the sensilla on abdominal segments three and four may have some function in hearing. When $D$. plexippus larvae were trisected, the anterior (thorax and head) and middle (from the thorax to between second and third prolegs) portions of the body continued to respond, usually just by pausing, to a $256 \mathrm{~Hz}$ tuning fork, although this response was faint, inconsistent, and required very loud sounds (Minnich, 1936). These results are difficult to 
integrate with my observations and ablations of the sensilla, especially considering that the posterior portion did not respond, despite the fact that it still possessed two abdominal sensilla on the fifth and sixth segments, in addition to the sensilla on the tenth segment (Minnich, 1936). If these abdominal sensilla do have some sort of auditory function, the fact that they are all on segments bearing prolegs might indicate that at particularly high sound intensities, perhaps they cause the prolegs to relax their grip on the substrate, causing the falling behaviour observed in some younger instar larvae. Regardless of any suspected purpose of these abdominal sensilla, the results of the current ablation experiments only indicate that they are not important in sound reception at least when the larvae are intact, so their actual function remains unknown.

\section{Evolution of sound receptors}

Given the simplicity of filiform sensilla, it is easy to see how they might have evolved from a mechanoreceptor seta, such as one of the many that cover the body of the larvae. There were only a few basic differences in the appearance of the short mechanoreceptor setae that cover the body of $D$. plexippus, and the filiform sensilla used for sound reception, as described above. This suggests that sound reception in larval Lepidoptera could potentially have more than one independent evolutionary origin. The pre-existence of chordotonal organs facilitated multiple independent evolution of tympanal ears in adult Lepidoptera (Yack, 2004), and the presence of mechanoreceptive setae on the body of larval Lepidoptera may be a similar exaptation.

\section{Comparison to Mamestra brassicae}

While there were certainly similarities in the near-field receptors of $D$. plexippus and $M$. brassicae, there were some basic differences. $M$. brassicae had four pairs of 
filiform sensilla on its thorax: two pairs on the first thoracic segment, and one each on the second and third segments (Markl and Tautz 1975). The location of the two filiform sensilla on the anterior segment of the thorax were approximately the same in $D$. plexippus and M. brassicae, however it is uncertain if the sensilla are analogous or homologous to D. plexippus. Danaus plexippus has far more setae overall than $M$. brassicae, so over the timespan that $D$. plexippus and $M$. brassicae are evolutionarily separated, many setae have been lost by $M$. brassicae or gained by $D$. plexippus. It is not unreasonable to suggest that a hypothetical ancestor to both species may have possessed filiform sensilla on the abdomen, like D. plexippus, and on all thoracic segments, like $M$. brassicae. In order to determine possible homology of these setae, chaetotaxy of first instar M. brassicae and D. plexippus must be compared, although at this taxonomic level, homology of some setae is disputed (Ballmer and Wright, 2008).

Selective ablation experiments of the sensilla on $M$. brassicae showed that these sensilla were all of the same relative importance in detecting near-field sound (Markl and Tautz 1975). Danaus plexippus, on the other hand, were mostly affected by the removal of a single pair of sensilla on its prothorax.

The overall shape of these sensilla were similar in D. plexippus and M. brassicae. Both pairs of sensilla on the prothorax of M. brassicae are bent, as are both pairs on the thorax of D. plexippus. The filiform hairs on M. brassicae were located in cuticular pits, (Markl and Tautz 1975), whereas the sensilla of D. plexippus inserted in dome shaped sockets, which raised above the cuticular surface.

The displacement angle threshold can be interpreted from the particle displacement threshold, and was calculated to be near $0.2^{\circ}$ at its lowest values (200 and $350 \mathrm{~Hz}$ ) (Tautz, 1979). This is similar to the values obtained for M. brassicae, which 
were usually $0.2^{\circ}$ but sometimes as low as $0.1^{\circ}$ (Tautz, 1978). Thus, it is likely that in order for a sensory cell to respond, that the displacement threshold acts as an absolute threshold. However, results of several experiments show that $D$. plexippus larvae can detect differences in sound intensity, and respond differently to them. This is contrary to what Tautz (1978) concluded about the sensory cells of M. brassicae, which could not encode stimulus intensity between 40 and $200 \mathrm{~Hz}$. Tautz (1978) stated that it was not biologically relevant to larvae how intense the stimulus was, only that it was present, so M. brassicae have an all-or-nothing behavioural response. If this is true, then may be evidence of independent evolution of sound receptors, since $D$. plexippus has been shown.

There are three ways in which $D$. plexippus could respond to differences in sound level. The first explanation is that the sound receptors are sensitive to the velocity at which the filiform sensilla move. In this case, they would be sensitive to particle velocity (Fig. 2.5). The second is that the sound receptors are sensitive to the displacement angle of the filiform sensilla. In this case, they would be sensitive to particle displacement (Fig. 2.6). The third explanation allows for the possibility of similar sensory cell activity of the sound receptors. Since they are shorter, the other filiform sensilla on the body of D. plexippus would be less sensitive to sound (Tautz, 1979). This may mean that the principal sound receptor is an all-or-nothing response, but exceeding the threshold of the other sensilla may elicit an even stronger response.

\section{Conclusion}

Response to sound 
Danaus plexippus larvae were most sensitive to frequencies between 100 and 200 $\mathrm{Hz}$, regardless of the method used to measure or calculate sound intensity. Larvae behaved differently at different sound intensities during behavioural audiogram trials. Observations of $D$. plexippus larvae in the present study were consistent with published descriptions of this species, which typically consisted of dorsally directed flicking in response to low-frequency sounds (Minnich, 1936; Rothschild and Bergström, 1997). These behaviours were also consistent with what has been reported in other species, although no other species has been reported to respond to sound by flicking only dorsally (Table 1.1).

\section{Function}

Danaus plexippus larvae are not heavily preyed upon by vertebrate predators, but they are strongly influenced by many aerial insects, particularly tachinid parasitoids and predatory wasps (Oberhauser and Solensky, 2004). This high predation and parasitoid selective pressure further reinforces the hypothesis that near-field hearing evolved for defense. The frequency and intensity of sounds to which $D$. plexippus larvae responded supports the hypothesis that sound reception in lepidopterous larvae is adapted to detect the flight sounds of these aerial parasitoids or predators. The behavioural responses of the larvae to sound are consistent with appropriate reactions to predators as well, as each behaviour observed may be effective at avoiding detection by predators or parasitoids, or directly defending against them.

\section{Sound receptors}

One pair of filiform sensilla on the prothorax was identified as the principal sound receptor, but the function of the other filiform sensilla could not be determined. The 
physical properties of all $D$. plexippus filiform sensilla were consistent with physical properties observed in other insects that use their setae to detect sound (Barth, 2004; Pflüger and Tautz, 1982; Tautz, 1979).

Comparisons between $D$. plexippus and $M$. brassicae revealed some differences and similarities, but none that cannot exclusively be explained by convergent, independent evolution of near-field hearing, or an ancestral near-field receptor that has simply diverged over time. However, the similarities that exist between the two species in terms of sensitivity, receptors, and behaviour also support evolution of near-field reception for a defensive purpose, since this function has been confirmed in M. brassicae.

Future research should focus on behavioural experiments with L. archippivora or other parasitoids and aerial predators, to confirm that the ability to detect sound is advantageous in $D$. plexippus. In addition, the possible role of volatile deterrent chemicals in the response of D. plexippus needs to be confirmed. If these chemicals are released in response to sound, they may increase effectiveness defensive of the flicking response. Electrophysiological and mechanical experiments on the filiform sensilla and associated sensory cell should also be undertaken. The role of the other filiform sensilla on the prothorax and abdomen of $D$. plexippus remains unknown, and such investigations might provide insight into their function. Determining sensory cell characteristics may also help elucidate the evolutionary origin of sound reception in D. plexippus and $M$. brassicae. However, a comparison of the chaetotaxy of first instar larvae of these two species should reveal from which primary setae their respective filiform sensilla originated, which may be a much simpler method of answering the question of whether sound reception is ancestral to both groups, or if it is the result of convergent evolution. 


\section{CHAPTER 3:}

\section{INTRODUCTION}

The ability of lepidopterous larvae to hear appears to be widespread, and preliminary observations of many species demonstrates a variety of different responses (Table 1.1). Although many species from several distantly related taxa have been observed to be responsive to sound, only one species, Mamestra brassicae Linn. (Lepidoptera: Noctuidae) has been extensively investigated (Markl and Tautz, 1975; Tautz and Markl, 1978; Tautz, 1978; Tautz, 1979). Chapter 2 of this thesis described the behaviour and anatomy of Danaus plexippus larvae, which either freeze, contract, or flick dorsally in response to sound, whereas Mamestra brassicae flicks laterally (Markl and Tautz, 1979). Other species only freeze, contract, or have other behaviours, such as the notodontids that wave their modified proleg "tails" in defense (Table 1.1). In adult Lepidoptera, tympanal hearing evolved independently several times (Minet and Surlykke, 2003). This may be explained by the fact that tympanal ears evolved from pre-existing chordotonal organs, which means that there only are few simple evolutionary steps required to form a functional ear (Yack, 2004). Similarly, in larval Lepidoptera, the purported diversity of responses to sound, and the diverse taxa that respond to sound, suggests that hearing receptors in larval Lepidoptera may have evolved independently (Table 1.1). The simplest type of near-field receptors described, and the type that is found in $M$. brassicae, are simple mechanoreceptive sensilla. Since caterpillar bodies are covered in similar mechanosensitive setae, any of these could potentially develop or lose sensitivity over time to particle displacement, depending on the different selective pressures facing a particular species. The objectives in this chapter were to perform a preliminary study of the behaviour on the responses to sound of six species representing 
four different superfamilies of Lepidoptera.

Before D. plexippus was chosen as the principal study organism for my thesis, some preliminary research was conducted on the behavioural responses of several other lepidopterous species in order to choose an ideal species. Most of my preliminary work focused on the eastern tent caterpillar Malacosoma americanum. Although I worked for a few months on rearing and testing this species, the fact that they were covered in setae made it difficult to locate putative receptors, and I eventually switched the focus of my thesis to D. plexippus. I did obtain some data from M. americanum however, which will be described in this chapter.

\section{Lasiocampoidea}

Newly hatched $M$. americanum immediately start spinning the tent, and silk is added each day by the larvae until they reach their sixth instar. The tent traps heat necessary for the caterpillars to survive cold spring weather, provide humidity to prevent desiccation during moulting, and protect the larvae from parasitoids or predators. The first five instars of $M$. americanum live gregariously in their tents, leaving on synchronized foraging expeditions to other parts of a tree three times per day. Pheromone and silk trails laid down by recruiter caterpillars lead the others to quality feeding sites (Fitzgerald, 1995).

Some individuals of M. disstria Hübner (Lepidoptera: Lasiocampidae) were inadvertently collected when searching for $M$. americanum, so these were tested as well. M. disstria, the forest tent caterpillar, does not make tents, but spins silken mats on leaves, branches, or trunks of trees, where the larvae aggregate and moult. M. disstria has a nomadic foraging strategy, since unlike other Malacosoma species, it is unrestrained by 
the need to return to collective tents or webs. $M$. disstria pass through five instars, of which the fourth and fifth are often more active (Fitzgerald, 1995).

At least two species of Malacosoma larvae have previously been reported to respond to acoustic stimuli (Myers and Smith, 1978; Fitzgerald, personal communication). Myers and Smith (1978) described freezing and lateral flicking responses to sound of the western tent caterpillar, M. californicum pluviale Dyar (Lepidoptera: Lasiocampidae), and determined that they were sensitive to frequencies between 200 and $2100 \mathrm{~Hz}$. However, they did not conduct behavioural audiograms, determine the function of their behaviour, or locate receptors (Myers and Smith, 1978). Although M. californicum pluviale and M. americanum are closely related, it was not known how similarly the two species responded to sound. Experiments using $M$. americanum were conducted to determine the frequencies to which they are most sensitive, and high speed videography was used to study their movement in more detail.

\section{Bombycoidea}

Automeris io F.(Lepidoptera: Saturniidae) and Antheraea (Telea) polyphemus Cramer (Lepidoptera: Saturniidae) have been previously reported to respond to sound (Minnich, 1936). Antheraea polyphemus is a large caterpillar, that has been shown to produce aposematic clicking and regurgitate as a defense. Automeris io are gregarious in early instars, and later instars have urticating spines that deter some predators. The behaviour of these two species was briefly reexamined by attempting behavioural audiograms. 


\section{Noctuoidea}

Spilosoma virginica F. (Lepidoptera: Arctiidae) has not been reported to respond to sound. However, at least one unidentified species of arctiid has been shown to hear (Minnich, 1936). These larvae are densely covered in long setae, and are generalists on a variety of herbaceous plants.

\section{Papilionoidea}

The behaviour of one other species, Papilio polytes was observed, which to the author's knowledge, has never been reported to respond to sound. This Asian butterfly is also known as the common mormon, and like other swallowtails, larvae possess osmeteria, a defensive structure that larvae evert when threatened (Burger et al. 1985). Behavioural audiograms were attempted on $P$. polyltes, and individuals were examined for putative near-field receptors. 


\section{MATERIALS AND METHODS}

\section{Animals}

A young colony of Malacosoma americanum was collected from around Carleton University campus (Ottawa, Ontario, Canada), by clipping the supporting branches around the small developing tent. $M$. amerianum larvae were provided an enclosure constructed from wood and mesh. Scaffolding made from wooden dowels was constructed upon which the larvae could build their tent, and the branches of the young colony were strapped with an elastic band around one of the horizontal pieces of dowel (Fig. 3.1A). A bridge was constructed using dowel, which led to a large sprig of Malus or Prunus, which allowed them to make daily foraging expeditions (adapted from Fitzgerald 1995). M. disstria were kept with M. americanum under the same conditions. Larvae and plants were kept in a room $21-23^{\circ} \mathrm{C}$, with a photoperiod of $16: 8(\mathrm{~L}: \mathrm{D})$, with fresh food provided ad libitum.

Gravid adult female Antheraea polyphemus (Fig. 3.2) and Automeris io (Fig. 3.3) were captured from the Ottawa area, and larvae were obtained from eggs laid from these females. Both species were fed oak (Quercus spp.; Fragales: Fragaceae) and maple (Acer spp.; Sapindales: Sapindaceae) sprigs collected from trees in the Carleton University area. Larvae were kept under the same conditions as Malacosoma spp.

Spilosoma virginica (Fig. 3.4) was also obtained from eggs laid by gravid adult females captured from the Ottawa area. S. Virginica were fed plantain (Plantago spp.; Lamiales: Plantaginaceae) collected from Carleton University campus. Larvae were kept under the same conditions as Malacosoma spp.

Papilio polytes pupae were purchased from London Pupae (Oxford, England), and allowed to fly freely in a small greenhouse on Carleton University campus. Eggs were 

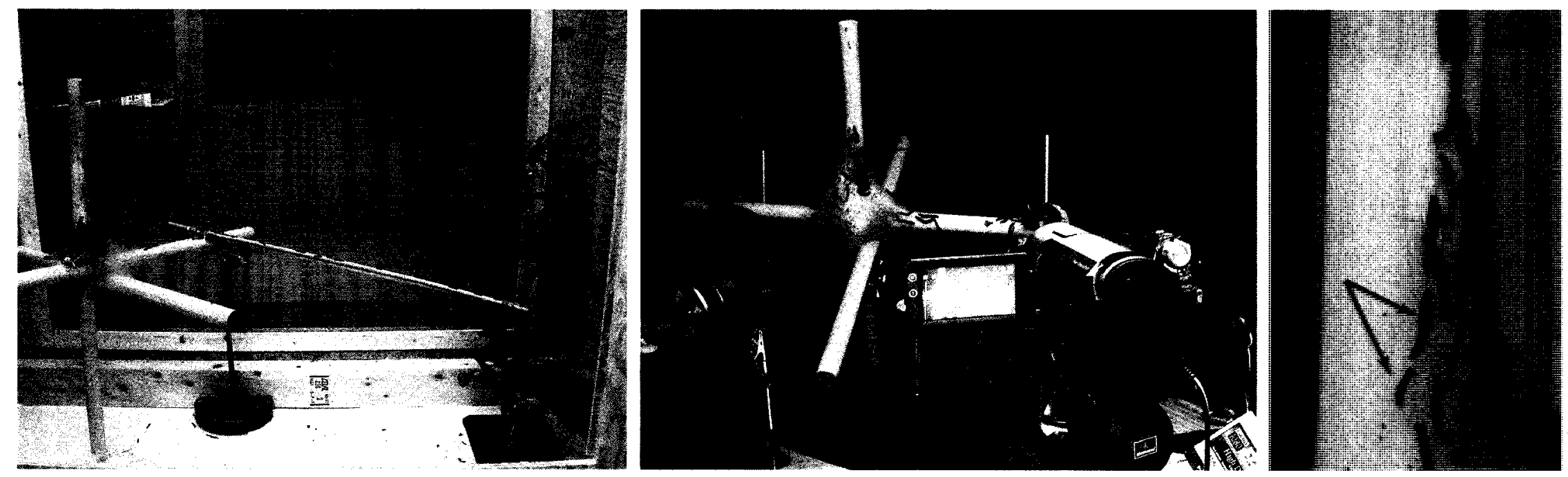

Figure 3.1. Malacosoma larvae setup. A: Enclosure featuring tent scaffolding and bridge for daily foraging expeditions built with wooden dowels and fresh Malus sprig (design adapted from Fitzgerald, 1995). B: Behavioural audiogram set-up with woofer directed at larvae on tent, with video camera recording trials. C: Malacosoma larvae walking on tent. Arrows indicate Malacosoma disstria, and all other larvae are Malacosoma americanum. 


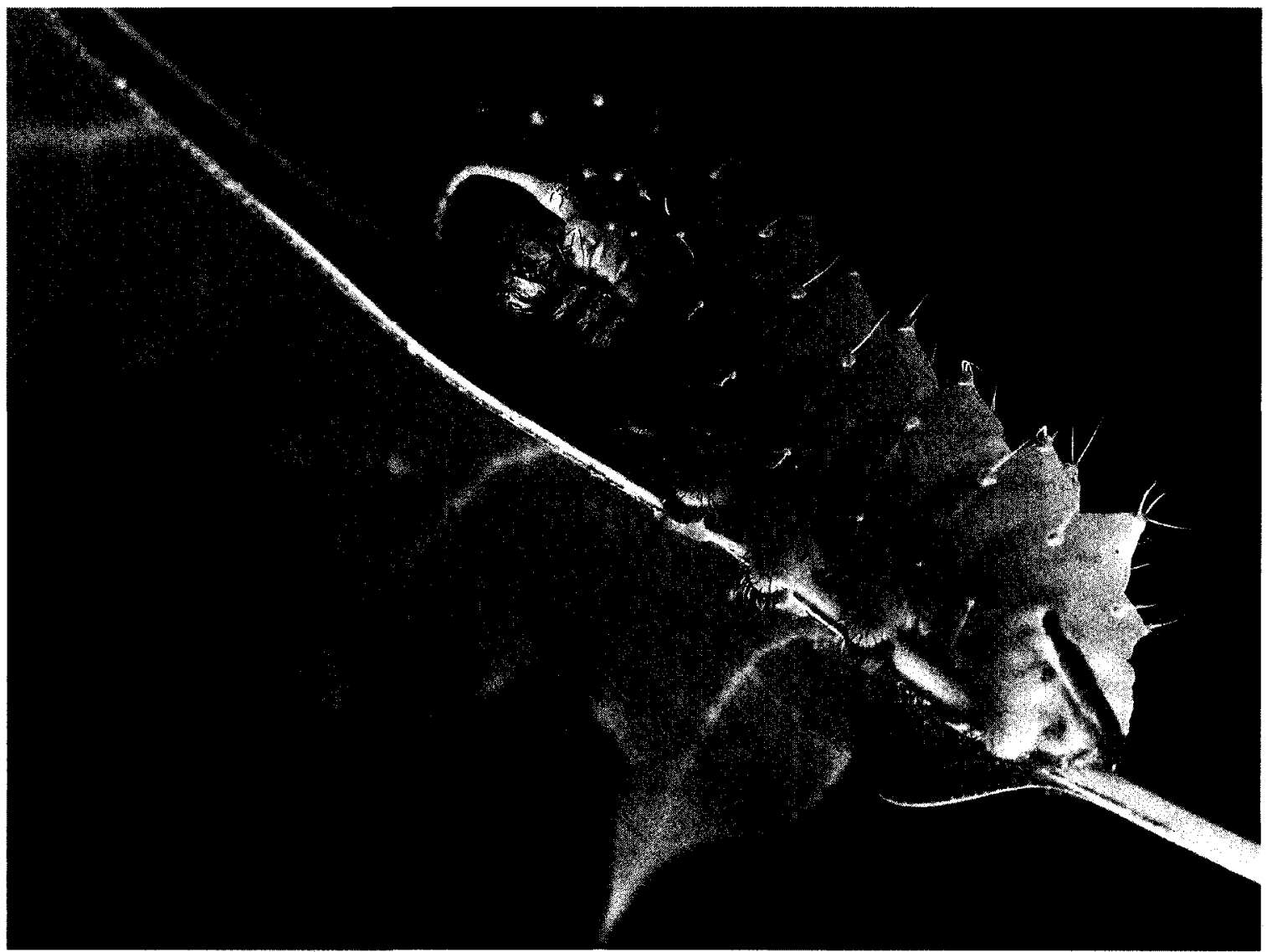

Figure 3.2. Fifth instar Antheraea polyphemus (Lepidoptera: Bombycoidea) larva. Photo: Sarah Brown, 2006. 


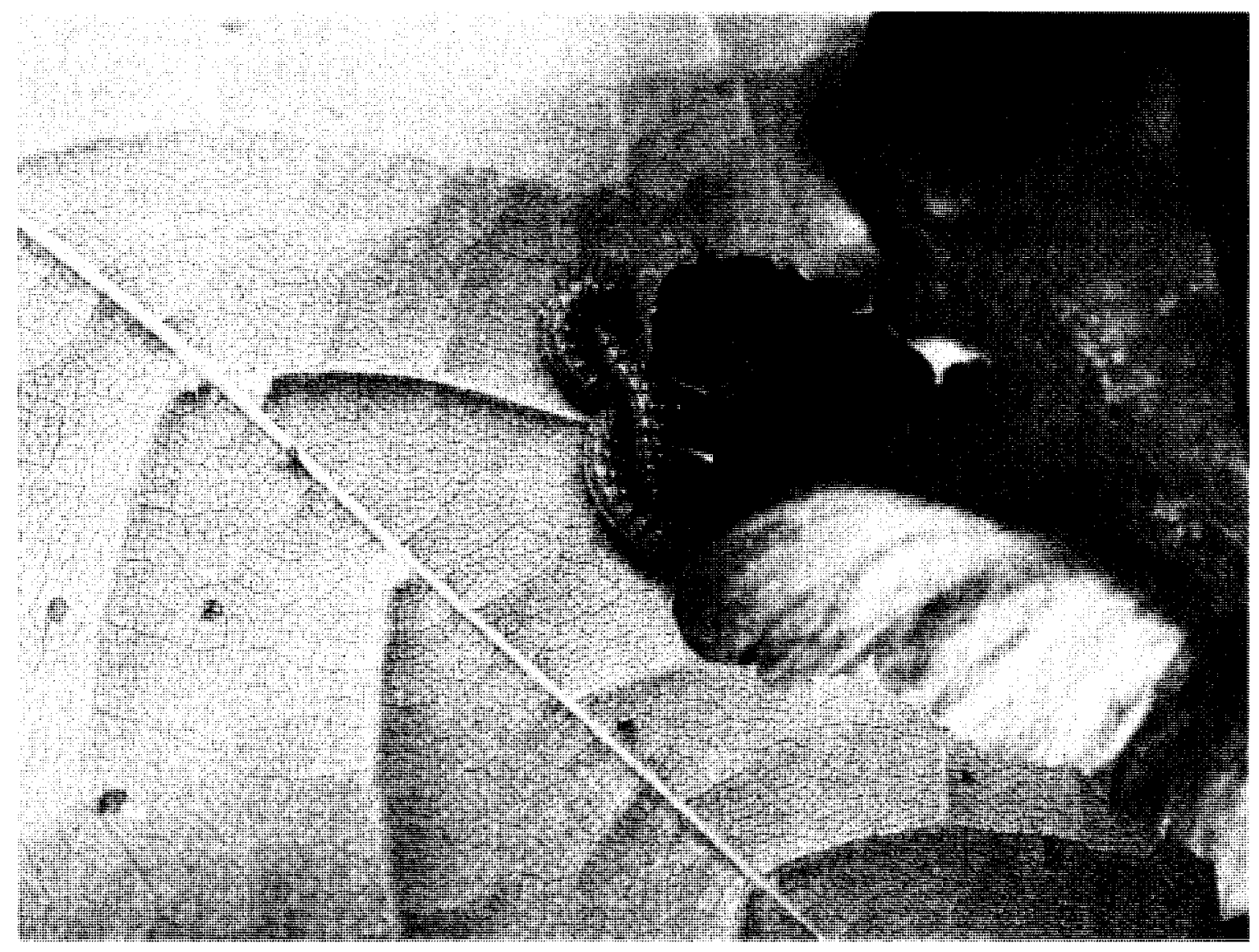

Figure 3.3. First instar Automeris io (Lepidoptera: Bombycoidea) larvae. Photo: Antoine Hnain, 2006. 


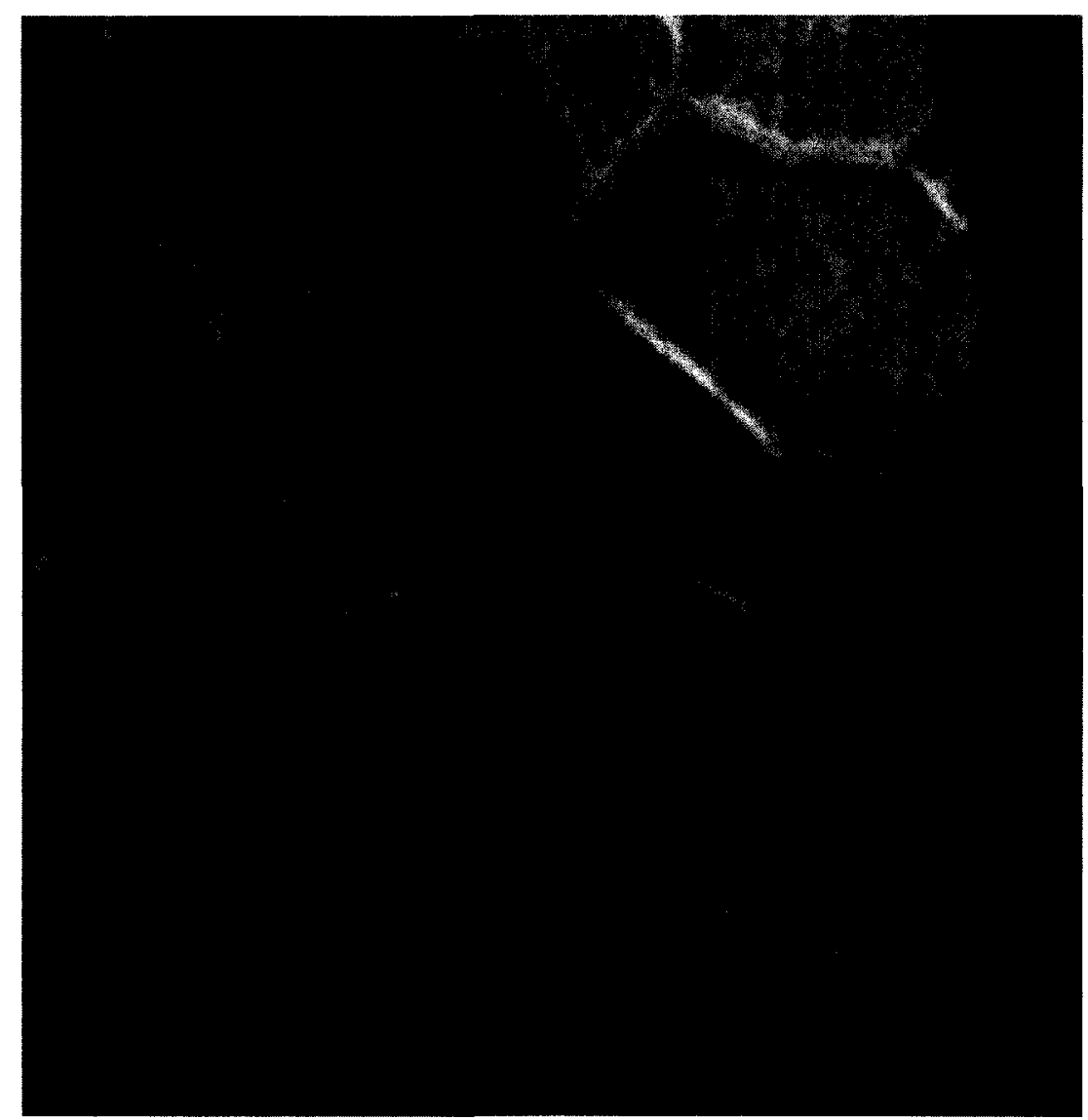

Figure 3.4. Two different instar individuals of Spilosoma virginica (Lepidoptera: Noctuoidea) larvae. 
laid by an unknown number of females on a lime tree, and larvae hatched from these eggs were used for this species. $P$. polytes larvae (Fig. 3.5) were kept in the same greenhouse.

Different experiments were performed on different species, although responses to sound were observed in all larvae. In addition, Malacosoma larvae were observed using high speed videography, and Malacosoma americanum and Papilio polytes larvae were examined to find setae that might act as near-field receptors.

\section{Response to Sound}

Behavioural audiograms were attempted with Malacosoma, Spilosoma virginica, Antheraea polyphemus, and Automeris io. However, due to small sample sizes, no actual audiograms were constructed. Instead, these trials were used to determine if the species responded to sound, how they responded to sound, and to approximate the frequencies to which they were most sensitive.

During audiogram trials with Malacosoma spp., larvae were allowed to remain on

the tent, which was placed in front of the speaker with a bridge leading to a large sprig of Malus sp. or Prunus sp. (Fig. 3.1B). Although this was a $M$. americanum colony, $M$. disstria larvae were also occasionally found on the tent, so observations were made of both species simultaneously whenever both were present (Fig. 3.1 C).

Larvae were usually placed approximately $200 \mathrm{~mm}$ away from a woofer, both of which were enclosed in a Faraday cage lined with acoustic foam $(3.1 \mathrm{~B})$. Pure tones were generated as described in Chapter 2, and audiograms were conducted with similar increases of $3 \mathrm{~dB}$ steps, although duration of silence varied. All trials were recorded on standard digital video (see Chapter 2 Methods). Where certain larvae were clearly only minimally responsive, tones of the highest intensity were played. Humming at the larvae 


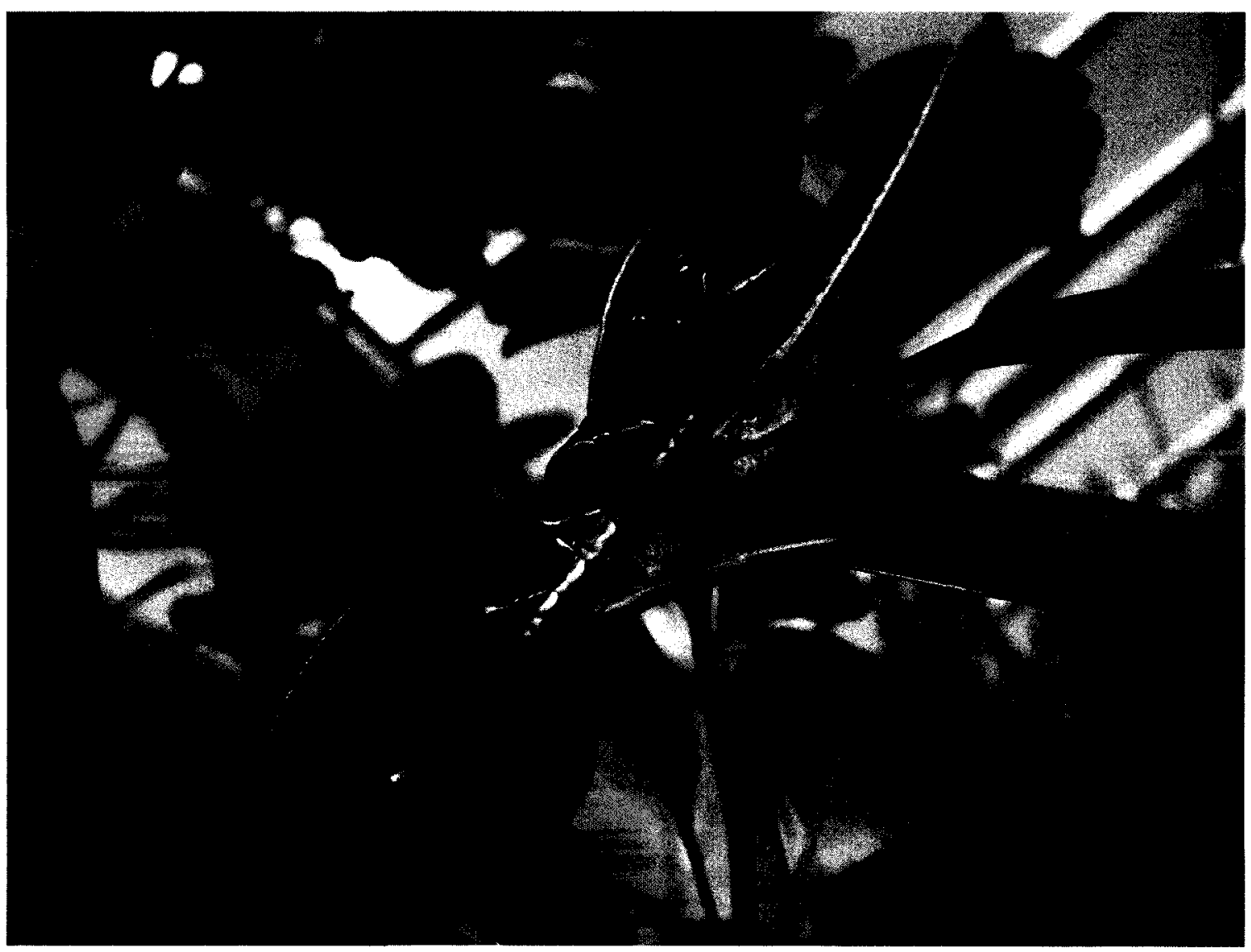

Figure 3.5. Fifth instar Papilio polytes (Lepidoptera: Papilionoidea) larvae. Photo: Veronica Bura, 2008. 
was occasionally used in impromptu attempts at making larvae respond, but these trials were only sometimes recorded to video.

During Malacosoma spp. behavioural audiogram trials, tones were played spaced one second apart with ten minutes of silence between different frequencies. Frequencies between 50 and $2500 \mathrm{~Hz}$ were used, with $50 \mathrm{~Hz}$ intervals. The entire Malacosoma americanum tent was brought into the sound proof room for trials with high speed video and laser vibrometry (see Chapter 2 Methods), although not all trials were performed using laser vibrometry. Videos from these trials were analyzed at a later date. Quantitative data obtained from these videos included the approximate response latency of freezes and flicks, and the time between flicks to one side and then the other.

Data for flick responses recorded from high speed video were analyzed for up to 44 flicks over 17 trials, using as many as 24 individuals. This represents the maximum number of individuals, because it was not possible to keep track of individuals between trials. The time at which sound began and the time at which the larvae began to move or at which they stopped was used for latency calculations. The time at which each larva reached its maximal distance curled to one side or the other was also recorded.

During behaviour trials for Antheraea polyphemus, larvae in their fourth or fifth instars and were tested in groups and placed on a sprig. Audiograms were conducted as above, with a few modifications. Tones were spaced five seconds apart with five minutes between different frequencies, and only frequencies of $50-1000 \mathrm{~Hz}$ were used.

All Automeris io observed in behavioural trials were in their first instar, on a sprig with the feeding groups that they naturally form in early instars. Audiograms were conducted as for Malacosoma spp., with a few modifications. Tones were spaced ten seconds apart with five minutes between different frequencies. Frequencies between 50- 
$700 \mathrm{~Hz}$ were tested, but since it quickly became obvious that they were only sensitive to very low frequencies, smaller intervals of $25 \mathrm{~Hz}$ were used between 50 and $200 \mathrm{~Hz}$.

Behavioural trials with Spilosoma spp. were conducted as for Antheraea polyphemus, with a few modifications. One or two individuals were placed on a sprig, and tones were spaced ten seconds apart with five minutes between different frequencies.

Behavioural trials with $P$. polytes were conducted as for Spilosoma spp., except only a single individual was tested during each trial.

\section{Anatomy}

Malacosoma americanum preserved in alcohol were examined under a binocular dissecting microscope in attempt to locate putative near-field receptors. Papilio polytes were injected with, and preserved in, $C \& C$ (Chauthani and Callahan, 1966). These were examined under a binocular dissecting microscope, and photographs and measurements of setae from three Papilio polytes larvae were obtained as in Chapter 2. 


\section{RESULTS}

All six species tested were responsive to sound, at least to some extent. The degree and type of response varied among species, and individuals of the same species also varied in level of responsiveness. Responses varied from the barely perceptible to vigorous responses that continued long after cessation of the stimulus. Responses observed were one of three types: freezing, slight contraction of the head and body, or flicking laterally. A freezing response consisted of a brief cessation of whatever movement in which the larva was previously engaged, which was usually locomotion, spinning silk, or eating. During a contraction, a larva retracted its head slightly and contracted its longitudinal muscles. Occasionally it also removed its legs from the substrate, while curling its head downwards. Flicking refers to the jerking of the anterior portion of the body from side to side or dorsally, while the prolegs grip the substrate. Larvae responded to different minimum intensities and frequencies, but generally seemed most sensitive to low-frequency sounds in the $100-500 \mathrm{~Hz}$ range. Descriptions of the responses of each species follow.

\section{Lasiocampoidea}

\section{Malacosoma americanum}

\section{General Description:}

Malacosoma americanum was among the most responsive larvae tested, and all three response types were observed in this species. They seemed to be sensitive to a wide range of frequencies, and their responses to sound were often vigorous. Larvae responded by freezing, contracting, and flicking their bodies side to side. Larvae were tested on the tent, which made it nearly impossible to track the movements of individuals. However, it 
was clear that some larvae were more sensitive to sound than others. Some responded vigorously at minimal intensities, and continued to respond long after cessation of any stimulus. Others did not respond at all to stimuli that were sufficient to cause nearly all of the other larvae on the web to flick repeatedly.

The small number of trials conducted, and the inherent difficulties in monitoring each individual within a large group of larvae on a tent, meant that it was not possible to construct a behavioural audiogram for Malacasoma americanum. However, larvae responded to sounds between 100 and $2400 \mathrm{~Hz}$, and subjectively appeared most sensitive to frequencies in the range of $150-400 \mathrm{~Hz}$.

Freezing:

M. americanum larvae were often active, and frequently walked across the tent or laid silk on it. These activities were evident on the laser trace that was recorded during high speed video trials, so it was possible to observe occasions when several larvae froze. Such events were captured twice by high speed videography. Figure 3.6 shows the laser trace from one of these recordings, in which it is clear that before the introduction of the stimulus, the laser recorded many vibrations caused by movement of larvae on the tent. In the first trial observed, these vibrations ceased approximately $110 \mathrm{~ms}$ following the sound (Fig. 3.6), and in the second trial, larvae froze after $50 \mathrm{~ms}$ (not shown). The low intensity vibrations recorded by the laser during and following the tone were caused by background level vibrations, evident from the associated video (not shown). This cessation of movement continued even following completion of the one second tone (Fig. 3.6). The freezing response seemed to occur almost simultaneously in all larvae on the tent in both recordings. Vibrations of the tent caused by sound were not sufficient to be detected by the laser vibrometer. 


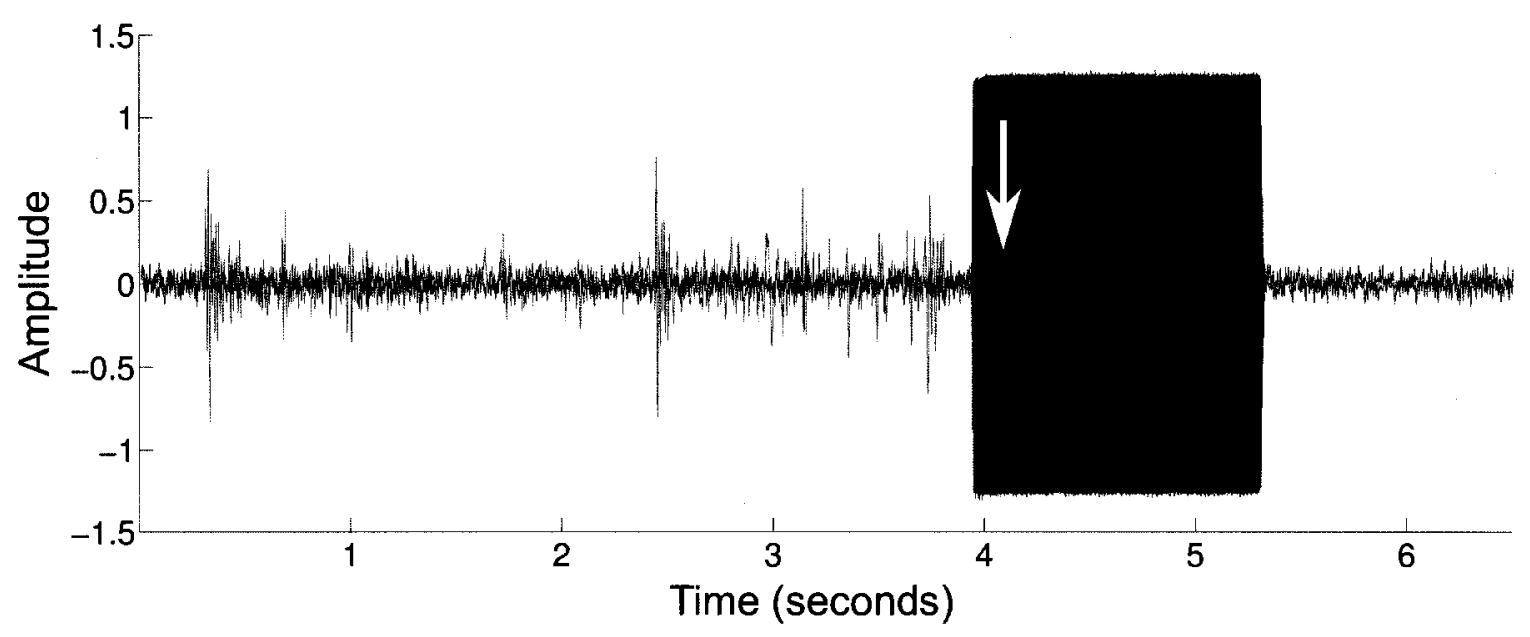

Figure 3.6. High speed sound and laser demonstrating freezing behaviour by Malacosoma americanum larvae. Laser vibrometer output (pink line) measures vibration caused by five larvae walking on the tent, before introduction of $200 \mathrm{~Hz}$ sound stimulus at $95 \mathrm{~dB}$ SPL, measured by microphone output (blue line), and the arrow indicates cessation of all activity following stimulation. 


\section{Flicking:}

Malacosoma americanum flicked laterally one to five times, with an average of twice, in response to $200 \mathrm{~Hz}$ tones at $95-99 \mathrm{~dB}_{\mathrm{SPL}}$ during high speed video trials $(\mathrm{N}: 23$, 95\% CI: 1.5.-2.5). Larvae flicked laterally by first contracting dorsal longitudinal muscles to raise their bodies slightly off of the substrate, then rapidly moving the anterior portion of their bodies to the left or right, usually until their head reached around to their abdomens (Fig. 3.7). The raising of the body and side to side flicking occurred as a single continuous motion, and flicks usually alternated from one side to the other. When the larvae stopped flicking, they paused briefly while curled to the side of their last flick, then slowly relaxed by moving their bodies back to a neutral position. During high speed trials, in response to tones of $95 \mathrm{~dB}_{\mathrm{SPL}}$ at $200 \mathrm{~Hz}$, larvae responded to sound by flicking with a mean latency of $253 \mathrm{~ms}$ (CI: 197 to $310 \mathrm{~ms} \min .50 \mathrm{~ms}$, max. $610 \mathrm{~ms}, \mathrm{n}=24$ ). The tent appeared to dampen vibrations caused by larvae flicking, and did not assist in the identification of latency (Fig. 3.8). Larvae that flicked multiple times completed a flick from one side to the other in $88.8 \mathrm{~ms}$ (95\% CI: 76.9 to $101 \mathrm{~ms}$, $\min .55 \mathrm{~ms}$, max. $162 \mathrm{~ms}$, $n=22)$.

Some individual larvae continued twitching, but not fully flicking, back and forth long after the stimulus had completed. During behavioural audiogram trials, a particularly responsive larva twitched for over ten minutes following cessation of any auditory stimulus, and responded to the lowest intensity of most frequencies presented. Anatomy:

Attempts at locating putative receptors on the larvae were unsuccessful. The $M$. americanum larvae were covered in many types of long setae, which made it very difficult to locate a specific type of seta with an expected shorter length and unknown 

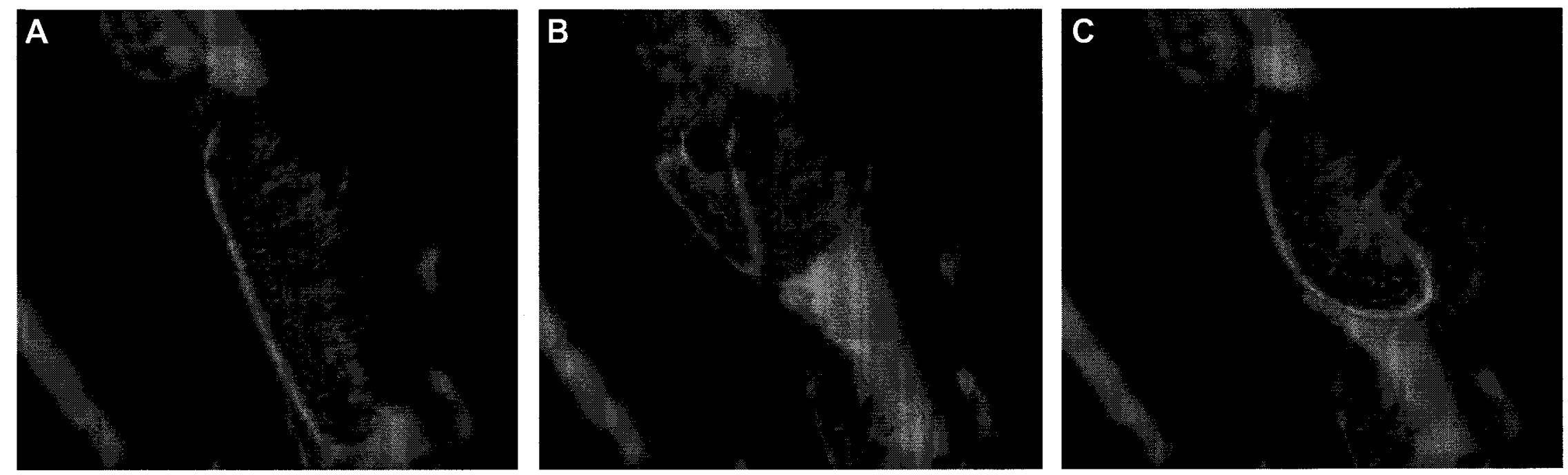

Figure 3.7. Malacosoma americanum responding to one second $200 \mathrm{~Hz}$ tone by flicking. A: Larva at rest, facing downward. This was the position of the larva until $192 \mathrm{~ms}$ following introduction of stimulus. B: Maximum extent of flick to right, reached at $255 \mathrm{~ms}$ following stimulus. C: Maximum extent of flick to left, reached at $525 \mathrm{~ms}$ following stimulus. 

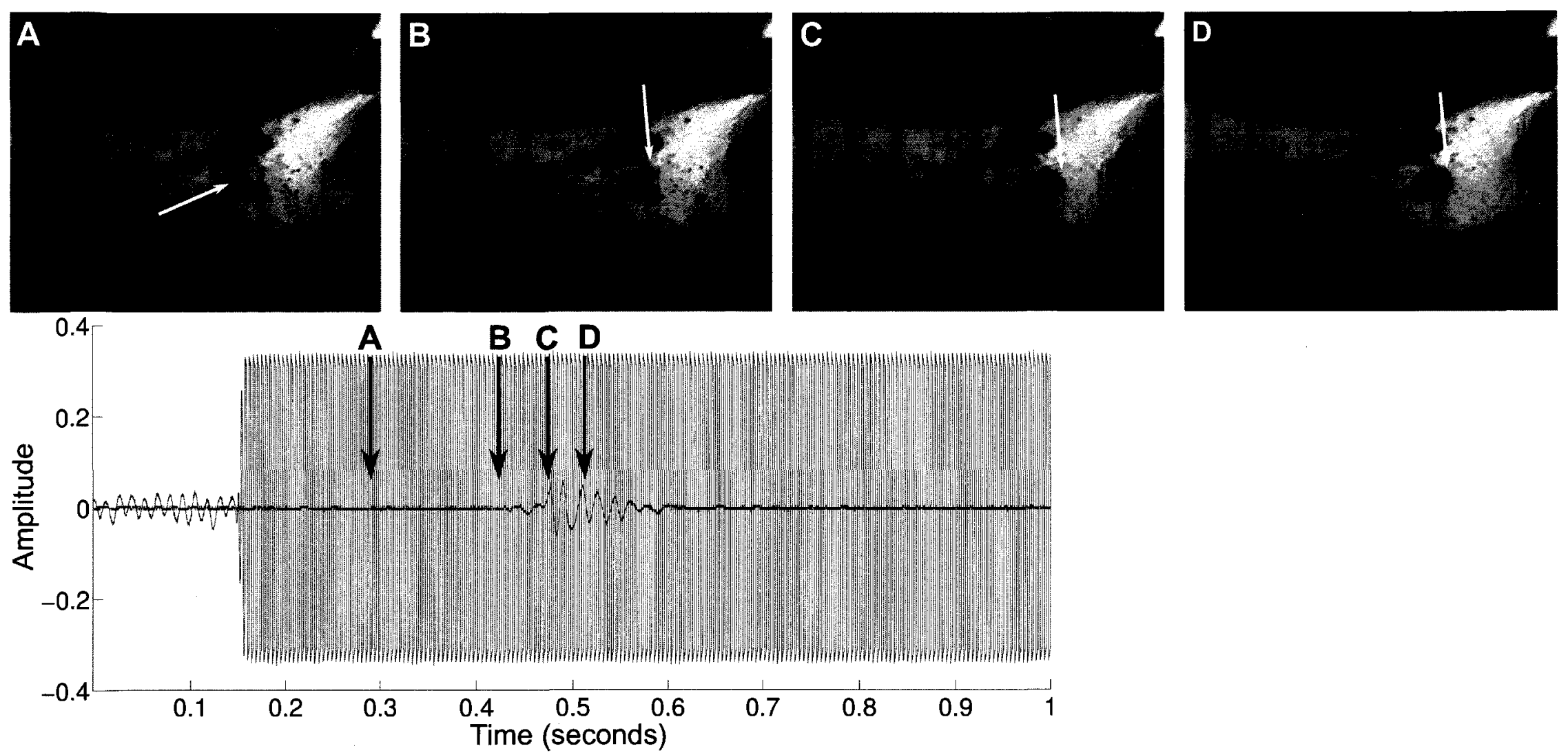

Figure 3.8. Malacosoma americanum larva flicking laterally once to its right side on the tent. Below, laser vibrometer output (pink line) measures vibration on tent near caterpillars, and microphone output (blue line) measures sound stimulus $(200 \mathrm{~Hz}, 95 \mathrm{~dB}$ SPL). A: Larva resting on tent before it begins to respond. B: Larva beginning to flick to right. There is no disturbance in the laser trace at this point. C: Larva at full extent of flick to right side. Larva wobbles slightly on the tent in this position due to its momentum, which is now visible as displacement of the laser. D: Larva pausing at extent of flick. Despite the fact that the larva is not moving, the displacement of the laser due to wobbling of the larva is still apparent. This demonstrates that the laser trace was not useful for determining response latency, due to its vibration damping effects. 
location.

Malacosoma disstria

Malacosoma disstria and M. americanum responded similarly to sound; their flicking behaviour was indistinguishable. However, M. disstria seemed to respond more frequently than M. americanum. Occasionally during behavioural audiogram trials, when a tone was played to a tent with many $M$. americanum and a single $M$. disstria resting on it, only M. disstria responded. Unfortunately, not enough $M$. disstria larvae were available to conduct behavioural audiograms with this species. Additionally, M. disstria was the only species tested from this chapter that was observed to flick so vigorously that it fell from the substrate. One example of this was recorded by high speed videography (Fig. 3.9).

\section{Bombycoidea}

Antheraea polyphemus

Antheraea polyphemus were among the least responsive of larvae that were tested. These larvae only responded by contracting, and even that response was rarely observed. During a contraction, larvae tucked their heads slightly under and into their prothorax. The most dramatic contraction by this species occurred at $100 \mathrm{~Hz}$ at approximately 86 $\mathrm{dB}_{\mathrm{SPL}}$, when the larva lifted its legs off the leaf during the contraction and curled its head downward.

Automeris io

First instar larvae of Automeris io responded vigorously to sound, although they were sensitive only to a narrow range of frequencies. Only two behavioural audiograms 

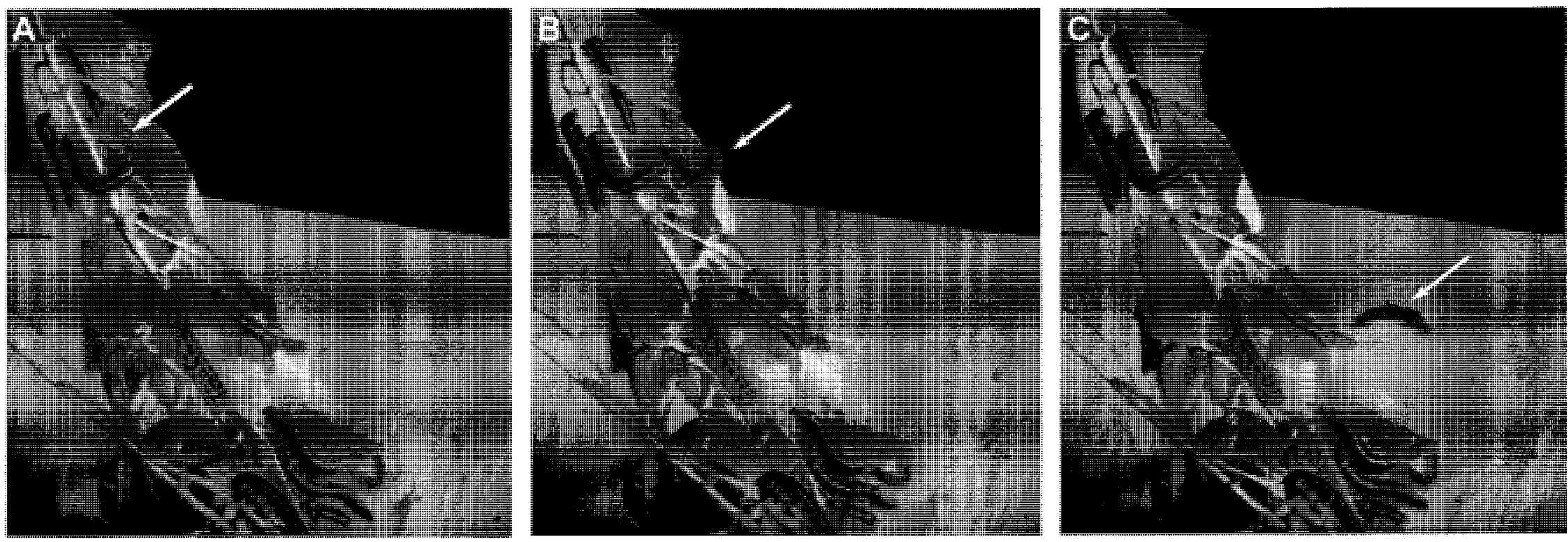

Figure 3.9. Malacosoma disstria responding to one second $200 \mathrm{~Hz}$ tone. A: Larva on leaf flicking, B: after losing its grip on the leaf, and $\mathbf{C}$ : fallen to the ground. Other larvae on Malus sprig are Malacosoma americanum. 
were completed using this species, but even from this limited data the larvae were clearly more responsive to some frequencies than others. They responded to sound with frequencies between 50 and $400 \mathrm{~Hz}$, and the larvae were most sensitive to $100 \mathrm{~Hz}$. The larvae responded consistently to $100 \mathrm{~Hz}$ at the lowest sound intensity tested, which was approximately $68 \mathrm{~dB}_{\mathrm{SPL}}$.

Automeris io larvae demonstrated two grades of response, contractions and lateral flicks. When the larvae contracted, they slowly raised the anterior portions of their bodies off the leaf, and then slowly lowered them. Flicks were composed of two distinct movements. The first part of a flick resembled a contraction in this species, except the movement was more rapid, as dorsal longitudinal muscles quickly contracted to raise the anterior portion of the body from the leaf. After the larvae reached this raised position, they began to jerk the anterior portion of their bodies back and forth. Unlike Malacosoma, the anteriors of Automeris io remained rigid and straight, and did not curl to the side. At frequencies to which the larvae were particularly sensitive, most larvae in the group would flick simultaneously.

\section{Noctuoidea}

\section{Spilosoma virginica}

Spilosoma virginica were relatively insensitive to sound. Freezing or pausing were the most frequently observed responses, although partial dorsal flicks were performed by two individuals in response to a $200 \mathrm{~Hz}$ tone at approximately $92 \mathrm{~dB}$ SPL. The flicks that were observed appeared to be rapid contractions of longitudinal muscles, but not to the point where the legs of the larvae were lifted off the leaf. 


\section{Papilionoidea}

Papilio polytes

Two of four Papilio polytes tested were responsive to sound. In the laboratory setting, one fourth instar $P$. polytes responded to loud ( $\left.>80 \mathrm{~dB}_{\mathrm{SPL}}+\right)$ sounds between 50 and $200 \mathrm{~Hz}$ by rapidly contracting its dorsal longitudinal muscles such that its head and thorax moved slightly backwards. A fifth instar larva responded in the same manner to a $200 \mathrm{~Hz}$ tone. In the greenhouse, a single fifth instar larva also responded to humming by everting its osmeteria.

Bodies of three fifth instar $P$. polytes larvae were examined, and two pairs of straight filiform sensilla were observed on the thorax. A short pair of sensilla was observed on the prothorax of the larvae, with an average length of $271 \mu \mathrm{m}$ (N: 5, SD: 13.45, min. $250 \mu \mathrm{m}$, max. $284 \mu \mathrm{m}, 95 \%$ CI: 254.4-287.8 $\mu \mathrm{m}$ ) (Fig. 3.10A). A longer pair of sensilla were noted on the mesothorax with mean length $540 \mu \mathrm{m}(\mathrm{N}: 4, \mathrm{SD}: 7.94$, min. $533 \mu \mathrm{m}, \max .551 \mu \mathrm{m}, 95 \%$ CI: 527.5-552.7 $\mu \mathrm{m})$ (Fig. 3.10B). 


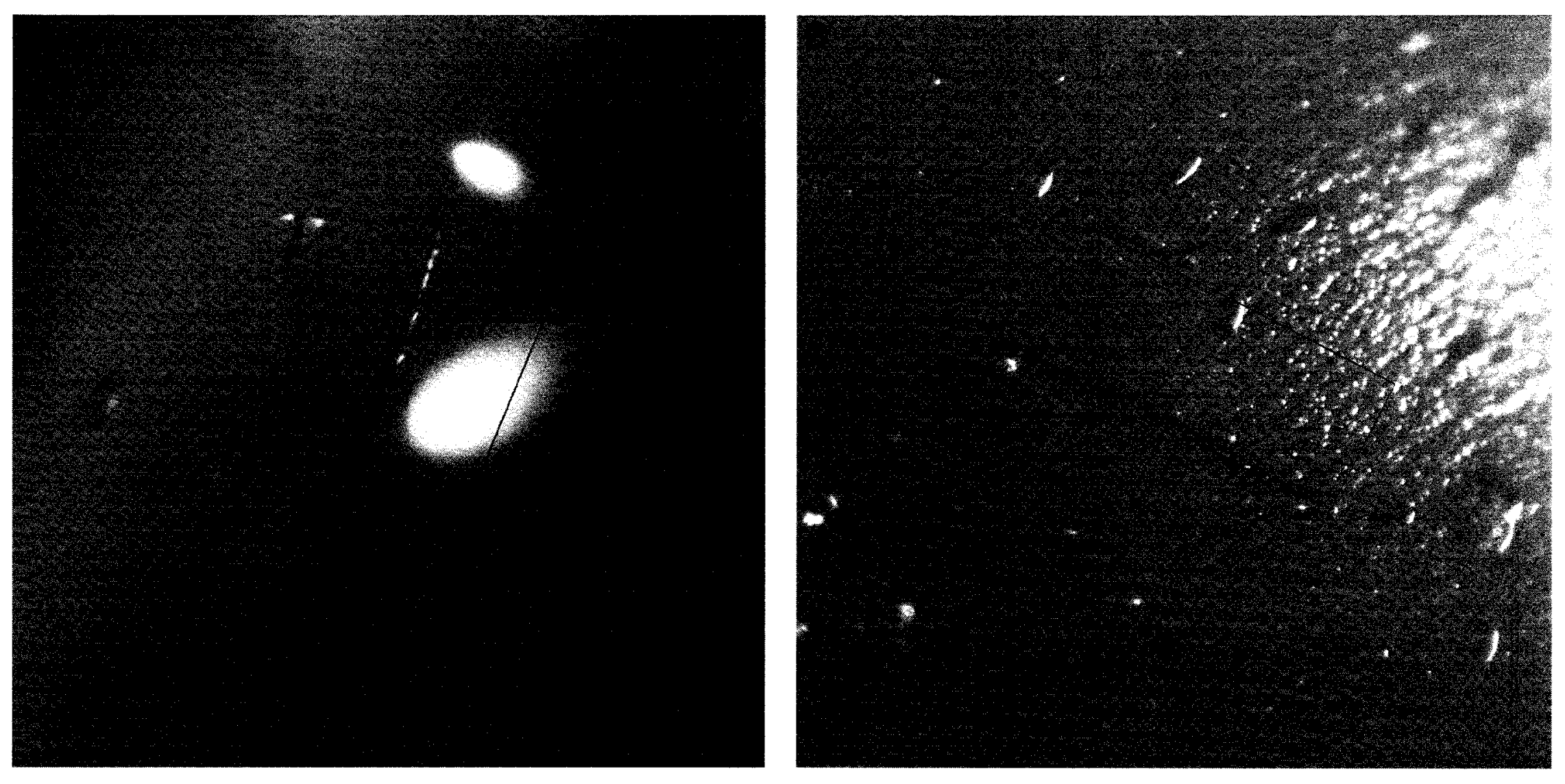

Figure 3.10. Putative receptor setae on the thorax of fifth instar Papilio polytes larva. A: Seta on prothorax, mean length $271 \mu \mathrm{m}$. B: Seta on mesothorax, mean length $540 \mu \mathrm{m}$. 


\section{DISCUSSION}

The species tested represented four different families: Saturniidae, Lasiocampidae, Noctuidae, and Papilionidae, and as many superfamilies. Although this investigation was preliminary, a wide range of behaviours and sensitivity to sound were observed among larvae examined.

\section{Lasiocampoidea}

Attempts were made to describe the behavioural responses of M. americanum, the frequencies to which they were sensitive, and to locate the near-field receptors in this species. However, a number of impediments made this task difficult (see Results). Myers and Smith (1978) were able to partly overcome these issues, and were able to roughly determine the frequencies to which $M$. californicum pluviale were responsive by recording the proportion of larvae on the tent that responded to each frequency. However, the proportion of larvae responsive to each frequency and the minimum intensity to which they respond at each frequency are not necessarily congruent.

Although data obtained from our behavioural audiogram experiments may provide a rough estimation of the sensitivity of $M$. americanum to sound, there were simply too few trial replications for the data to attain statistical significance. Also, larvae were constantly going in and out of the tent, changing position, or leaving to forage, so there was no way to reliably gauge the responsiveness of individuals. It was not known if larvae sensitive to sound behaved differently, perhaps by retreating into the tent more frequently than those that were less responsive. The aforementioned tendency of larvae to bump into one another when flicking introduced more uncertainty, as it was not known if all larvae that appeared to be responding were doing so because they had actually heard 
the stimulus.

Considering the limited amount of data obtained, it was not possible to compare sensitivity between these species, except to say that the range of frequency sensitivity was similar. M. californicum pluviale were responsive to frequencies between 200 and $2100 \mathrm{~Hz}$ (Myers and Smith, 1978), whereas M. americanum were responsive to a slightly larger range of sounds, from 100 to $2400 \mathrm{~Hz}$.

Variation in responsiveness to sound between individuals of M. americanum existed, as has been observed in other species (Minnich, 1936). One possible explanation as to why some individuals were not responsive is that they were in the process of moulting. Minnich (1936) and Gnatzy and Tautz (1977) observed that moulting larvae are unresponsive to sound, because the cuticle and dendritic sheath of sensilla lose sensitivity during the 30-60 minute period of ecdysis (Zacharuk and Sheilds 1991). This may explain why some other species were sometimes non-responsive, but $M$. americanum larvae moult inside their web (Fitzgerald, 1995), so they would not have been visible during trials.

Myers and Smith (1978) found that $M$. californicum pluviale were less likely to flick when they were walking on a flat surface, as opposed to on the tent. These larvae froze on a flat surface with the same frequency as they flicked on the tent (Myers and Smith, 1978). We did not observe this, but when individual M. americanum larvae that were responsive on the tent were transferred to a sprig, they generally became nonresponsive. This may be a slightly different manifestation of the same phenomenon. Myers and Smith (1978) attributed their observations to either a physiological change that occurred in response to leaving the tent, or that the tent somehow aided in reception of sound or vibration. Our observations suggest that the latter proposition is not likely, as 
larvae were just as responsive when they aggregated together on the leaves during feeding expeditions. It is also unlikely that sound or other vibrations would transmit very well through the tent, because laser vibrometry showed that it had somewhat of a damping effect. If a physiological change occurred, Myers and Smith (1978) suggested that either being near other individuals or the tent itself triggered the physiological response, and Fitzgerald (1995) suggested that basking on the tent was responsible for this difference. He argued that basking was sufficient to elevate the temperature of the larvae such that their response time was shortened and response intensified. However, since we found similar results, and our experiments were conducted indoors, the larvae would not have raised their temperature by basking on the tent. Additionally, the responsiveness of larvae during foraging expeditions suggests that tent itself is not likely the cause of this behavioural variance.

\section{Bombycoidea}

\section{Antheraea polyphemus}

No useful information was obtained from studying Antheraea polyphemus, other than to confirm earlier reports that this species does respond to sound occasionally, and only by contracting (Minnich, 1936). The larvae tested here were perhaps less responsive than those observed by Minnich (1936), as he found that two thirds of Antheraea polyphemus larvae responded to tuning forks at 256 and $512 \mathrm{~Hz}$.

\section{Automeris io}

Observing that first instar Automeris io responded was perhaps the most useful information obtained by this research. Only primary setae are present in first instar 
lepidopterous larvae (Zacharuk and Shields, 1991), which means that the near-field receptors must exist in first instar Automeris io larvae as modifications of one or more pairs of these primary setae. Another species, Nymphalis (Vanessa) antiopa Linn. (Nymphalidae: Papilionoidea) was reported by Minnich (1925) to also be fully capable of responding to sound shortly after hatching in their first instar. Both species must share the same homologous setae in this first instar (Zacharuk and Shields, 1991), which severely limits the number of setae that could possibly be near-field receptors. This observation is highly suggestive of a common ancestry of hearing in lepidopterous larvae, at least between Bombycoidea and Papilionoidea, especially if they use the same pair of setae. Further research must be undertaken on both of these species to determine if the pair or pairs of setae responsible for hearing in the first instar of each species is in the same location. Based on chaetotaxy of species in which the location of the sensilla are known, candidates for such a near-field receptor include prothoracic subdorsal (SD) 1 and SD2, mesothoracic and metathoracic SD1 (Kitching, 1984).

\section{Papilionoidea}

Although $P$. polytes had only mild responses, they may not have been typical responses that occur in its natural environment. It is likely that the testing environment was not ideal for this species. Larvae were kept in a greenhouse that was far warmer and more humid than the laboratory in which they were tested. One larva responded to humming by everting its osmeteria, which occurred in the warm greenhouse. The larva did this only once, when it was previously undisturbed that day. Subsequent humming did not result in similar behaviour.

The two pairs of long setae discovered on the thorax of $P$. polytes may function as 
near-field sound receptors in this species. They were in a similar location as the setae that Mamestra brassicae (Markl and Tautz, 1975) and D. plexippus (Chapter 2) use to hear. The pair of setae on the mesothorax of $P$. polytes is approximately the same length as the four pairs of setae that function as near-field receptors in Mamestra brassicae larvae (Markl and Tautz, 1975). Ablation experiments are required to confirm that either or both of these pairs of setae serve an auditory function in this species.

\section{Comparison and Function}

No experiments were performed to determine the function of hearing in $M$. americanum or any other species tested. However, the function of hearing in Mamestra brassicae has been clearly shown to be effective at defending the larvae against predatory wasps (Tautz and Markl, 1978). Mamestra brassicae with their nearfield receptors removed are far more susceptible to attack from predatory wasps than intact larvae (Tautz and Markl, 1978). Somewhat compelling evidence also exists that Malacosoma californicum pluviale uses its hearing ability to escape flying parasitoids. Larvae of this species are particularly sensitive to frequencies between 200 and $1000 \mathrm{~Hz}$ (Myers and Smith, 1978), and Tachinomyia similis (Diptera: Tachinidae), a parasitoid of $M$. californicum pluviale, produces flight sounds mainly in the bandwidth of $350-550 \mathrm{~Hz}$. Not only does this bandwidth fall into the best frequency range of the larvae, but playbacks of actual wingbeat recordings of the parasitoid also elicited responses (Myers and Smith, 1978). The close relation of Malacosoma americanum with this species, the similarities in frequency sensitivities, and the fact that both species face high selective pressure from parasitoids (Fitzgerald, 1995), is highly suggestive of a similar function for these receptors. Although little data was available, frequencies to which other larvae were 
sensitive also fell into the range of wingbeat frequencies of some known predators and parasitoids (Tautz and Markl, 1979; Myers and Smith, 1978). Given the probable function of hearing in Mamestra brassicae and Malacosoma californicum pluviale, it is likely that hearing in these other species also functions to detect flying predators or parasitoids.

Additionally, both Malacosoma americanum and Automeris io were highly gregarious in the instars studied, with close physical contact. This gregarious behaviour might provide protection from enemies in two ways. Firstly, the physical closeness may have increased the responsiveness of the group as a whole. Flicking larvae inevitably bumped into adjacent larvae on the tent or leaf, which seemed to provide some positive feedback to either begin or continue flicking. Although this phenomenon was not specifically investigated in Automeris io or Malacosoma spp., transmission of defensive behaviours occurs in other species. Cornell et al. (1987) found that when a single larva of Hamearis lucina Linn. (Lepidoptera: Riodinidae) was presented with a tactile stimulus that simulated an attack, that the larva responded by thrashing, and that up to $70 \%$ of neighbouring larvae responded with similar thrashing. Since groups of Malacosoma americanum and Automeris io of larvae are usually full siblings in early instars (Fitzgerald, 1995), kin selection may have facilitated evolution of this behaviour. If predators or parasitoids hovering over a colony cause most larvae to respond, those that do not are still afforded some protection by their responsive siblings.

The second way that this might afford the larvae additional protection is that flicking could be more effective when many larvae respond simultaneously. It may be more difficult to lay eggs on a larva when it is amongst a group caterpillars simultaneously thrashing than it is to parasitize a solitary caterpillar demonstrating the 
same behaviour. Myers and Smith (1978) suggested that this might explain why they found that larvae in a group on the tent responded more vigorously than solitary caterpillars.

Evidence that larvae use their sound for defensive purposes is more compelling for those species that were more actively responsive to sound. While freezing might make a caterpillar less visually conspicuous, and flicking is an effective defense against predators (Evans, 1982), it is not clear how a small contraction that is unaccompanied by a cessation of other movements might defend a caterpillar against an attacker. Inconsistencies in responsiveness also bring into question how useful their behaviour could be. It is possible that conditions were not conducive to responsiveness in some species, or it could be that the larvae do not need to respond to sound. This would depend on whether it has adapted other ways of defending itself against predation, or if it faces other threats that were more important in shaping its evolutionary history. In this latter case, responding to sound would be a vestigial behaviour that is non-detrimental to the larvae.

Naturally, no two species face the exact same selective pressures. Natural selection and evolutionary constraints shape the behaviour and morphology of all species, and these factors were different for every species of caterpillar that we examined. For example, Antheraea polyphemus rarely responded, these larvae have other defences that function against predators that might be more effective than flicking. When threatened, Antheraea polyphemus larvae produce acoustic aposematic signals by clicking their mandibles to warn predators of impending regurgitation, which is an effective defense (Brown et al. 2007). P. polytes larvae also defend themselves by everting their osmeteria, which emit volatile repellent chemicals (Burger et al. 1985). 


\section{Conclusion}

A variety of responses were observed in the different species and individuals of larvae examined. Malacosoma larvae did not always consistently respond, but were sensitive to a very wide range of frequencies. Automeris io larvae, on the other hand, were highly sensitive and responded vigorously, but only to a comparatively small range of frequencies. Given the nature and intent of these experiments and observations, it was subject to many imprecisions. Thus, no quantitative data or conclusions can be drawn. Rather, the purpose was to confirm responses to sound in some species that had already been tested, and qualitatively describe behaviour in general terms, as exploratory work. Such data is still useful, as it confirms previously known information about some species, and includes new data for species that have never been described to respond to sound. This could open doors to new research on these species and comparative work that could reveal why some species are more responsive than others, and how hearing might have evolved. 


\section{CHAPTER 4: GENERAL DISCUSSION}

The previous chapters have examined the behaviours of several species of lepidopterous larvae that hear near-field sound. These, and those that have been described in previous publications (see Table 1.1), are plotted onto a phylogeny in Figure 4.1. It is apparent from this phylogeny that the vast majority of near-field hearing representatives occur in a small cluster of macrolepidopteran superfamilies. Since hearing has been observed in all lepidopterous larvae that have been extensively tested (Minnich, 1936), it is likely that exploration of these other groups will reveal many more species that are able to hear. Studying a wider diversity of taxa may provide valuable information about the evolution of near-field hearing in Lepidoptera; focusing only on a small number of closely related species is less likely to accomplish this. However, using information obtained from the previous chapters and published research, some aspects of the evolution of near-field hearing are briefly discussed.

\section{Location of receptors}

Although ablation experiments have not been conducted with Papilio polytes, the length and location of two pairs of filiform sensilla on the thorax are similar to the confirmed near-field receptors of Mamestra brassicae and Danaus plexippus. This is highly suggestive, but not conclusive, evidence that these filiform sensilla function as near-field receptors in this species. If they are indeed near-field receptors, none of the three species that possess such receptors have them in the same location on their body. This could be taken as evidence that near-field hearing evolved more than once in the evolutionary history of Lepidoptera, or it could be indicative that an ancestor had at least eight sensilla on the thorax (as in Mamestra) and one on the twelfth abdominal segment 


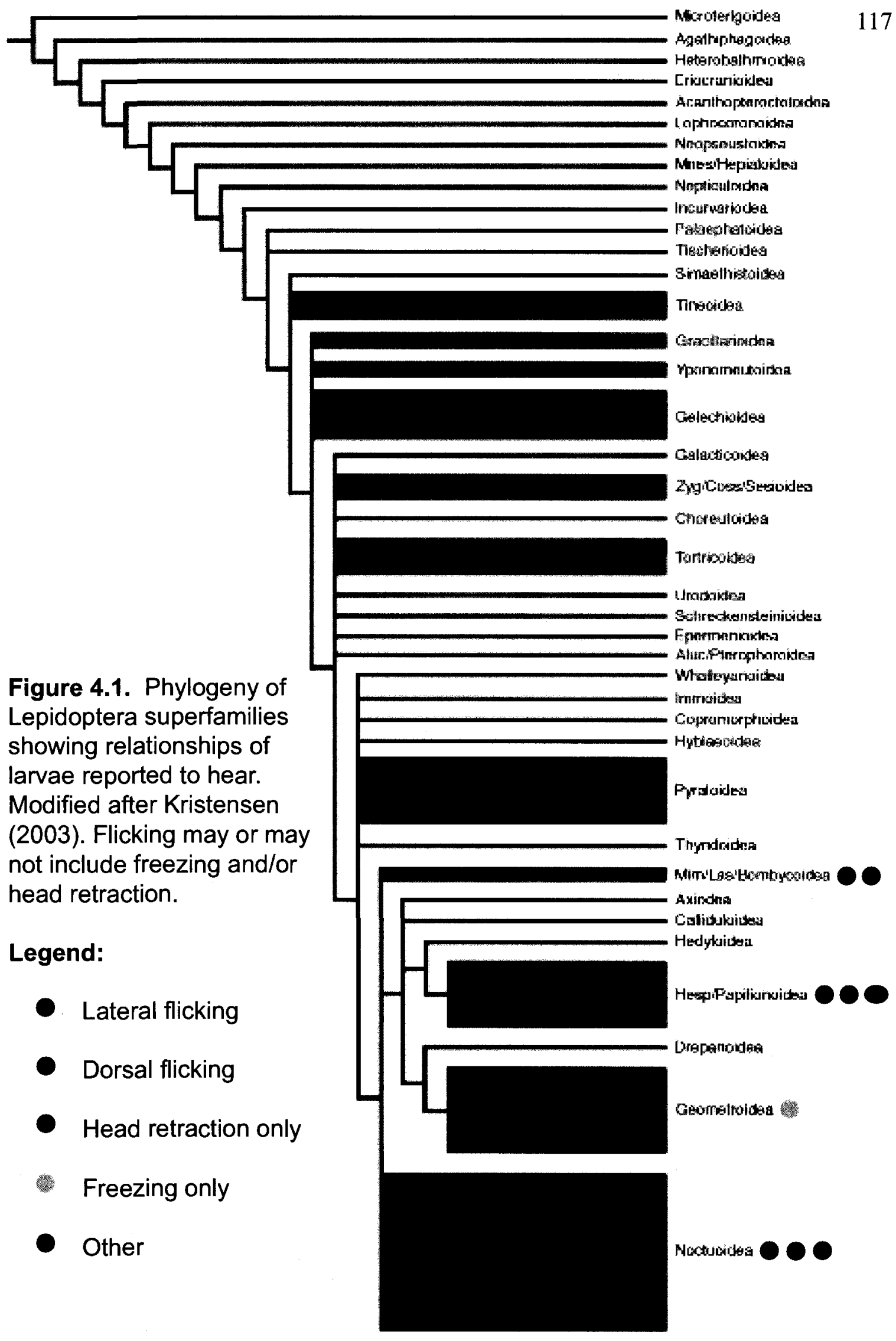


(as in Danaus). This highly speculative hypothetical situation illustrates the unreliability of using receptor location as the only character to determine ancestry.

\section{Insect flight sounds}

Although flying insects are not efficient pressure wave emitters (Markl and Tautz 1975), their wings emit strong rhythmic air motions in flight. Markl and Tautz (1975) explained that a wasp with a wing beat frequency of $165 \mathrm{~Hz}$, radius of $10 \mathrm{~mm}$, and amplitude of surface vibration of $50 \mathrm{~mm}$ results in a surface velocity of $5 \mathrm{~m} / \mathrm{s}$, which means that the caterpillar can detect a wasp at $500 \mathrm{~mm}$ away at the threshold values of Mamestra brassciae. Near-field sound is also best suited to lower frequencies (Beranek, 1954), such as most insect flight sounds. It should not be surprising that larvae evolved the type of hearing more suited to detect this type of sound. Additionally, being able to hear only near-field sound means that sounds produced at large distances are filtered out, because they cannot be detected. Sounds produced far away are unimportant to the larvae, and needlessly responding to them would be counter-productive.

\section{Paleoecology}

Both tympanal and near-field ears may have evolved from pre-existing sensory organs in Lepidoptera, which is part of the reason that tympanal ears have arisen so many times (Yack, 2004). However, the ears in some adult Lepidoptera, evolved in response to predation by echolocating microbats, which became a threat long after most major groups of Lepidoptera had already diverged (Grimaldi and Engel, 2005). Conversely, hearing in larvae likely evolved in response to aerial insect predators and parasitoids, and the first evidence of parasitoid and predatory Hymenoptera is from the early Jurassic, around the 
time that the first representatives of Lepidoptera existed (Grimaldi and Engel, 2005). Parasitoid Diptera, such as Tachinidae, on the other hand, did not appear until the Tertiary, which is probably long after near-field hearing had evolved (Grimaldi and Engel, 2005). This does not mean, of course, that all Lepidoptera hear near-field sound. Near-field hearing likely evolved sometime in the Cretaceous period, following or coinciding with the angiosperm radiation. Before this time, the majority of caterpillars were detritivorous, or endophagous borers or miners (Grimaldi and Engel, 2005). In these habitats, vibrational reception would be more important than near-field sound, since sound would be blocked by the substrate in which the larvae lived, whereas vibrations would be transmitted through such substrates. Only after the major life history transition to feeding on angiosperms was made by first representatives of Apoditrysia were the vast majority of species exposed to flight sounds of parasitoids and predators. Thus, nearfield hearing likely evolved during this time in this group, at the earliest. Tineoidea has mostly externally folivorous ancestors and diverged from Lepidoptera just prior to the angiosperm radiation (Grimaldi and Engel, 2005). This suggests that Tineoidea is an appropriate outgroup for this hypothesis, and thus should not be able to hear, unless they evolved near-field receptors independently. The above hypothesis also predicts that representatives of other Ditrysian groups should contain representatives with the ability to hear near-field sound. Some basal groups, however, may have representatives where near-field hearing has evolved independently. One might expect that in extant exophagous species, whose ancestors were endophagous, near-field hearing might have evolved independently.

All exophagous Lepidoptera were potentially exposed to flying predators and parasitoids throughout their evolutionary history. Of course different species face a wide 
range of selective pressures, but predation and parasitism appear to be important to all extant species of Lepidoptera (Haukioja, 1993). However, unless they evolved and subsequently lost another effective defensive mechanism, it seems likely that macrolepidoptera, whose most recent common ancestor was an external folivore, mostly retained the ability to hear near-field sounds. It should be noted that although it may be unlikely that macrolepidopteran taxa would lose their ability to hear, it remains possible that additional near-field receptors may have evolved in addition to existing ones.

These observations provide suggestions for directions that future research might take. Investigations of a broader range of species than those already described (Fig. 4.1) may provide a broader context of near-field hearing Lepidoptera, which might assist in understanding its evolution, and the function of various behavioural responses observed. However, more detailed examination of species that have already been described is not without utility. The work presented in Chapter 2 on monarch larvae only describes the behaviour and anatomy of this species. This research answered some questions, but raised some as well. Analyzing the physiological characteristics of monarch near-field sensory cells is a logical next step in determining if hearing is the result of independent, convergent evolution between D. plexippus and Mamestra brassicae. However, preliminary research in Chapter 3 shows that several other species, such as Automeris io or Malacosoma americanum, would provide excellent opportunities for future research as well. 


\section{LITERATURE CITED}

Arnaud, P. H. (1978). A host-parasite catalog of North American Tachinidae (Diptera). USDA, Misc. Pub., 1319.

Allen, G.R. D. Kamien, O. Berry, P. Byrne and J. Hunt. (1999). Larviposition, host cues, and planidial behavior in the sound-locating parasitoid fly Homotrixa alleni (Diptera : Tachinidae). J. Insect Beh. 12, 67-79.

Bacher, S., J. Casas, and S. Dorn. (1996). Parasitoid vibrations as potential releasing stimulus of evasive behaviour in a leafminer. Physiol. Entomol. 21,33-43.

Ballmer, G.R. and D.M. Wright. (2008). Life history and larvael chaetotaxy of Ahmetia achaja (Lepidoptera, Lycaenidae, Lycaeninae, Teclini, Cheritrina). Zootaxa. 1845, 47-59.

Beranek, L.L. (1954). Acoustics. New York, NY: McGraw-Hill Book Company.

Barth, F.G. (2004). Spider mechanoreceptors. Curr. Opin. Neurobiol. 14, 415-422.

Barth, F.G. and A. Höller. (1999). Dynamics of arthropod filiform hairs. V. The response of spider trichobothria to natural stimuli. Phil. Trans. R. Soc. Lond. B. 354, 183-192.

Bennet-Clark, H. C. (1971). Acoustics of insect song. Nat. 234, 255 -259

Bennet-Clark, H.C. (1984). A particle velocity microphone for the song of small insects and other acoustic measurements. J. Exp. Biol. 108, 459-463.

Bowers, M.D. and Stamp, N.E. (1997). Fate of Host-Plant Iridoid Glycosides in Lepidopteran Larvae of Nymphalidae and Arctiidae. J. Chem. Ecol. 23, 2955-2965.

\section{Burger, B.V., Z. Munro, M. Röth, H. S. C. Spies, V. Truter, H. Geertsemaand}

A. Habich. (1985). Constituents of osmeterial secretion of pre-final instar larvae of citrus swallowtail, Papilio demodocus (Esper) (Lepidoptera: Papilionidae). J. 
Chem. Ecol. 11, 1093-1113.

Bushbeck, E.K. and N.J. Strausfeld. (1997). The relevance of neural architecture to visual performance: Phylogenetic conservation and variation in dipteran visual systems. J. Comp. Neurol. 383, 282-304.

Brower, L.P. (1995). Understanding and misunderstanding the migration of the monarch butterfly (Nymphalidae) in North America: 1857-1995. J. Lepid Soc. 49, 304-385.

Brown, S.G., G.H. Boettner, and J.E. Yack. (2007). Clicking caterpillars: acoustic aposematism in Antheraea polyphemus and other Bombycoidea. J. Exp. Biol. 210, 993-1005.

Camhi, J.M. (1984). Neuroethology: Nerve cells and the natural behavior of animals. Sunderland, MA: Sinauer Associates.

Castellanos, I. and P. Barbosa. (2006). Evaluation of predation risk by a caterpillar using substrate-borne vibrations. Anim. Beh. 72, 461-469.

Chauthani, A.R. and P.S. Callahan. (1966). A dissection technique for studying internal anatomy of different stadia of Noctuidae. Ann. Ent. Soc. Amer. 59, $1017-$ 1018.

Conner, W. E. (1999). 'Un chant d'appel amoureux': Acoustic communication in moths. J. Exper. Biol. 202, 1711-1723.

Cornell, J. C., N.E. Stamp, and M.D. Bowers. (1987). Developmental change in aggregation, defense and escape behavior of buckmoth caterpillars, Hemileuca lucina (Saturniidae). Behav. Ecol. Sociobiol. 20, 383 -388.

Dudley, R. (2000). The Biomechanics of Insect Flight: Form, Function, Evolution. Princeton, NJ: Princeton University Press.

Evans, E.W. (1982). Influence of weather on predator/prey relations: stinkbugs and tent 
caterpillars. J. N. Y. Entomol. Soc. 90, 241-246.

Ewing, A.W. and H.C. Bennet-Clark. (1968). The antenna of Drosophila as a 'love song' receptor. Physiol. Entomol.. 3, 33-36.

Ewing, A.W. (1989). Arthropod Bioacoustics. Ithaca, NY: Comstock Cornell University Press.

Fitzgerald, T. (1995). The Tent Caterpillars. Ithaca, NY: Cornell University Press.

Fletcher, N. H., 1978. Acoustical response of hair receptors in insects. J. Comp. Physiol. A. 127:185-189.

Fletcher, L.E., J.E. Yack, T.D. Fitzgerald, and R.R. Hoy. (2006). Acoustic communication in the Cherry Leaf Roller Caloptilia serotinella (Gracillarioidea: Gracillariidae). J. Insect Beh. 19, 1-18.

Forrest, T.G., H.E. Farris, and R.R. Hoy. (1995). Ultrasound acoustic startle response in scarab beetles. J. Exp. Biol. 198, 2593-2598.

Frohawk, F.W. (1903). Life-history of Vanessa antiopa. The Entomologist. 2-5.

Fullard, J.H. (1982). Cephalic influences on a defensive behaviour in the dogbane tiger moth, Cycnia tenera. Physiol. Entomol. 7, 157-162.

Gentry, G.L. and L.A. Dyer. (2002). On the conditional nature of neotropical caterpillar defenses against their natural enemies. Ecol. 83, 3108-3119.

Gibson, G. and I. Russell. (2006). Flying in Tune: Sexual Recognition in Mosquitoes. Curr. Biol. 16, 1311-1316.

Göpfert, M.C., H. Briegel, and D. Robert. (1999). Mosquito hearing: Sound-induced antennal vibrations in male and female Aedes aegypti. J. Exp. Biol. 202, 2727-2738.

Göpfert, M.C. and D. Robert. 2000. Active auditory mechanics in mosquitoes. Phil. Trans. R. Soc. Lond. B. 268, 333-339. 
Gnatzy, W. and J. Tautz. (1977). Sensitivity of an insect mechanoreceptor during moulting. Physiol. Entomol. 2, 279-288.

Grimaldi, D. and M.S. Engel. (2005). Evolution of the insects. New York, NY: Cambridge University Press

Gross, P. 1993. Insect behavioural and morphological defenses against parasitoids. Ann. Rev. Entomol. 38, 251-73.

Gwynne, D.T. (1995). Phylogeny of the Ensifera (Orthoptera): A hypothesis supporting multiple origins of acoustic signalling, complex spermatophores and maternal care in crickets, katydids, and weta. J. Orth. Res. 4, 203-218.

Haukioja, E. (1993). Effects of food and predation on population dynamics,. In Caterpillars: ecological and evolutionary constraints on foraging. (Eds. N.E. Stamp and T.M. Casey). p. 425-447. New York, NY: Chapman and Hall.

Hawkins, B.A. (1994). Pattern and process in host-parasitoid interactions. New York, NY: Cambridge University Press.

Hawkins, B.A., H.V. Cornell, and M.E. Hochberg. (1997). Predators, parasitoids, and pathogens as mortality agents in phytophagous insect populations. Ecol. 78, 21452152.

Hogue, C.L. (1972). Protective function of sound perception and gregarousness in Hylesia larvae (Saturniidae: Hemileucinae). J. Lepidop. Soc. 26, 33-34.

Hoy, R.R. and D. Robert. (1996). Tympanal hearing in insects. Ann. Rev. Entomol. 41, 433-450.

Humason, G.L. (1997). Humason's Animal Tissue Techniques. $5^{\text {th }}$ ed. Baltimore, MD: John Hopkins University Press.

Hunt, J. and G.R. Allen. (1998). Fluctuating asymmetry, call structure and the risk of 
attack from phonotactic parasitoids in the bushcricket Sciarasaga quadrata (Orthoptera: Tettigoniidae). Oecol. 116, 356-364.

Iwao, S. and W.G. Wellington. (1970). Influence of behavioural differences among tent caterpillar larvae on predation by a pentatomid bug. Can. J. Zool. 48, 896-

Johnson, A.J.J. (1893). Sensibility of larvae to sound. Entomol. Rec. 4, 240-241.

Kanou, M and T. Shimozawa. (1984). A threshold analysis of cricket cercal interneurons by an alternating air-current stimulus. J. Comp. Physiol. 154, 357-365.

Kirchner, W.H. (1994). Hearing in honeybees: the mechanical response of the bee's antenna to near field sound. J. Comp. Physiol. 175, 261-265.

Kitching, I.J. (1984). The use of larval chaetotaxy in butterfly systematics, with special reference to the Danaini (Lepidoptera: Nymphalidae). Syst. Entomol. 9, 49-61.

Klots, A.B. (1969). Audition by Cerura larvae (Lepidoptera: Notodontidae). N.Y. Entomol. Soc. J. 77, 10-11.

Kristensen, N.P. (2003) (ed.) Lepidoptera: Moths and Butterflies 2. Handbuch der Zoologie/Handbook of Zoology. New York, NY: Walter de Gruyter, Inc.

Landolfa, M.A. and J.P. Miller. (1995). Simulus-response properties of cricket cercal filiform receptors. J. Comp. Physiol. A. 177, 749-757.

Lane, K.A., K.M. Lucas, and J.E. Yack. (2007). Hearing in a diurnal, mute butterfly, Morpho peleides (Papilionoidea, Nymphalidae). J. Comp. Neuroethol. 508, 677868.

Lynch, S.P. and R.A. Martin. (1993). Milkweed host plant utilization and cardenolide sequestration by monarch butterflies in Louisiana and Texas. In: Biology and conservation of the monarch butterfly (Eds. S.B. Malcom and M.P. Zalucki). pp. 107-123. 
Markl, H. and J. Tautz. (1975). The sensitivity of hair receptors in caterpillars of Barathra brassicae L. (Lepidoptera, Noctuidae) to particle movement in a sound field. J. Comp. Physiol. 99, 79-87.

May, M.L and R.R. Hoy. (1991). Habituation of the ultrasound-induced acoustic startle response in flying crickets. J. Exp. Biol. 159, 489-499.

Michelsen, A. and Nocke, H. (1974). Biophysical aspects of sound communication in insects. Adv. Insect Physiol. 10, 247-296.

Michelsen, A., W. F. Towne, W. H. Kirchner, and P. Kryger. (1987). The acoustic near field of a dancing honeybee. J. Comp. Physiol. A 161, 633 -643.

Miller, L. A. and A. Surlykke. (2001). How some insects detect and avoid being eaten by bats: Tactics and countertactics of prey and predator. BioSci. 51, 571-582.

Minet, J. and A. Surlykke. (2003). Auditory and sound producing organs. In: Lepidoptera, Moths and Butterflies. Vol.2: Morphology and physiology. (ed. N.P. Kristensen) pp. 289-323. Berlin, NY: Walter de Gruyter.

Minnich, D. E. (1925). The reactions of the larvae of Vanessa antiopa Linn. to sounds. J. Exp. Zool. 42, 443-468.

Minnich, D. E. (1936). The responses of caterpillars to sounds. J. Exp. Zool. 72, 439-453

Myers, H.M and J.N.M. Smith. (1978). Head flicking by tent caterpillars: a defensive response to parasite sounds. Can. J.Zool. 56, 1628-1631.

Nakamatsu, Y, and T. Tanaka. (2005).How does the ectoparasitoid wasp Euplectrus separatae (Hymenoptera: Eulophidae) recognize a suitable oviposition site on the host larva Pseudaletia separata (Lepidoptera: Noctuidae)? Appl. Entomol. Zool. 40, 185-191.

Nicolas, G. and D. Sillans. (1989). Immediate and latent effects of carbon dioxide on 
insects. Ann. Rev. Entomol. 34, 97-116.

Oberhauser, K.S. and K. Kuda. (1997). A Field Guide to Monarch Caterpillars

(Danaus plexippus). St. Paul, MN: University of Minnesota.

Oberhauser, K.S. and M.J. Solensky. (Eds). (2004). Monarch Butterfly Biology and Conservation. Ithaca, NY: Cornell University Press.

Oberhauser, K., I. Gebhard, C. Cameron, and S. Oberhauser. (2007). Parasitism of monarch butterflies (Danaus plexippus) by Lespesia archippivora (Diptera: Tachinidae). Am. Midl. Nat. 157, 312-328.

Oliai, S.E. and B.H. King. (2000). Associative learning in response to color in the parasitoid wasp Nasonia vitripennis (Hymenoptera: Pteromalidae). J. Insect Beh. $13,55-69$.

Pflüger, H. and J. Tautz. (1982). Air movement sensitive hairs and interneurons in Locusta migratoria. J. Comp. Physiol. 145, 369-380.

Rodríguez, R.L. and M.D. Greenfield. (2004). Behavioural context regulates dual function of ultrasonic hearing in lesser waxmoths: bat avoidance and pair formation. Physiol. Entomol. 29, 159-168.

Roeder, T. (1999). Octopamine in invertebrates. Prog. Neurobiol. 59, 1-31.

Rothschild, M. and G. Bergstrom. (1997). The monarch butterfly caterpillar (Danaus plexippus) waves at passing Hymenoptera and jet aircraft—are repellent volatiles released simultaneously? Phytochem. 45, 1139-1144.

Rousse, P., F. Chiroleu, J. Veslot, and S. Quilici. (2007). The host- and microhabitat olfactory location by Fopius arsanus suggests a broad potential host range.

Rybak, F., T. Aubin, B. Moulin, and J. Jallon. (2002). Acoustic communication in Drosophila melanogaster courtship: Are pulse- and sine-song frequencies 
important for courtship success? Can.J.Zool. 80, 987-996.

Rydell, J., S. Kaerma, H. Hedelin, and N. Skals. (2003). Evasive response to ultrasound by the crepuscular butterfly, Manataria maculata. Naturwiss. 90, 80-83.

Ryo, N., Y. Ishikawa, and S. Tatsuki. (2006). Ultrasonic courtship song in the Asian corn borer moth, Ostrinia furnacalis. Naturwiss. 93, 292-296.

Sannino, L. and B. Espinosa. (1999). Morphological notes on Mamestra brassicae (Lepidoptera Noctuidae). Il Tobacco. 7, 13-24.

Shaw, S.R. (1994). Detection of airborne sound by a cockroach "vibration detector": a possible missing link in insect auditory evolution. J. Exp. Biol. 193, 13-47.

Schniederkotter, K. and R. Lakes-Harlan. (2004). Infection behavior of a parasitoid fly, Emblemasoma auditrix, and its host cicada Okanagana rimosa. J. Insect. Sci. 4, $1-4$.

Skelhorn, J. and C. Rowe. (2006). Predator avoidance learning of prey with secreted or stored defences and the evolution of insect defences. Anim. Beh. 2, 348-350.

Smith, M.T. (Ed). (1999). Audio Engineer's Reference Book, (2nd ed). Boston, MA: Focal Press.

Sombati S, and G. Hoyle. (1984). Generation of specific behaviors in a locust by local release into neuropil of the natural neuromodulator octopamine. J Neurobiol 15, $481-506$

Speight, M.R. (1999). Ecology of Insects: Concepts and Applications. Wiley-Blackwell, New Jersey.

Stamp, N.E. (1982). Behavioural interactions of parasitoids and Baltimore checkerspot caterpillars (Euphydryas phaeton). Environ. Entomol. 11, 100-104.

Stamp, N.E. (1984). Interactions of parasitoids and checkerspot caterpillars Euphydryas 
spp. (Nymphalidae). Res. Lepid. 23, 2-18.

Stamp, N.E. (1992). Relative susceptibility to predation of two species of caterpillar on plantain. Oecologia. 92, 124-129.

Stamp, N.E. and Bowers, M.D. (1991). Indirect effect on survivorship of caterpillars due to presence of invertebrate predators. Oecologia. 88, 325-330.

Stamp, N.E. and Bowers, M.D. (1993). Presence of predatory wasps and stinkbugs alters foraging behaviour of cryptic and non-cryptic caterpillars on plantain (Plantago laceolata). Oecologia. 95, 376-384.

Stireman III, J.O. (2002). Host location and selection cues in a generalist tachinid parasitoid. Entomologia Experimentalis et Applicata. 103, 23-34.

Stumpner, A. and D. von Helversen. (2001). Evolution and function of auditory systems in insects. Naturwiss. 88, 159-170.

Tautz, J. (1977). Reception of medium vibration by thoracal hairs of caterpillars of Barathra brassicae L. I. Mechanical properties of the receptor hairs. J. Comp. Physiol. 118, 13-31.

Tautz, J. (1978). Reception of Medium Vibration by Thoracal Hairs of Caterpillars of Barathra brassicae L II. Response characteristics of the sensory cell. (Lepidoptera, Noctuidae). J. Comp. Physiol. A. 125, 67-77.

Tautz, J. (1979). Reception of particle oscillation in a medium - an unorthodox sensory capacity. Naturwiss. 66, 452-461.

Tautz, J. and H. Markl. (1978). Caterpillars detect flying wasps by hairs sensitive to airborne vibration. Behav. Ecol. Sociobiol. 4, 101-110.

Triblehorn, J.D. and Yager, D.D. (2005). Timing of praying mantis evasive responses during simulated bat attack sequences. J. Exp. Biol. 208, 1867-1876. 
Trigo, J.R. (2000). The chemistry of antipredator defense by secondary compounds in Neotropical Lepidoptera: Facts, perspectives and caveats. J. Braz. Chem. Soc. 11, $551-561$.

Tutt, J.W. (1893). Note on sensibility of larvae to sound. Entomol. Rec. 4, 241.

Urquhart, F.A. (1960). The Monarch Butterfly. Toronto, ON: University of Toronto Press.

Vet, L.E.M. and K. Bakker. (1985). A comparative functional approach to the host detection behaviour of parasitic wasps. 2. A quantitative study on eight Eucoilid species. Oikos. 44, 487-489.

Virant-Doberlet, M. and A. Cokl. (2004). Vibrational Communication in Insects. Neotropical Entomology. 33, 121-134.

Webb, J.C., J.L. Sharp, D.L. Chambers, and J.C. Benner. (1976). Acoustical properties of the flight activities of the Caribbean fruit fly. J. Exp. Biol. 64, 761772.

Wells, H. and P.H. Wells. (1992). The monarch butterfly: a review. Bull. Calif. Acad. Sci. 91, 1-25.

White, T.R., Weaver III, J.S., and Agee, H.R. (1983). Response of Cerura borealis (Lepidoptera: Notodontidae) larvae to low-frequency sound. Ann. Ent. Soc. Amer. 76, 1-5.

Wiese, K. (1976). Mechanoreceptors for near-field water displacements in crayfish. $J$. Neurophysiol. 39, 816-833.

Yack, J. E. (2004). The structure and function of auditory chordotonal organs in insects. Microscopy Res. Tech. 63, 315-337.

Yack, J.E. and J. Dawson. (2008). Insect Ears. In: The Senses: A Comprehensive 
Reference. Audition. Vol. 3 (Eds. A.I. Basbaum, A. Kaneko, G.M. Shepherd, and G.P. Westheimer) pp. 35-53. New York, NY: Elsevier Inc.

Yack, J. E., and Fullard, J. H. (1993). What is an insect ear? Ann. Ent. Soc. Am. 86, 677-682.

Yack, J. E., and Fullard, J. H. (2000). Ultrasonic hearing in nocturnal butterflies. Nature 403, 265-266.

Yack, J. E., Otero, L. D., Dawson, J. W., Surlykke, A., and Fullard, J. H. (2000). Sound production and hearing in the blue cracker butterfly Hamadryas feronia (Lepidoptera, Nymphalidae) from Venezuela. J. Exp. Biol. 203, 3689-3702.

Yack, J.E., M.L. Smith, and P.J. Weatherhead. (2001). Caterpillar talk: Acoustically mediated territoriality in larval Lepidoptera. Proc. Nat. Acad.Sci. 98, 11371-11375.

Yager, D.D. (1999). Structure, development, and evolution of insect auditory systems. Microscopy Res. Tech. 47, 380-400.

Yager D.D., M.L. May, and M.B. Fenton. (1990). Ultrasound-triggered, flight-gated evasive maneuvers in the praying mantis, Parasphendale agrionina (Gerst.). I: freeflight. J. Exp. Biol. 152, 17-39.

Zacharuk, R.Y. and V.D. Shields. (1991). Sensilla of immature insects. Ann. Rev. Entomol. 36, 331-354. 


\section{APPENDIX I}

Sources of Danaus plexippus larvae:

\section{Gaïa Nature}

180 Giard

Granby, Quebec J2G 9H8

Telephone: 450-776-7442

Fax: 450-372-6190

E-mail: info@gaianature.com

Website: http://www.gaianature.com

\section{Monsieur Papillon}

33 St-Georges

Chambly, Quebec J3L 3J8

Telephone: 450-658-5252

E-mail: info@monsieurpapillon.com

Website: http//monsieurpapillon.com/

\section{Wish Upon a Butterfly}

419 Mt. Air Road

New Castle, Pennsylvania 16102

United States of America

Telephone: 724-667-7107

Email: butterflies@wishuponabutterfly.com

Website: http://www.wishuponabutterfly.com 